\title{
WestVirginiaUniversity
}

THE RESEARCH REPOSITORY @ WVU

Graduate Theses, Dissertations, and Problem Reports

2000

\section{Computational model of ductile erosion by single particle impact}

Chandrakant Rai

West Virginia University

Follow this and additional works at: https://researchrepository.wvu.edu/etd

\section{Recommended Citation}

Rai, Chandrakant, "Computational model of ductile erosion by single particle impact" (2000). Graduate Theses, Dissertations, and Problem Reports. 1086.

https://researchrepository.wvu.edu/etd/1086

This Thesis is protected by copyright and/or related rights. It has been brought to you by the The Research Repository @ WVU with permission from the rights-holder(s). You are free to use this Thesis in any way that is permitted by the copyright and related rights legislation that applies to your use. For other uses you must obtain permission from the rights-holder(s) directly, unless additional rights are indicated by a Creative Commons license in the record and/ or on the work itself. This Thesis has been accepted for inclusion in WVU Graduate Theses, Dissertations, and Problem Reports collection by an authorized administrator of The Research Repository @ WVU. For more information, please contact researchrepository@mail.wvu.edu. 


\title{
COMPUTATIONAL MODEL OF DUCTILE EROSION BY SINGLE PARTICLE IMPACT
}

\section{Chandrakant Rai}

\author{
Thesis submitted to the \\ College of Engineering and Mineral Resources \\ at West Virginia University \\ in partial fulfillment of the requirements \\ for the degree of
}

Master of Science in Mechanical Engineering

Kenneth H. Means, Ph.D., Chair

Victor H. Mucino, Ph.D.

Bruce Kang, Ph.D.

Department of Mechanical Engineering

Morgantown, West Virginia University

2000

Keywords: Computational Model, Ductile, Erosion, and Single Particle, Impact 


\section{ABSTRACT \\ Computational Model of Ductile Erosion by Single Particle Impact}

\section{Chandrakant Rai}

Erosion by solid particle impact is a common problem in many industrial applications. It results due to mechanical contact between the particle and the metal surface, which in turn result in potential material losses. Erosion of machine parts by the small solid particle entrained in liquid or gaseous working environment is a serious problem in many industrial applications. Numerous experiments have been conducted to obtain empirical relations for predicting material loss due to these impacts and to arrive at an appropriate material for a particular working environment. But with so many new materials being used for different applications, and operating at different temperatures, conducting experiments for each of them is becoming increasingly difficult. In this thesis, use of a finite element model was proposed, which takes into account various boundary conditions and predict loss of ductile material due to erosion.

An aluminum metal model was developed in LS-INGRID and analyzed using LSDYNA3D. The Aluminum metal model was used to simulate the experimental work of Sheldon. The results of the model were checked with experimental results of Sheldon and a close comparison was observed. Several parameters such as velocity of erodent, angle of attack and size of erodent, were varied and their influence on erosion was studied. The results were presented in the form of graphs between the critical volume and the parameter affecting erosion. A good correlation was observed between these parametric studies and experimental results. 


\section{ACKNOWLEDGEMENTS}

I would like to express my sincere gratitude to Dr Ken Means for having provided me an opportunity to work under him. I thank him for his valuable guidance and suggestions during the course of this work.

I would also like to thanks my other committee members, Dr. Bruce Kang and Dr. Victor Mucino for being in my committee.

This gives me a great opportunity to express my gratitude, to my parents Mr. and Mrs. Niranjan Rai for being a constant source of strength and support. A special thanks goes to my brother Abhijeet.

I would like to extend my appreciation to Salem for his help that he has provided me. Also thanks to all my roommates and friends for their help and support. 


\section{TABLE OF CONTENTS}

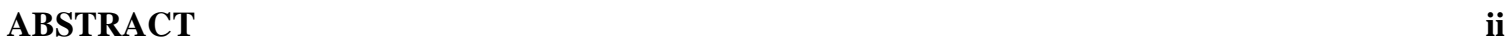

ACKNOWLEDGEMENTS iii

$\begin{array}{ll}\text { CHAPTER } 1 & 1\end{array}$

1.1 INTRODUCTION 1

$\begin{array}{lr}\text { CHAPTER 2 } & 4\end{array}$

2.1 DUCTILE EROSION MODELS 4

2.2 BRITTLE EROSION MODELS 8

2.3 PARAMETERS AFFECTING EROSION 10

2.4 SINGLE PARTICLE EROSION 13

2.5 MULTIPLE PARTICLE EROSION 19

$\begin{array}{lr}\text { CHAPTER } 3 & 22\end{array}$

3.1 INTRODUCTION 22

3.2 MATERIAL PROPERTIES 22

3.2.1 PARTICLES 24

3.3 PLASTICITY THEORY 25

3.3.1 FLOW CURVE

3.3.2 YIELDING CRITERIA FOR DUCTILE METALS 29

3.3.3 YIELD SURFACE $\quad 30$

3.3.4 PLASTIC STRESS-STRAIN RELATIONS 31

3.4 RATE INDEPENDENT PLASTICITY

3.5 FAILURE ANALYSIS

3.6 ASSUMPTIONS 40

$\begin{array}{ll}\text { CHAPTER } 4 & 41\end{array}$

4.1 INTRODUCTION 41

4.2 FINITE ELEMENT MODEL 41

4.3 MESH GENERATION $\quad 42$

4.4 MATERIAL MODELS

4.5 BOUNDARY AND INITIAL CONDITIONS

4.6 PARAMETRIC MODELLING

4.7 MODEL SOLUTION

4.8 POST PROCESSING 
CHAPTER 5

5.1 INTRODUCTION

61

5.2 PARAMETRIC RANGES

61

5.3 MODEL VALIDATION

62

5.4 ALUMINUM MODEL

CHAPTER 6

6.1 CONCLUSIONS

77

6.2 RECOMMENDATIONS FOR FUTURE WORK

APPENDIX A 


\section{CHAPTER 1}

\subsection{INTRODUCTION}

Erosion and corrosion of metal parts is a major problem faced by industry today. Erosion is a physical phenomenon while corrosion is a chemical one. Erosion occurs due to relative motion between two surfaces, whereas corrosion occurs when a metal object is exposed to an oxidizing environment. The damage caused to the machine parts by these phenomena can be enormous. Hence the determination of material loss is very important in predicting the failure of the component parts. A clear understanding of the effect of single particle impact with various parameters is needed to understand this erosion phenomenon.

The erosion of a metal surface due to impact of solid particles is termed as solid particle erosion. It is the loss of material that results from the impact of small solid particles. In some cases solid particle erosion is useful phenomenon, as in sand blasting and high speed abrasive waterjet cutting, but it is a serious problem in many engineering systems, including steam and jet turbines, pipelines and valves carrying particulate matter, and fluidized bed combustion systems. The erosion phenomenon is not a simple one to be modeled in a deterministic way. Solid particle erosion can occur in a gaseous or liquid medium containing solid particles. But this is more significant in gaseous medium than in liquid medium. Solid particle erosion can be expected, whenever hard particles are entrained in a gas or liquid medium impinging on a solid at any significant velocity. Manifestations of solid particle erosion in service usually include thinning of components, surface roughening, and lack of directional grooving characteristic of abrasion and in some cases the formation of ripple patterns on metals.

The erosion rate, $\mathrm{E}$, is commonly given in terms of mass or volume of the material removed per unit mass of the erodent impacted. Volume is preferred more because it permits thickness loss comparisons between materials of different densities. The erosion rate of metals and ceramics are different. Erosion rate shows a power law velocity dependence, which is given by 


$$
\mathrm{E}=\mathrm{kv}{ }^{\mathrm{n}}
$$

Where $\mathrm{k}$ is a constant and $\mathrm{n}$ is a velocity exponent that generally depends on the material and erosion conditions. Therefore, the phenomenon by which erosion takes place is different for ductile materials and brittle materials. Ductile material erosion takes place by considerable plastic flow and the material undergoes very large plastic strains before fracture occurs, while brittle material erosion is due to the crack formation in the surface and the resultant chipping of the material.

There are various parameters that effect the phenomenon of erosion. They are erodent velocity, angle of attack of the erodent, temperature, erodent shape, erodent size and properties of the target surface and the erodent. The velocity of the erodent has direct effect on the erosion rate. The erosion rate increases with the increase in velocity for both ductile and brittle materials.

The effect of the angle of attack on the erosion rate is different for brittle and ductile materials. In ductile materials the erosion loss is maximum at lower angles of incidence i.e., around $20^{\circ}-30^{\circ}$ whereas in brittle materials the erosion loss is maximum at normal incidence i.e., around $90^{\circ}$. The erodent size is directly proportional to erosion rate but only up to a limiting size. The temperature has a great influence on the erosion rate. The temperature rise affects the properties of the target surface, making it soft and ductile. This in turn changes the mechanism by which the erosion takes place. The particle shape also has a significant effect on the erosion rate, as the shape of the particle determines the contact area between the erodent and the target surface.

The effect of impact of single solid particle is termed as single particle erosion. Erosive wear of materials in practice generally involves long times of exposure under steady state conditions. However, by its nature, solid particle erosion is a discrete accumulative process and the single impact event is clearly worthy of as accurate understanding as possible. Many experimental works were conducted in the past to determine the loss of material due to single particle impacts. Several theories have been proposed to explain the phenomenon of erosion due to these impacts. The result of these theories has been used to extrapolate the erosion loss for several single particle impacts over certain area. 
In addition, the theories proved to be of great importance in developing the models that predict the rates of erosion during multiple particle impact.

Most of the models available in the literature are based on the experimental works on various materials. However, with many new materials and surface coatings being used for different applications and operating at different temperatures, conducting experiments for each one of them is becoming increasingly difficult. Even though a large number of investigations have studied specific erosion problems and obtained solutions with some degree of practical satisfaction, there is little information that can be carried over to predict erosion under new and untried circumstances. Hence, in the current work, the use of a finite element model was proposed, which takes into account various boundary conditions and predicts the loss of material due to erosion. The model was developed and solved using a finite element code called LS-DYNA3D. (The results of the model were checked with experimental results and a close correlation was observed. Several parameters such as velocity of erodent, angle of attack, were varied and their influence on erosion was studied). 


\section{CHAPTER 2}

\subsection{DUCTILE EROSION MODELS}

Ductile materials undergo weight loss by the process of plastic deformation in which the material is removed by the displacing action or the cutting action of the eroding particle. On ductile materials, the impacting material causes severe, localized plastic strain to occur that eventually exceeds the strain to failure of the deformed material. These deformations are produced by loss of kinetic energy and by work during the impact by external forces on the particle.

Finnie [1958] first developed a model for the erosion of ductile material. He developed the model by considering the micro-machining mechanism. He treated the problem by assigning a plastic response character to the material through a flow stress $\sigma_{\mathrm{f}}$. The trajectory of the particle was calculated using a number of simplifying assumptions and the volume removed was equated to the volume swept out by the particle tip. This is given by the expression:

$$
\mathrm{V}=\left(\mathrm{mv}_{0}^{2} / \sigma_{\mathrm{f}} \mathrm{Kd}\right) \mathrm{g}(\alpha)
$$

Where

$\mathrm{m}$ is the mass of the particle, $\mathrm{v}_{0}$ is the impact velocity, $\mathrm{K}$ is the ratio of the vertical force to horizontal force on the particle, $\mathrm{d}$ the depth of cut, and $\mathrm{g}(\alpha)$ is a function describing the effect of attack angle $\alpha$.

Further taking average value of Force Ratio as $\mathrm{K}=2$, Finnie derived equations for eroded volume as given below. 


$$
\begin{array}{ll}
\mathrm{V}=\left(\mathrm{mv}_{0}^{2} / 2 \sigma_{\mathrm{f}} \mathrm{d}\right)\left[\sin 2 \alpha-3 \sin ^{2} \alpha\right] ; & \alpha<18.5 \\
\mathrm{~V}=\left(\mathrm{mv}_{0}^{2} / 6 \sigma_{\mathrm{f}} \mathrm{d}\right) \cos ^{2} \alpha ; & \alpha>18.5
\end{array}
$$

In his studies, Finnie experimentally showed that the material removal varies with the direction and the velocity of the eroding particle and predicted the velocity exponent as $\mathrm{n}=2$. This model was not feasible for attack angle $\alpha=90^{\circ}$ as it gave zero erosion rate at normal incidence.

Bitter [1963] developed a model to account for erosion at all angle of attacks. He considered erosion to consist of two simultaneous processes, indentation deformation wear for high angle of attack and cutting wear for low angles. For ductile materials at low angles, the cutting wear predominates, while at high angles deformation wear predominates. Later it was simplified by Nelson et.al., who presented equations which gave a good fit to the experimental data.

Sheldon and Kanhere [1972] examined the mechanism of single particle erosion of ductile materials. They developed a model to describe the deformation and machining actions observed using indentation theory and energy balance equation. Their results differ from previous calculations, giving the erosion volume as

$$
\mathrm{V}=\mathrm{K}\left(\mathrm{d}^{3} \mathrm{v}_{0}{ }^{3} \rho_{\mathrm{p}}{ }^{3 / 2} / \mathrm{H}^{3 / 2}\right)
$$

Where $\mathrm{d}$ is the spherical particle diameter,

$\rho_{\mathrm{p}}$ is the particle density,

$\mathrm{H}$ is the Vickers hardness value of the material.

This theory leads to greater velocity exponent $n=3$ rather than $n=2$ as expected from energy arguments. He also showed that material removal action has the same characteristics as multiple-particle erosion of surface.

Tilly [1973] proposed a two-stage mechanism of erosion, he showed that the first stage is when the particle strikes the surface to produce indentation and possibly remove a chip of 
metal. The second stage is when the particle breaks up and fragments are projected radially from primary site. These fragments may produce secondary damage. He was able to account for a reported decrease in erosion with decreasing particle size and introduced the concept of minimum particle size for this type of mechanism.

Hutchings et al., in 1974 explained the material removal mechanism of aluminum surface impacted obliquely by $3 \mathrm{~mm}$ steel ball at velocities up to $250 \mathrm{~m} / \mathrm{s}$. They showed the formation of overhanging lip at the exit end of the crater by the shearing of the surface layers. This lip is detached from the surface by the propagation of ruptures at the base of the lip, this phenomenon is characteristic of the particular metal, and takes place above a certain critical impact velocity.

They also showed that material is more readily removed from work hardened copper than from annealed copper. The deformation is concentrated in the surface layers aiding the formation of fragile lip for the work hardened, whereas in annealed metal the impact energy is spread through a large volume.

In one of his theoretical studies in 1981, Hutchings proposed the erosion of metals by multiple spheres impacting at normal incidence employing critical plastic strain as the failure criterion. He incorporated two material strength properties: dynamic hardness and erosion ductility, the high values of which are needed for good resistance to erosion and also predicted a velocity exponent of 3.0. Further investigation of these properties is needed. Hutchings assumed that material is removed by platelet mechanism, but until a better understanding of the micromechanisms involved in the erosion at normal incidence such a mechanism cannot be assumed. He formulated erosion rate, assuming no strain hardening and constant strain increment with each impact as given by the equation.

$$
\mathrm{E}=\mathrm{k}\left(\alpha \rho \sigma^{1 / 2} \mathrm{v}^{3} / \varepsilon_{\mathrm{c}} \mathrm{P}^{3 / 2}\right)
$$

Where

$\alpha$ is fraction of volume of indentation which is plastically deformed $\mathrm{v}$ is impact velocity

$\mathrm{P}$ constant pressure of resistance by the target material for indentation

$\rho$ target material density

$\varepsilon_{\mathrm{c}}$ critical strain 
In 1981, Bellman et al., extended the sequential observation technique to include erosion at glancing angles of incidence. The authors provided experimental evidence to show that the material removal during erosion involves the deformation of the surface material into platelets by repeated impacts. These eventually become detached and would be expected to form thin plate like debris particles. They observed the same mechanism of platelet formation for both spherical and angular impacting particles. They observed the formation of three distinct types of craters; indentation, plowing, and smear craters on the stress free surface, due to the impact of the particles. Depending on the impingement angle, the frequency of occurrence of these craters varies.

In 1986, Hutchings et al., considered that the surface temperature rise due to erosion leads to softening of near surface region, so that a layer of work hardened material beneath this acts as an anvil against which softer material is deformed. They estimated the temperature rise and considered published evidence for and against softening and concluded that it was not necessary to postulate a thermally softened surface layer as an essential feature of erosion mechanism under all conditions.

Although the platelet mechanism proved to be a predominant material removal mechanism at $90^{\circ}$ angle of incidence and the micro-mechanism proved to be a predominant mechanism at low angles of incidence, neither theory offer clear mechanisms for either cutting or deformation wear. Morrison et al., argued that because velocity exponent, particle size effect, and surface features are similar for all angles of incidence, a single mechanism of erosion is appropriate at all angles of incidence. They considered that indentation, plowing and cutting involve similar plastic deformation behavior and occurs at all angles of incidence.

In 1995 Levy made an effort to combine all his experimental and theoretical results correlating with other theories in a book. He explained the erosion mechanism in ductile metals as a series of operations resulting in the formation of platelets and craters. Initial 
impacts produce platelets without material loss. Adiabatic shear heating occurs on the impacted surface causing the formation of work hardened zone, beneath its surface, which acts as an anvil increasing the efficiency of the hammer like impacting particles. When the anvil is fully in place and the platelets are fully formed, maximum, steady state, material removal condition occurs.

\subsection{BRITTLE EROSION MODELS}

The mechanism of erosion of brittle materials is quite different from that of ductile materials. Brittle erosion is due to the crack formation in the surface and the resultant chipping of the material. The material is removed by the intersection of cracks, which radiate out from the point of impact of the eroding particle. Many engineering materials like glass, iron oxide, aluminum oxide etc., fall under this category. Where as ductile erosion is due plastic deformation, material is removed when the localized plastic strain exceeds strain to failure in the deformed material. Generally materials behaving plastically exhibit a ripple surface pattern while those behaving in a brittle manner show typical fracture surface, and material removal takes place by propagation of this fracture surface into the material. Brittle materials generally show less resistance to erosion than the ductile materials.

In 1960, Finnie conducted several experiments with an elastic sphere striking perpendicularly onto brittle material like glass, which remains elastic until fracture. He proposed with some equations, that the maximum tensile stress in the material occurs at the surface in the radial direction around the periphery of the contact area. The maximum radial stress was expressed in terms of density, velocity, Poisson's ratio and modulus of elasticity of the impacting sphere and the Poisson's ratio, modulus of elasticity of the surface. A ring crack was observed in the brittle material.

A model proposed by Sheldon et al., [1966] assumes that erosion occurs as the result of Hertzian contact stresses during impact. These stresses cause the cracks to grow from preexisting flaws in the target surface. The peculiarity of brittle material is that the fracture stress is not constant but is a function of the stressed volume, this effect is 
usually attributed to the presence of surface and volume flaws. The average fracture stress of a particular material then must be described in a statistical sense, hence Weibull distribution was used in this analysis. The crack propagation occurs at a load, which is related to the distribution of surface flaws through the Weibull distribution. The Weibull parameters used in this analysis are, a quantity which describes the flaw distribution, denoted by $m$, and a scaling stress denoted $\sigma_{0}$, which is a measure of strength of material. The approximate area $A$ of cracked material is calculated for a particle penetration depth $h$, and the volume removed per impact is set proportional to $A h$. The erosion rate $\mathrm{W}$, was expressed in terms of the particle size $r$, the particle velocity $v_{0}$, and Weibull constants $m$ and $\sigma_{0}$.

$$
\mathrm{W}=k_{1} r^{a} v_{o}^{b}
$$

Where the exponents $a$ and $b$ are given by:

$a=3(m-0.67) /(m-2) \quad$ for round particles

$a=3.6(m-0.67) /(m-2) \quad$ for angular particles

$b=2.4(m-0.67) /(m-2)$ for either shape

For particles much stiffer than the target, the constant $k_{l}$ is given by

$$
k_{1}=E^{0.8(m+1) /(m-2)} \rho^{1.2(m-0.67) /(m-2)} \sigma_{o}^{-2 m /(m-2)}
$$

Where $\mathrm{E}$ is the modulus of elasticity of the target, and

$\rho$ is the density of the particle.

They compared the experimentally determined exponents $a$ and $b$ with the theoretical predicted exponents and obtained satisfactory agreement for several brittle materials like glass, magnesium oxide and graphite.

Another model was proposed by Evans et al., which was based on the assumption that the plastic deformation contributes to the process of crack formation and surface chipping. The model assumes that the erosion rate is proportional to the amount of material removed by each impact event. The volume loss per impact is calculated from the depth $h$ of penetration and the maximum size of the lateral cracks formed during impact. Since the lateral size is proportional to the radial crack size $\mathrm{c}_{\mathrm{r}}$, the volume loss $V$ is given by the following equation

$$
V=\pi \mathrm{c}_{\mathrm{r}}^{2} h
$$


In 1978, Hockey et al., showed evidence of plastic deformation in brittle materials. They used transmission electron microscopy to observe the dislocation structures beneath impact craters in magnesium oxide and aluminum oxide. They explained that plasticity is due to the compressive component of the stress field below the impacting particle. High dislocation densities were observed in all cases, although the relative extents of dislocation damage and crack propagation compared with the indentation size varied with the material. Later Evans et al., developed a theory to explain the phenomenon of erosion, in which he included the effects of elastic as well as plastic waves generated by impacting particle. The erosion rate ' $\mathrm{E}$ ' is given by:

$$
\mathrm{E} \alpha v_{0}^{3.2} \mathrm{~d}^{3 / 2} \rho^{1.3} \mathrm{~K}_{\mathrm{Ic}}{ }^{-4.3} \mathrm{H}^{-0.25}
$$

In more recent studies Wiederhorn et al., came with some changes to the Evans et al., model. They assumed that the dynamic effects may be neglected and that the particle penetration depth be determined by equating the plastic work done to the incident kinetic energy of the particle. The erosion rate predicted by Wiederhorn et al., is given by:

$$
\mathrm{E} \alpha v_{0}^{2.4} \mathrm{~d}^{2 / 3} \rho^{1.2} \mathrm{~K}_{\mathrm{Ic}}^{-4.3} \mathrm{H}^{-0.25}
$$

Where $\mathrm{E}$ is the erosion rate.

$v_{0}$ is the particle velocity

$\mathrm{d}$ is the particle diameter

$\rho$ is the density of the particle

$\mathrm{K}_{\mathrm{Ic}}$ is the material toughness

$\mathrm{H}$ is the material hardness

\subsection{PARAMETERS AFFECTING EROSION}

The parameters that effect the erosion process are listed as follows:

- Erodent Velocity.

- Erodent Shape. 
- Erodent Size.

- Angle of Attack.

- Temperature.

- Mechanical Properties of target and the erodent.

\subsubsection{Erodent Velocity}

The velocity of the erodent plays very important role in the erosion process. As the velocity of the particle increases the initial kinetic energy of the particle increases, consequently it has more potential to degrade the surface than a particle moving at a lesser velocity. Hence it is directly related to the erosion. Experimental work was conducted in the past to determine the volume loss per impact due to change in velocity. Finnie [1960] based on his work on SAE 1020 steel reported that erosion was proportional to simple power of velocity. That is

$$
\varepsilon=b v^{\mathrm{n}}
$$

Where $v$ is the velocity of erodent and $\mathrm{n}$ was 2.0 , however he subsequently reported work on other materials giving a range of values of $\mathrm{n}$ between 2.05 and 2.44. Sheldon's theory predicted a velocity exponent of $n=3$. Ductile materials seem to exhibit a velocity dependence of $v^{\mathrm{a}}$, where the exponent ' $\mathrm{a}$ ' has a value of $2.4-2.7$, somewhat greater than value of 2 predicted in theory, the reason for this may be due to particle size effect or particle fragmentation. Sheldon showed that velocity exponent for steel exhibit a size effect showing variation with particle size, however copper and aluminum seem to be independent of particle size over the size range tested.

In 1970 Sheldon et al., showed the importance of tangential forces in the wear process. They explained that for normal impact the erosion rate of brittle materials is proportional to $v^{\mathrm{b}}$. Sheldon determined that the power function ' $\mathrm{b}$ ' for oblique angle impact was not the same as that determined from velocity studies using normal impact angles. He concluded from these results that the tangential forces contribute to the wear of brittle materials at oblique angle impacts. Brittle materials are considerably more dependent on particle velocity and size than ductile materials. Brittle materials show a velocity exponent of order 3 or higher, values as high as 6.5 have been reported for tests involving $90 \mu \mathrm{m}$ steel spheres against glass [Finnie, 1960]. 


\subsubsection{Erodent shape}

The shape of the particle is also very important in predicting the erosion rate due to impact. The shape of the particle actually determines the contact area between the particle and the metal surface during an impact. For both ductile and brittle materials, more effective erosion is generally found to be associated with angular particles [Finnie, 1960]. Sheldon et al., conducted some experiments and attempted to show ductile behavior in normally brittle materials. They impacted spherical and angular silicon carbide particles against brittle materials like glass, aluminum oxide. They observed that the erosion rate was more in case of angular particles than the spherical particles.

In more recent studies carried by Hutchings et al., two different shapes of particles i.e., steel spheres of $9.5 \mathrm{~mm}$ diameter and $8 \mathrm{~mm}$ square steel plates, were accelerated using a compressed gas gun system. These experiments were designed to investigate two classes of surface deformation that occurred at oblique impact angles. One class, termed as plowing deformation was caused by spherical particles and the second class, termed as cutting deformation, was caused by angular particles.

\subsubsection{Erodent Size}

For ductile materials, relative erosion is essentially independent of particle size for sizes greater than a critical value. For brittle materials the size of material is directly proportional to the erosion rate. The larger the size of the erodent, the greater the volume of material removed by impact.

\subsubsection{Angle of Attack}

Angle of incidence or the angle of attack of the particle onto the surface of the target is another parameter, which greatly influences erosion. The influence of impact angle can also help in distinguishing between ductile and brittle materials. For ductile materials the erosion loss is maximum at lower angles of incidence i.e., around $20-30^{\circ}$ whereas in brittle materials the erosion loss is maximum at normal incidence i.e., around $90^{\circ}$. Many experimental studies have confirmed this general behavior [Figure 2.1]. 


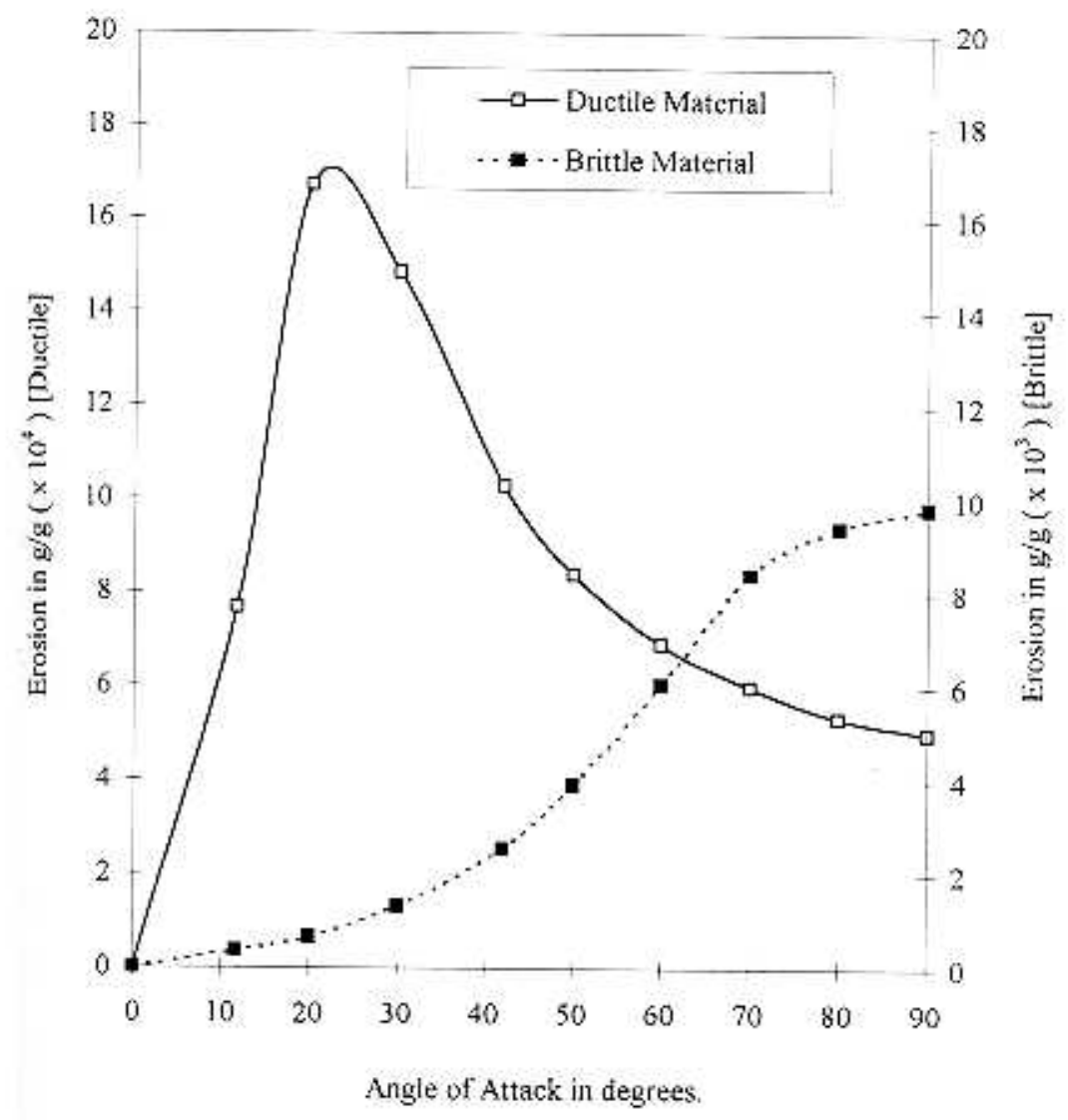

Figure : Erosion Behaviour of Brittle and Ductile Materials.

Figure 2.1 Erosion Behavior of Brittle and Ductile Materials

\subsection{SINGLE PARTICLE EROSION}

The effect of impact of a single solid particle is termed as single particle erosion. Various models are available in literature to model the erosion of ductile and brittle materials. Most of them are empirical models based on experimental results. A few analytical models are also available, which have highly restricted applications. 
Finnie [1958] proposed an erosion model derived from an analysis of the equations of motion of a single particle during its impact with a ductile surface. The particle trajectory through the material was used to estimate the volume of surface material displaced by the particle. This estimate was subjected to the following assumptions.

- Cutting of the surface is purely by plastic deformation.

- No cracks propagate ahead of the cutting particle and

- Material removal is entirely due to the displacing or cutting action of the abrasive particle.

This approach is not suitable for brittle materials.

The idealized two-dimensional picture of the cutting mechanism that takes place during erosion is shown in Figure 2.2.

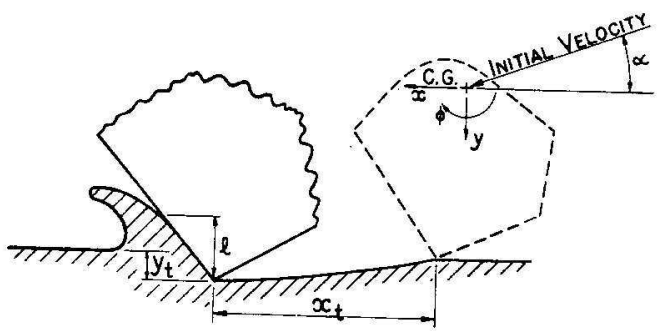
Idealized picture of abrasive grain striking a surface and removing material. Initially
the velocity vector of the particle's center of gravity makes an angle $\alpha$ with the surface.

Figure 2.2 Idealized picture of the cutting mechanism.

Finnie's single particle erosion model has the form

$$
\begin{aligned}
& \mathrm{w}=\left(\rho \mathrm{mV} \mathrm{V}^{2} / \mathrm{p} \psi \mathrm{K}\right) \mathrm{F}(\alpha) \\
& F(\alpha)=\left\{\begin{array}{cc}
1 / \sin 2 \alpha-6 / K \sin ^{2} \alpha & \text { for } \tan (\alpha)<\mathrm{k} / 6 \\
\mathrm{~K} / 6 \cos ^{2} \alpha & \text { for } \tan (\alpha)>\mathrm{k} / 6
\end{array}\right\}
\end{aligned}
$$

Here $\mathrm{w}$ represents the represents the mass of the material removed from the surface by single particle impact. $\rho$ is the density of the surface material and $m$ is the mass of the 
impacting particle. The parameter $\mathrm{p}$ is the horizontal component of contact stress, and is equivalent to "plastic flow stress". It is assumed that constant plastic flow stress is reached immediately upon contact, this implies that the average contact stresses remain constant during cutting. The parameter $\mathrm{K}$ is the ratio of vertical to horizontal force component acting on the particle .It is assumed to be constant over the duration of the cut. The parameter $\psi$ is the ratio of the length over which the abrasive particle contacts the surface to the depth of cut made by the particle and this ratio was also assumed to be constant during the cut. Scratch test experiments have shown a variation in the value of the force ratio $\mathrm{K}$ from 1.6 to 2.4 for ductile materials, to values as high as 6 . Values of $\psi$ ranging from 2 to 10 have been observed in metal cutting experiments for different angles of impact $\alpha$. This observation has lead to the conclusion that only the leading edge of the abrasive particle contacts the surface during most of the erosion process. Finnie's model inadequately described the erosion process, because no erosion was predicted at normal impact. He accounted for erosion at high angles which was not predicted by his model by taking into account three effects, which he assumed might be the reason for erosion at higher angles. The three effects he gave are as follows

- Variation from the assumed angle.

- Roughening of the surface.

- Surface embrittlement by cold work.

Finnie et al., [1967] proposed that $\mathrm{p}$ is approximately equivalent to the Vickers's Hardness Number (VHN) of the material being eroded.

In 1972, Sheldon and et al., used a gas projectile gun to accelerate individual particles of silicon carbide, steel and glass shot about $3 \mathrm{~mm}$ diameter at various velocities on to both eroded and uneroded surfaces. They noted considerable evidence of deformation adjacent to the crater in annealed material. Observations of the impact craters showed that the displaced crater material appear to have flowed in the direction of the particle incidence until the material fractured at high-accumulated strains. They found a small difference in the velocity dependence of erosion between eroded and uneroded surface. The displaced lip material detached earlier on previously eroded surfaces.

Hutchings [1981] presented a simple analytical model for erosion at normal incidence by platelet formation. He considered spherical particles for two reasons: first, because it was 
clear that, with spherical projectiles at normal incidence, platelet formation is the dominant mechanism of erosion [Bellman and Levy, 1980] second, because a firmer foundation existed for the theoretical analysis of sphere impact than for the impact of angular particles.

Hutchings proposed "critical strain" as a suitable criterion to determine failure, i.e., removal of fragment occurs when the maximum plastic strain within the fragment reaches a critical value $\varepsilon_{\text {c. }}$. Hutchings illustration of energy balance for a single impact is shown in Figure 2.3.

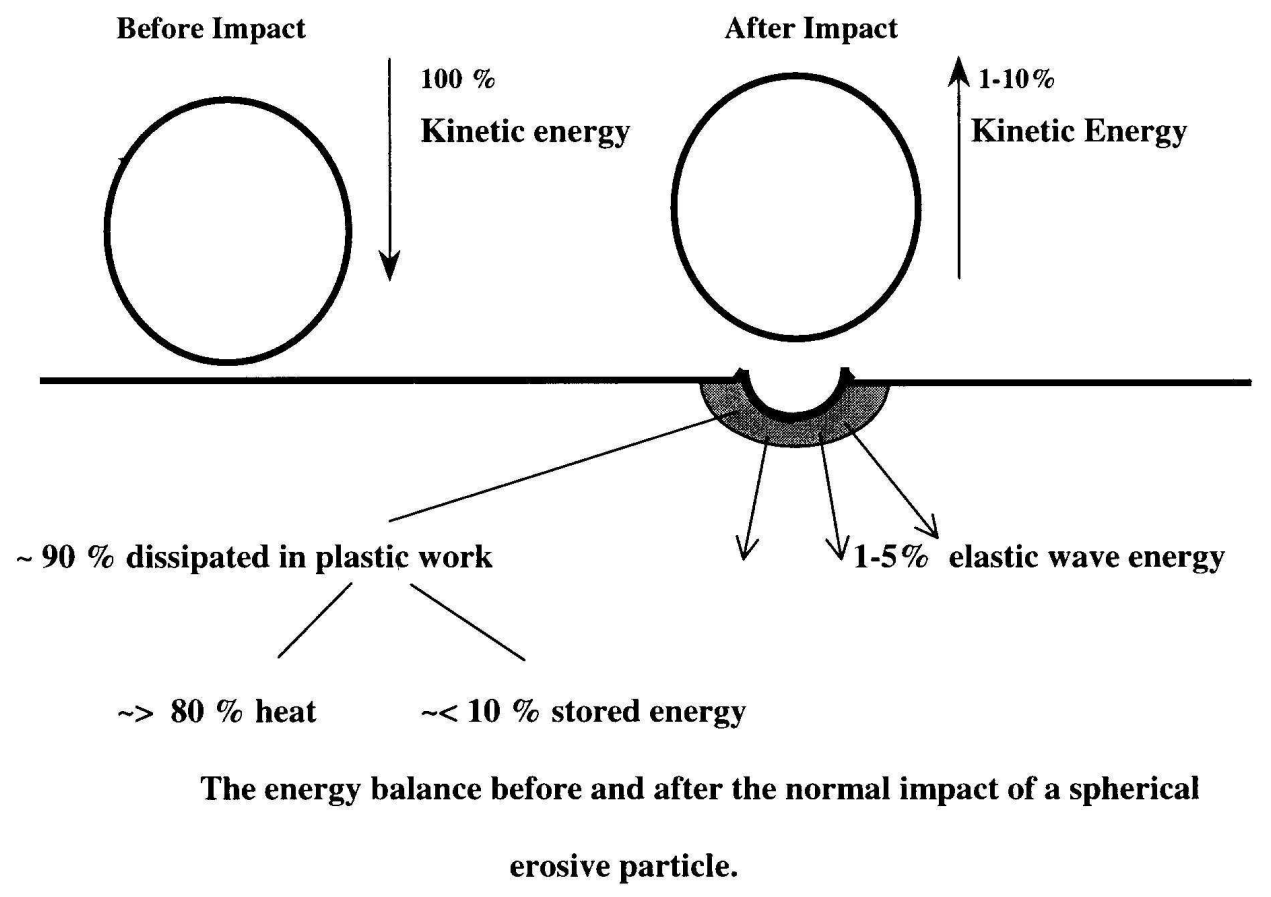

Figure 2.3 Energy balance for a single particle impact

He considered the target to be struck by a large number of spherical projectiles distributed at random over the surface, each travelling at the same velocity and therefore causing the same pattern of plastic deformation in the target on impact. He assumed that the whole volume plastically deformed by each impacting sphere is subjected to a plastic strain increment $\Delta \varepsilon_{\mathrm{p}}$ of the same magnitude and that the strain are directed circular symmetry about the line of impact of the sphere Figure 2.4. 


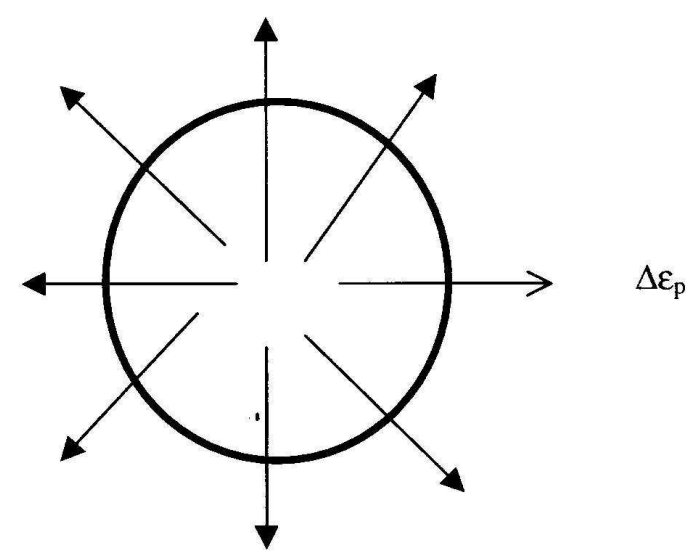

The plastic strain associated with one impact is assumed to be directed radially outwards in the plane of the surface [Hutchings, 1981]

Figure 2.4 Plastic Strain associated with single particle impact

Material at any point on the surface will therefore be subjected to successive increments of strain of magnitude $\Delta \varepsilon_{\mathrm{p}}$, randomly oriented in the plane of the surface. After $\mathrm{N}$ impacts the expectation value of the resultant strain at the point may be shown from random walk theory to be $\Delta \varepsilon_{\mathrm{p}} \mathrm{N}^{1 / 2}$. If $\mathrm{N}_{\mathrm{f}}$ is the mean number of impacts needed to cause detachment of material then application of the failure criterion gives

$$
\Delta \varepsilon_{\mathrm{p}} \mathrm{N}_{f}^{1 / 2}=\varepsilon_{\mathrm{c}}
$$

Hutchings, for simplicity assumed the metal being eroded as rigid perfectly plastic solid with no work hardening. The eroding particles were assumed to be rigid non-deforming spheres of radius $r$ and density $\sigma$. The mass $m$ of one sphere is therefore given by

$$
\mathrm{m}=4 \pi \mathrm{r}^{3} \sigma / 3
$$

and its kinetic energy at impact velocity $v$ is $\mathrm{m} v^{2} / 2$.

The behavior of the metal target was assumed to resist indentation with a constant pressure $\mathrm{P}$ (analogous to the quasi-static indentation hardness). Elastic forces were ignored. An examination of the energy balance during the impact indicated that at least $90 \%$ of the initial kinetic energy of the particle is dissipated $\mathrm{n}$ plastic deformation in the target, and this is confirmed that it is permissible, for the purpose of this calculation, to ignore elastic effects. Figure 2.3 illustrates how the kinetic energy of an erosive particle is 
partitioned after normal impact. Assuming that all the initial kinetic energy of the particle is available to form indentation, the volume of which will therefore be given by

$$
\mathrm{V}=\mathrm{m} v^{2} / 2 \mathrm{P}
$$

This relationship will be approximately true for impact on metal by erosive particles of any shape at impact velocities typical of erosion, provided that the particle does not fracture or deform and the elastic effects are neglected.

He assumed that the volume of metal, which is plastically deformed around an indentation, is some fraction $\alpha$ of the volume of indentation. Therefore the volume of material, which is plastically strained by each impact, is $\alpha m v^{2} / 2 \mathrm{P}$; which is called "elementary volume". After $\mathrm{N}_{f}$ impacts the volume loss per impact is therefore $\alpha m v^{2} / 2 \mathrm{PN}_{f}$. If the target material has density $\rho$ then the erosion $\mathrm{E}$ defined as the mass loss from the target per unit mass of impinging particles is given by

$$
\mathrm{E}=\alpha \rho v^{2} / 2 \mathrm{PN}
$$

For a quasi-static indentation by a rigid sphere of radius $r$, Tabor has shown that the average strain introduced into a metal is given by

$$
\varepsilon=0.2 \mathrm{a} / r
$$

where $a$ is the final chordal radius of the indentation and $\varepsilon$ is the strain in an equivalent uniaxial compression test.

By equating the initial kinetic energy of the impacting sphere with the work done in forming the indentation, it was shown that

$$
\alpha=2^{1 / 2} r v^{1 / 2}\left(\frac{2 \sigma}{3 P}\right)^{1 / 4}
$$

By combining the above equations, the erosion is given by

Where $\alpha$ is fraction of volume of indentation, which is plastically deformed. $\varepsilon_{\mathrm{c}}=$ critical

$$
E=0.033 \frac{\alpha \rho \sigma^{1 / 2} v^{3}}{\varepsilon_{c}^{2} P^{3 / 2}}
$$

strain

$\sigma=$ density of particle

$\rho=$ target material density

$\mathrm{P}=$ constant pressure of resistance by the target material for indentation

$v=$ impact velocity 
$r=$ radius of spherical particle

$a=$ final chordal radius of the indentation

$\varepsilon=$ strain in an uniaxial compression test

Bitter [1963] assumed that both types of erosion mechanisms - cutting and deformation, occur simultaneously. The model uses particle and surface material properties as well as empirically determined deformation wear and cutting wear factors. The Bitter model has the form

$$
w_{i}=\left(w_{i}\right)_{\mathrm{d}}+\left(w_{i}\right)_{\mathrm{c}}
$$

Good correlation with experiment was obtained and the variation of wear with impact angle was well described. As mentioned earlier, Bitter assumed "deformation wear" to be the dominant wear mechanism at normal incidence and "cutting wear" at shallow angles. But Bitter presented little justification for his assumptions.

Ives et al., carried further studies of erosion impact by single particle, they impacted spherical glass particles and angular aluminum oxide particles against annealed AISI type steel at various angles. They found that at lower angles the material was deformed and displaced from the crater into a lip at the exit end and sides. But at higher angles of incidence, a more uniform lip of material around the crater was produced. Transmission electron microscopy studies were carried out to investigate the subsurface damage. The damage consisted of high density of dislocations formed in a well-defined zone around the crater, extending a few micrometers in all directions.

More recent studies of single particle erosion were carried out by Hutchings et al. Two projectiles one steel sphere of $9.5 \mathrm{~mm}$ diameter and other a $8 \mathrm{~mm}$ square steel plate, were accelerated using a compressed gas gun system. These experiments were designed to investigate two classes of surface deformation that occurred at oblique impact angles. One class, termed as plowing was usually caused by spherical particles and the second class, termed as cutting deformation, was caused by angular particles.

\subsection{MULTIPLE PARTICLE EROSION}

In most of the applications, the erosion is carried by a stream of particle impacts. Simple consideration of the effects of these flux of particles, incident on a surface for certain 
length of time, suggests that many new complex aspects are added to the basic phenomenon. These include particle impacts within the incident stream, a wide range of simultaneous attack angles, particle fragmentation, particle embedding and surface shielding due to rebounding particles. Clearly multiple particle erosion exposures must be conducted in order to measure meaningful erosion rates of materials for application purpose. Also a clear understanding of the phenomenon is needed to calculate the erosion rates in materials.

The design techniques used in many experiments on the multiple particle impact erosion are basically of two types. In one, the specimen is moved under controlled velocity through slowly moving erosive stream. The exposure may be intermittent but can be continued for a long period of time. The second one involves exposing a stationary specimen to a stream of particles. In order to confine the erosive stream a nozzle or flight tube is used. Since the erosion rate is proportional to the power of particle velocity, accurate measurement of impact velocity is necessary in both cases.

Hutchings formulated a model for erosion of metals by spherical particles impacting at normal incidence predicting mass wear per unit mass of impacting particles. They assumed that the material removal was due to the formation and detachment of platelets of material. They showed that the detachment occurs when the plastic strain in the deformed material reaches a maximum or "critical" value. This strain was termed as "erosion ductility" of the material.

Sundararajan and Shewmon derived a model for erosion produced by particles impacting at normal angles using the criterion of a critical plastic strain needed for material removal. They assumed that the removal of extruded material takes place along the rim of the indentation crater. This model showed better correlation with experimental results compared to Hutchings model.

In 1992, Pack et al., conducted an experimental study of a high velocity, low impingement angle of jet of water/sand and the effects of this type of erosion on a variety of commonly utilized industrial materials. They showed the relationship between depth of penetration and the material types for given test parameters.

Grant et al., developed an experiment to expose a solid specimen to a stream of erosive particles. The specimen was moved at controllable velocity through a slowly moving 
erosive stream. This design allowed for accurate measurement of impact velocity. They collected experimental data for impact velocities varying from $85 \mathrm{~m} / \mathrm{s}$ to $137 \mathrm{~m} / \mathrm{s}$ for several metals. They predicted erosion rate at attack angles ranging from $30^{\circ}$ to $60^{\circ}$.

The above ductile erosion models are based on the experimental work of several investigators, these models predicted erosion loss for the specific erosion problems with some degree of practical satisfaction. However there is little information to predict erosion under new and untried circumstances. Hence, in the current work the use of a finite element model was proposed to predict material loss. The FEM model can be used to predict material loss for any new material without any degree of complexity, by just changing the material properties card in the model. The current FEM model was compared with Sheldon's and Hutchings theoretical models and a good degree of correlation was observed between the FEM model and the theoretical works. 


\section{CHAPTER 3 \\ MODEL DEVELOPMENT - PRELIMINARY CONSIDERATION}

\subsection{INTRODUCTION}

As mentioned in the previous chapter, most of the existing models for erosion are empirical based on experimental results. Most of these models are valid for a fixed set of materials and environmental conditions. But there are several new materials, which are used for different applications, and it is very costly to conduct experiments for each of them. Hence a finite element model was proposed in the current work, which takes into account all the conditions and estimates volume loss due to erosion. The model developed does not need experimental results except for the basic material properties and their behavior. Finite element software INGRID and LS-DYNA3D were used to develop and solve the model.

In the current work, a procedure was adopted to estimate loss of metal due to particle impacts. The aluminum model was developed and for this model, the work of Sheldon et al., was simulated using the erosion estimation procedure. Several parameters were varied in the model and the loss of material due to erosion was calculated. The parameters that were varied include angle of attack of the particle on to the target surface, velocity of the particle and particle size.

The present work can be extended to several metals and the erosion procedure can be adopted in calculating erosion loss. By changing the material properties, new models can be created and effect of size, velocity and angle of attack of particles on volume loss can be observed. Once the pre-model is ready, the material properties of the particle and the target surface are very important for dynamic solutions.

\subsection{MATERIAL PROPERTIES}

The material properties of the model play an important role in avoiding numerical errors. In the present work the material properties of the target metal and the impacting particle 
are key factors. The mechanical properties of the metal and that of the spherical particle are obtained from mechanical handbooks.

The mechanical properties of metals are highly dependent on temperature for large temperature ranges. The modulus of elasticity of metals decreases as the temperature increases and vice versa. Elevated temperature values of elastic modulus of metals may be determined by tensile testing at the designated temperature. At high temperature, the properties depend on strain rate also. This is due to the viscoelastic behavior of metals at elevated temperatures. Increasing strain rate increase flow stress, the strains rate dependence of strength increases with increasing temperature. The yield stress and flow stress at lower plastic strains are more dependent on strain rate than the tensile strength. The effect of temperature was not considered in the present work. The heat generated and the temperature rise due to particle impact was also not considered in the present work. Also, the metals behave in a different way when they are subjected to constant stress for a long period of time at elevated temperatures. This is called as 'creep'. The initial creep strain that occurs at a diminishing rate is designated as primary (first-stage) creep, that which occurs at a minimum and almost constant rate as secondary (second-stage) creep, and that which occurs at an accelerating rate as tertiary (third-stage) creep. This creep behavior can be obtained through creep, creep-rupture and stress-rupture tests. During a particle impact the period of impact is very small. Therefore, the viscoelastic effects and creep effects are negligible. Consideration of elastic-plastic behavior is very appropriate in modeling erosion.

For analyzing the ductile behavior of metals, mainly the following material properties are needed at the desired operating temperatures.

1. Modulus of Elasticity

2. Poisson's ratio

3. Density

4. Yield Stress

5. Ultimate tensile strength

6. Fracture toughness 
Both yield stress and the ultimate tensile strength decrease as the temperature increases. These are functions of strain rate also. Fracture toughness is the material property that has to be compared with the stress concentration factor in order to determine the crack propagation in plasticity analysis.

\subsubsection{PARTICLES}

The geometry of the deformation due to the impact of solid particles mostly depends on the shape, velocity and the orientation of the impacting particle. Some researchers broadly classified them into rounded and angular particles. The spherical particle has a point contact with the target surface whereas angular particle has either line contact or area contact. A Spherical particle will generally deform the surface by plowing, displacing the material to the side and in front of the impacting particle. The deformation caused by an angular particle depends on the orientation of the particle, as it strikes the surface and on whether the particle rolls forward or backwards during contact. If the particle rolls forward, it is termed as type I cutting as illustrated in Figure 3.1. This type of cutting indents the surface and raises the material onto prominent lip, which is vulnerable to removal by subsequent nearby impacts. The third type occurs over only narrow range of particle geometries and impact orientations. This happens when the particle rolls backward and a true machining action occurs. This is shown in Figure 3.1.

It has been shown that single impacts of spheres remove no material except above a critical velocity. The angular particle impacts remove material only for a small fraction of possible particle orientations. In majority of cases, direct material removal does not occur, but a lip of material remains attached at the end of the crater.

In the current work spherical glass particles of $3 \mathrm{~mm}$ diameter were considered. Glass particles were treated as rigid in the analysis. 

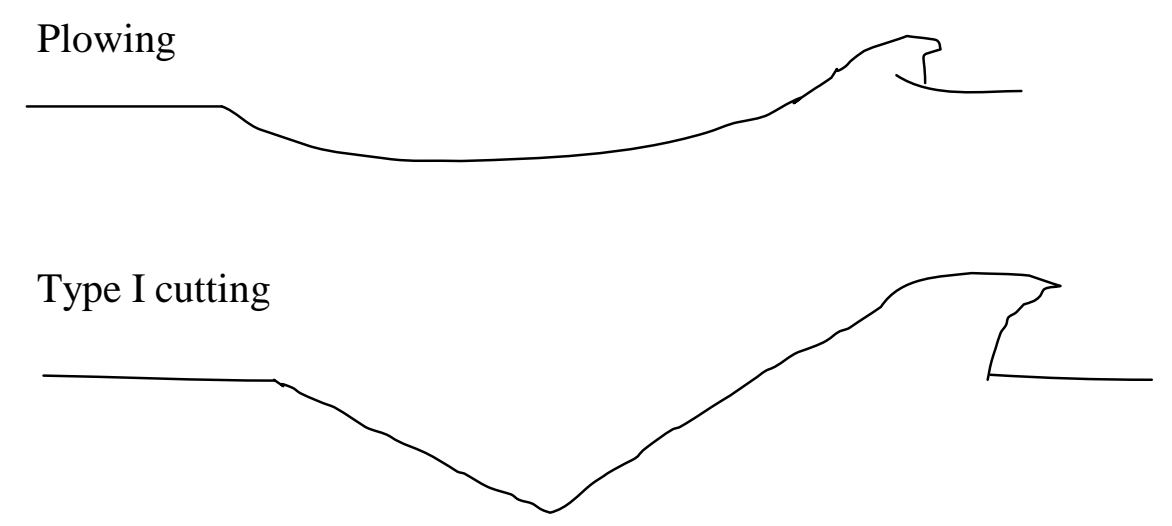

Type II cutting

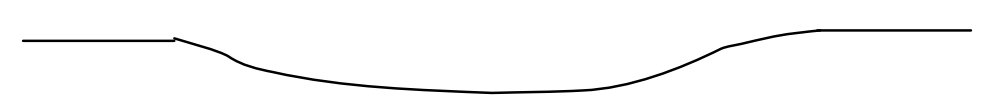

Figure 3.1 Basic Types of Impact Damage

\subsection{PLASTICITY THEORY}

The theory of plasticity deals with the behavior of materials at strains where Hooke's law is no longer valid. A number of aspects of plastic deformation make the mathematical formulation of theory of plasticity more difficult than the description of behavior of elastic solid. For example, plastic deformation is not a reversible process like elastic deformation. Elastic deformation depends only on the initial and final states of stress and strain, whereas the plastic strain depends on the loading path by which the final state is achieved. In plastic deformation stress-strain relation is non-linear.

\subsubsection{FLOW CURVE}

A true stress-strain curve is frequently called a flow curve. Flow curve is of fundamental interest in plasticity, because it gives the stress required to cause the metal to flow plastically at any given strain. The simple mathematical expression for the flow curve is of the form

$$
\sigma=\mathrm{K} \varepsilon^{\mathrm{n}}
$$

Where $\mathrm{K}$ is the stress at $\varepsilon=1.0$ and

$\mathrm{n}=$ the strain hardening coefficient which is the slope of the log-log plot of the above equation. 
This equation can be valid only from the beginning of plastic flow to the maximum load at which the specimen begins to neck down.

The true stress-strain curve for a typical ductile metal such as aluminum is shown in Figure 3.2a. Aluminum has a flow curve with a gradual transition from elastic to plastic behavior, with no yield point. Whereas metals like low carbon steel, show a localized, heterogeneous type of transition from elastic to plastic deformation which produces a yield point in the stress-strain curve.

Hooke's law is followed up to some yield stress $\sigma_{0}$, beyond yield stress the metal deforms plastically. Most metals strain-harden in this region, so that increases in strain require higher values of stress than the yield stress $\sigma_{0}$. The stress and strain are not linearly related in this region. As shown in the Figure 3.2a after the load is released the metal has a permanent set plastic strain, however a small amount of plastic strain $\left(\varepsilon_{2}-\varepsilon_{3}\right.$ as shown in Figure) will disappear with time. This is known as anelastic behavior. Generally anelastic strain is neglected in plasticity theory.

Usually stress-strain curve on unloading will not be exactly linear and parallel to the elastic portion of the curve as shown in Figure 3.2b. The hysteresis behavior resulting from unloading and loading from a plastic strain is generally neglected in plasticity theories.

If a material is deformed plastically beyond yield stress in one direction e.g., in tension and then after unloading to zero stress it is reloaded in the opposite direction e.g., in compression, it is found that yield stress on reloading is less than the original yield stress. The dependence of yield stress on loading path and direction is called the Bauschinger effect. The Bauschinger effect is commonly ignored in plasticity theory, and it is assumed that the yield stress in tension and compression are the same. 


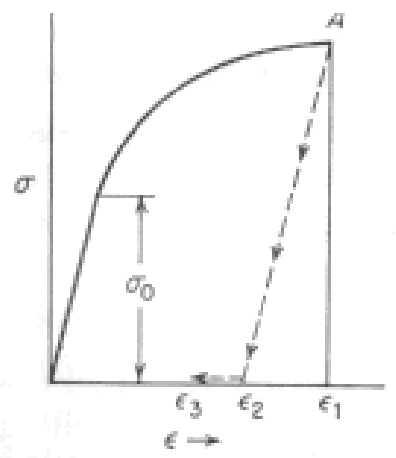

(a)

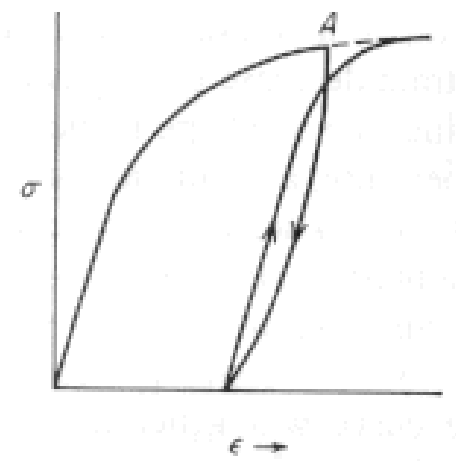

(b)

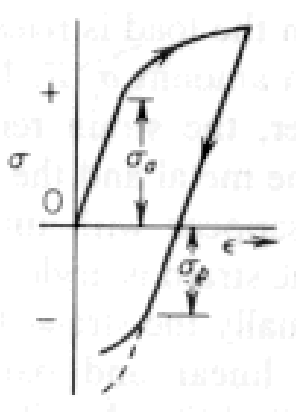

(c)

Figure 3.2 Typical true stress-strain curves for a ductile metal

Even the simple mathematical expression for the flow curve that is given by the equation can result in considerable mathematical complexity when it is used with the equations of the theory of plasticity. Therefore, in this field it is common practice to devise idealized flow curves, which simplify the mathematics without deviating too far from physical reality. The idealized flow curves are shown in Figure 3.3. The flow curve for a rigid, perfectly plastic material is shown in Figure 3.3a. This material is completely rigid (zero elastic strain) until the axial stress equals $\sigma_{0}$, after which the material flows plastically at a constant flow stress (zero strain hardening). This type of behavior is approached by a ductile metal, which is in a highly cold worked condition. Figure 3.3b shows the flow curve for a perfectly plastic material with an elastic region. A material such as plain carbon steel, which has a pronounced, yield point elongation, approaches this behavior. A more realistic approach is to approximate the flow curve by two straight lines corresponding to the elastic and plastic regions [Figure 3.3c]. This type of curve results in somewhat more complicated mathematics.

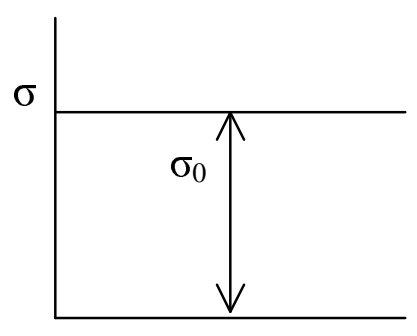

$\varepsilon$

Figure 3.3a

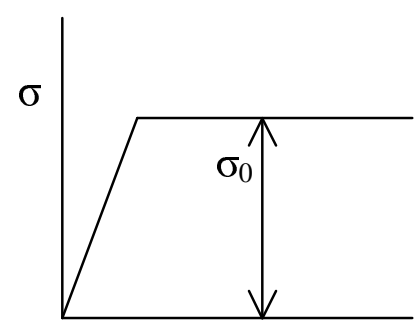

$\varepsilon$

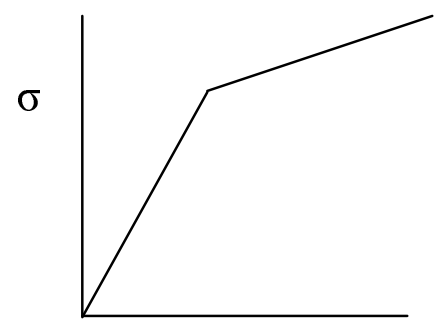

$\varepsilon$

Figure $3.3 \mathrm{c}$ 


\subsubsection{Hydrostatic and Deviator components of Stress}

The total stress tensor can be divided into hydrostatic or mean stress tensor $\sigma_{m}$, which involves only pure tension or compression, and a deviator stress tensor $\sigma_{i j}$, which represents shear stress in the total state of stress. Hydrostatic component of the stress tensor produces only elastic volume changes and does not cause plastic deformation. It has been shown by experiments that the yield stress of metals is independent of the hydrostatic stress, although the fracture strain is strongly influenced by the hydrostatic stress. Because, the stress deviator involves the shearing stresses, it is important in causing plastic deformation, it is also useful in formulating theories of yielding.

The hydrostatic or mean stress is given by

$$
\sigma_{m}=\frac{\sigma_{k k}}{3}=\frac{\sigma_{x}+\sigma_{y}+\sigma_{z}}{3}=\frac{\sigma_{1}+\sigma_{2}+\sigma_{3}}{3}
$$

The decomposition of the stress tensor is given by

$$
\sigma_{i j}=\sigma_{i j}^{\prime}+\frac{\delta_{i j} \sigma_{k k}}{3}
$$

Therefore, deviator stress is given by

$$
\begin{aligned}
& \sigma_{i j}^{\prime}=\sigma_{i j}-\sigma_{m} \delta_{i j} \\
& \sigma_{i j}^{\prime}=\left|\begin{array}{l}
\frac{2 \sigma_{x}-\sigma_{y}-\sigma_{z}}{3} \tau_{x y} \tau_{x z} \\
\tau_{y x} \frac{2 \sigma_{y}-\sigma_{z}-\sigma_{x}}{3} \tau_{y z} \\
\tau_{z x} \tau_{z y} \frac{2 \sigma_{z}-\sigma_{x}-\sigma_{y}}{3}
\end{array}\right|
\end{aligned}
$$

Referring $\sigma_{i j}^{\prime}$ to a system of principal axes

$$
\sigma_{i j}^{\prime}=\frac{2 \sigma_{1}-\sigma_{2}-\sigma_{3}}{3}
$$




\subsubsection{Invariants of Stress and Strain}

It is frequently useful to simplify the representation of a complex state of stress or strain by means of invariant functions of stress and strain. If the plastic stress-strain curve (flow curve) is plotted in terms of invariants of stress and strain, approximately the same curve will be obtained regardless of the state of stress. For example, the flow curves obtained in a uniaxial-tension test and a biaxial-torsion test of a thin tube with internal pressure will coincide when the curves are plotted in terms of invariant stress and strain functions. The most frequently used invariant function to describe plastic deformation is the effective stress $\bar{\sigma}$ or effective strain $\bar{\varepsilon}$.

$$
\begin{gathered}
\bar{\sigma}=\frac{\sqrt{2}}{2}\left[\left(\sigma_{1}-\sigma_{2}\right)^{2}+\left(\sigma_{2}-\sigma_{3}\right)^{2}+\left(\sigma_{3}-\sigma_{1}\right)^{2}\right]^{1 / 2} \\
d \bar{\varepsilon}=\frac{\sqrt{2}}{2}\left[\left(d \varepsilon_{1}-d \varepsilon_{2}\right)^{2}+\left(d \varepsilon_{2}-d \varepsilon_{3}\right)^{2}+\left(d \varepsilon_{3}-d \varepsilon_{1}\right)^{2}\right]^{1 / 2}
\end{gathered}
$$

The above equation for critical strain can be simplified as

$$
d \bar{\varepsilon}=\left[\frac{2}{3}\left(d \varepsilon_{1}^{2}+d \varepsilon_{2}^{2}+d \varepsilon_{3}^{2}\right)\right]^{1 / 2}
$$

or in terms of total plastic strain

$$
\bar{\varepsilon}=\left[\frac{2}{3}\left(\varepsilon_{1}^{2}+\varepsilon_{2}^{2}+\varepsilon_{3}^{2}\right)\right]^{1 / 2}
$$

The strains used in the above equations should be the plastic portion of the total strain, denoted by $\varepsilon_{i}^{P}$, where $\varepsilon_{i}^{P}=\varepsilon_{i}($ total $)-\varepsilon_{i}$ (elastic). In dealing with problems in metalworking the elastic strain is negligible, but in plasticity problems involving strains at a notch, overstressing of pressure vessels, etc., the elastic strains usually cannot be ignored.

\subsubsection{YIELDING CRITERIA FOR DUCTILE METALS}

The problem of deducing mathematical relationships for predicting the conditions at which plastic yielding begins when a material is subjected to any possible combination of stresses is an important consideration in the field of plasticity. In uniaxial loading as in a 
tension test, macroscopic plastic flow begins at yield stress $\sigma_{0}$. It is expected that yielding under a situation of combined stresses can be related to some particular combination of principal stresses. There is at present no theoretical way of calculating relationship between the stress components to correlate yielding for a three-dimensional state of stress with yielding in the uniaxial tension test.

The yielding criteria are essentially empirical relationships. However, a yield criterion must be consistent with a number of experimental observations, the chief of which is that pure hydrostatic pressure does not cause yielding in a continuous solid. As a result of this, the hydrostatic component of a complex state of stress does not influence the stress at which yielding occurs. Therefore we look for the stress deviator to be involved with yielding. Moreover, for an isotropic material, the yield criterion must be independent of the choice of axes, i.e., it must be an invariant function. These considerations lead to the conclusion that the yield criteria must be some function of the invariants of the stress deviator. At present Von-Mises' or Distortion-Energy criterion is generally accepted criteria for predicting the onset of yielding in ductile metals. Von Mises proposed that yielding would occur when the second invariant of the stress deviator $\mathbf{J}_{2}$ exceeded some critical value.

$$
\mathrm{J}_{2}=\mathrm{k}^{2}
$$

Where $\mathrm{J}_{2}=1 / 6\left[\left(\sigma_{1}-\sigma_{2}\right)^{2}+\left(\sigma_{2}-\sigma_{3}\right)^{2}+\left(\sigma_{3}-\sigma_{1}\right)^{2}\right]^{1 / 2}$

The constant $\mathrm{k}$ is evaluated by relating it to yielding in the tension test.

$$
\mathrm{k}=\sigma 0 / \sqrt{3}
$$

The general form of Von-Mises yield criterion is given by

$$
\sigma_{0}=\frac{1}{\sqrt{2}}\left[\left(\sigma_{1}-\sigma_{2}\right)^{2}+\left(\sigma_{2}-\sigma_{3}\right)^{2}+\left(\sigma_{3}-\sigma_{1}\right)^{2}\right]^{1 / 2}
$$

\subsubsection{YIELD SURFACE}

The relationships that have been developed for yield criteria, can be represented geometrically by a cylinder oriented at equal angles to the $\sigma_{1}, \sigma_{2}, \sigma_{3}$ axes. A state of stress, which gives a point inside of the cylinder, represents elastic behavior. Yielding begins when the state of stress reaches the surface of the cylinder, which is called yield 
surface. The radius of the cylinder is the stress deviator and the axis of the cylinder is the hydrostatic component of stress. Since plastic deformation is not influenced by hydrostatic stress, the generator of the yield surface is a straight line parallel to the axis, so that the radius of the cylinder is constant. As plastic deformation occurs, the yield surface expands outward, maintaining its same geometric shape.

The yield surface shown in Figure is a circular cylinder if it represents the Von Mises' yield criterion. If a plane is passed through this surface parallel to the $\sigma_{2}$ axis, it intersects on the $\sigma_{1} \sigma_{3}$ plane as an ellipse.

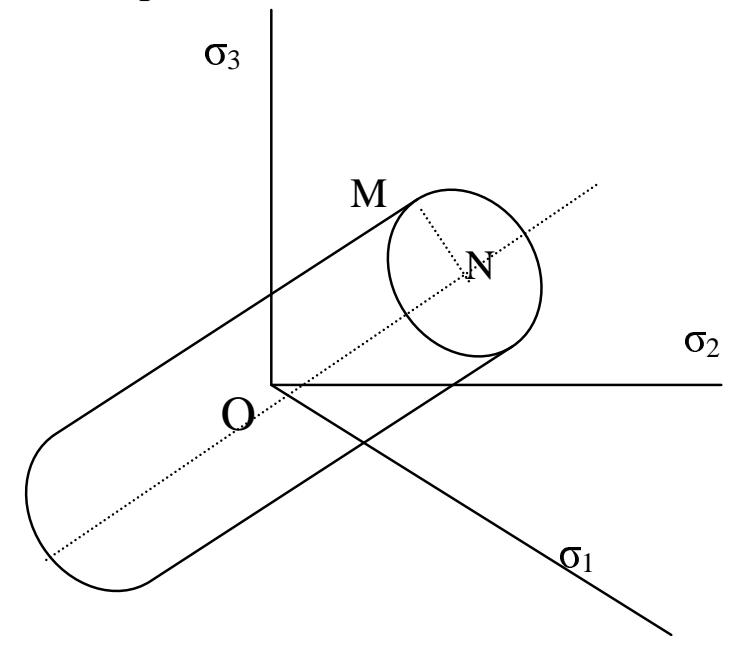

Figure 3.4 Yield surface for Von-Mises' criterion

The yield surface for the maximum shear- stress criterion is a hexagonal cylinder. Yield surface even though is an important concept in plasticity theory; there is no extensive body of experimental data on the shape of the surface. Drucker has shown that the total plastic strain vector must be normal to the yield surface, so any acceptable yield surface must be convex about its origin. Because of normality there is no component of total strain vector that acts in the direction of $\sigma_{\mathrm{m}}$. Therefore, the hydrostatic component of stress does not act to expand the yield surface. As the deviatoric component of stress acts in the same direction as the total strain vector their dot product causes the plastic work, as the yield surface is expanded by plastic deformation.

\subsubsection{PLASTIC STRESS-STRAIN RELATIONS}

It is necessary to consider the relations between stress and strain in plastic deformation. In elastic region the strains are uniquely determined by the stresses through Hooke's law 
with out regard to how stress state was achieved, this is not the case for plastic deformation. In plastic region the strains are not uniquely determined by stresses but depend on the entire history of loading. Therefore, in plasticity it is necessary to determine the differentials or increments of plastic strain throughout the loading path and then obtain the total strain by integration or summation.

There are two general categories of plastic stress-strain relationships. Incremental or flow theories relate the stresses to the plastic strain increments. Deformation or total strain theories relate the stresses to the total plastic strain. Deformation theory simplifies the solution of plasticity problems, but the plastic strains are in general cannot be considered independent of loading path. Except for the particular class of loading paths in which all stresses increase in the same ratio, proportional loading, the plastic strains are independent of the loading path and depend only on the final state of stress.

Levy-Mises Equations (Ideal Plastic Solid): The relationship between stress and strain for an ideal plastic solid, where the elastic strains are negligible, are called flow rules or the Levy-Mises equations. If we consider yielding under uniaxial tension, then $\sigma_{1}^{\prime} \neq 0$, $\sigma_{2}=\sigma_{3}=0$, and $\sigma_{m}=\sigma_{1} / 3$. Therefore the deviatoric stresses, which cause yielding, are

$$
\begin{aligned}
& \sigma_{1}^{\prime}=\sigma_{1}-\sigma_{m}=\frac{2 \sigma_{1}}{3} ; \quad \sigma_{2}^{\prime}=\sigma_{3}^{\prime}=\frac{-\sigma_{1}}{3} \\
& \sigma_{1}^{\prime}=-2 \sigma_{2}^{\prime}=-2 \sigma_{3}^{\prime}
\end{aligned}
$$

From the condition of constancy of volume in plastic deformation

$$
d \varepsilon_{1}=-2 d \varepsilon_{2}=-2 d \varepsilon_{3}
$$

Therefore $\frac{d \varepsilon_{1}}{d \varepsilon_{2}}=\frac{\sigma_{1}^{\prime}}{\sigma_{2}^{\prime}}$

This can be generalized to the Levy-Mises

$$
\frac{d \varepsilon_{1}}{\sigma_{1}^{\prime}}=\frac{d \varepsilon_{2}}{\sigma_{2}^{\prime}}=\frac{d \varepsilon_{3}}{\sigma_{3}^{\prime}}=d \lambda
$$

These equations express the fact that at any instant of deformation the ratio of the plastic strain increments to the current deviatoric stresses is constant. By using $[\mathrm{Eq}]$ the above equations can be written in terms of the actual stresses 


$$
d \varepsilon_{1}=\frac{2}{3} d \lambda\left[\sigma_{1}-\frac{1}{2}\left(\sigma_{2}+\sigma_{3}\right)\right]
$$

$d \lambda$ is evaluated using the effective strain, which yields $\overline{d \varepsilon}=\frac{2}{3} d \lambda \bar{\sigma}$.

The Levy-Mises equations then can be written as

$$
d \varepsilon_{1}=\frac{\overline{d \varepsilon}}{\bar{\sigma}}\left[\sigma_{1}-\frac{1}{2}\left(\sigma_{2}+\sigma_{3}\right)\right]
$$

Prandtl-Reuss Equations (Elastic-Plastic Solid): The Levy-Mises equations can only be applied to problems of large plastic deformation, like metalworking, because they neglect elastic strains. But in plasticity problems involving strain at a notch etc., elastic strains usually cannot be neglected. Therefore to treat the important, but more difficult problems in the elastic-plastic region it is necessary to consider both elastic and plastic components of strain. Prandtl and Reuss proposed these equations.

The total strain increment is the sum of an elastic strain increment $d e^{E}$ and a plastic strain increment $d \varepsilon^{P}$.

$$
d \varepsilon_{i j}=d e_{i j}^{E}+d \varepsilon_{i j}^{P}
$$

The elastic strain increment is given by

$$
d e_{i j}^{E}=\frac{1+v}{E} d \sigma_{i j}^{\prime}+\frac{1-2 v}{E} \frac{d \sigma_{k k}}{3} \delta_{i j}
$$

The plastic strain increment is given by the Levy-Mises equations, which can be written as

$$
d \varepsilon_{i j}^{P}=\frac{3}{2} \frac{\overline{d \varepsilon}}{\bar{\sigma}} \sigma_{i j}^{\prime}
$$

Thus, the stress, strain relations for an elastic-plastic solid are given by

$$
d \varepsilon_{i j}=\frac{1+v}{E} d \sigma_{i j}^{\prime}+\frac{1+2 v}{E} \frac{d \sigma_{k k}}{3} \delta_{i j}+\frac{3}{2} \frac{d \bar{\varepsilon}}{\bar{\sigma}} \sigma_{i j}^{\prime}
$$




\subsection{RATE INDEPENDENT PLASTICITY}

A material is called nonlinear if stresses $\{\sigma\}$ and strains $\{\varepsilon\}$ are related by a strain dependent matrix rather than matrix of constants. Thus the computational difficulty is that equilibrium equations must be written using material properties that depend on strains, but strains are not in advance. Plastic flow is often a cause of material nonlinearity.

Rate-independent plasticity is characterized by irreversible straining that occurs in a material once a certain level of stress is reached. The plastic strains are assumed to develop instantaneously, that is independent of time.

Plasticity theory provides a mathematical relationship that characterizes the elastic-plastic response of materials. There are three parts in the rate-independent plasticity theory: a yield criterion, a flow rule, and a hardening rule. The general theory and its special forms are contrived to fit experimental data.

Yield Criterion: The yield criterion determines the stress level at which yielding is initiated. For multi-component stresses, we define a yield function $F$, which is a function of stresses $\{\sigma\}$ and quantities $\{\alpha\}$ and $\mathrm{W}_{\mathrm{p}}$ associated with the hardening rule. Yielding occurs when

$$
F\left(\sigma, \alpha, \mathrm{W}_{\mathrm{p}}\right)=0
$$

If we evaluate $F$ using given values of $\{\sigma\},\{\alpha\}$, and $\mathrm{W}_{\mathrm{p}}$, then the possible results are $F<$ 0 and $F=0$, these results mean that the material is in the elastic range or is yielding. The result $F>0$ is not physically possible, as it indicates a state of stress that does not satisfy constitutive law. Similarly, the respective results $d F<0$ and $d F=0$ imply elastic unloading and continued yielding. The result $d F>0$ is not possible in plastic regime.

Flow Rule: The flow rule determines the direction of plastic straining and is given as:

$$
\left\{d \varepsilon^{p l}\right\}=\lambda\left\{\frac{\partial Q}{\partial \sigma}\right\}
$$

Where $\lambda$ =plastic multiplier (which determines the amount of plastic straining) $Q=$ function of stress, $Q=Q\left(\sigma, \alpha, \mathrm{W}_{\mathrm{p}}\right)$, termed the plastic potential, it has units of stress (which determines the direction of plastic straining). 
If $Q=F$ the flow rule is termed as 'associative' and the plastic strains occur in a direction normal to the yield surface. If $Q \neq F$ the flow rule is 'nonassociative'. Associated flow rules are commonly used for ductile metals, but nonassociated rules are better suited to soil and granular materials.

Hardening Rule: The hardening rule describes the changing of the yield surface with progressive yielding, so that the conditions (i.e., stress states) for subsequent yielding can be established. Two hardening rules are work (or isotropic) hardening and kinematic hardening. In work hardening, the yield surface remains centered about its initial centerline and expands in size as the plastic strains develop. For materials with isotropic plastic behavior this is termed isotropic hardening. Kinematic hardening assumes that the yield surface remains constant in size and the surface translates in stress space with progressive yielding as shown in Figure 3.5.

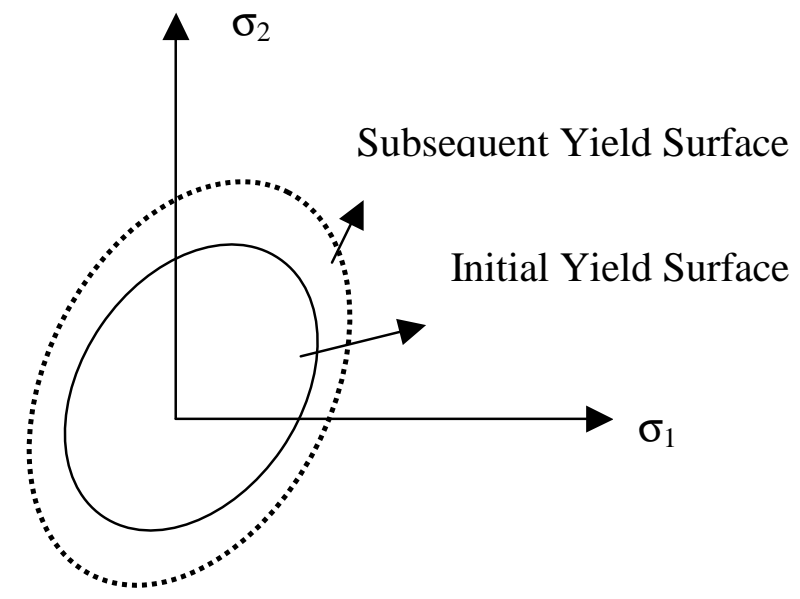

Isotropic Work Hardening

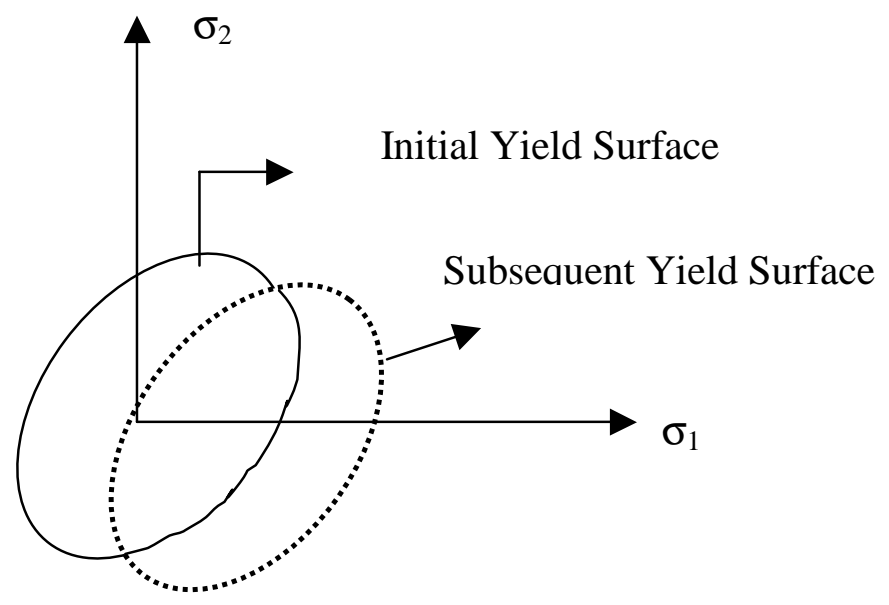

Kinematic Hardening

Figure 3.5 Hardening Rules

In the equation $F\left(\sigma, \alpha, \mathrm{W}_{\mathrm{p}}\right)=0,\{\alpha\}$ locates the center of the yield surface in stress space. Initially, before any plastic strains appear, $\{\alpha\}=\{0\}$. In kinematic hardening the center moves in the direction of plastic straining, so $\{\alpha\}$ is nonzero. The parameter $\mathrm{W}_{\mathrm{p}}$ describes how the yield surface grows, in isotropic hardening, $\mathrm{W}_{\mathrm{p}}$ is nonzero but $\{\alpha\}$ is zero. The quantities $\{\alpha\}$ and $\mathrm{W}_{\mathrm{p}}$ are defined as

$\{\alpha\}=\int C\left\{d \varepsilon^{p}\right\} \quad$ and $\quad W_{p}=\int\{\sigma\}^{T}\left\{d \varepsilon^{p}\right\}$ 
Where $C$ can be assumed to be a material constant. For pure kinematic hardening, $C=H$ (the strain hardening parameter). $W_{p}$ can be identified as plastic work per unit volume. If we use $W_{p}$ in the above function $F$, it implies a work hardening model, otherwise if we use effective plastic strain $\varepsilon_{e f}^{p}$, it implies a strain-hardening model. Either model can be used to represent isotropic hardening.

Incremental stress - strain relation analogous to the relation $\{\sigma\}=\{E\}\{\varepsilon\}$ of elasticity but valid into the elastic - plastic region, is derived as follows.

Differentiating the function $F$ we get

$$
d F=0=\left\{\frac{\partial F}{\partial \sigma}\right\}^{T}\{d \sigma\}+\left\{\frac{\partial F}{\partial \alpha}\right\}^{T}\{d \alpha\}+\frac{\partial F}{\partial W_{p}} d W_{p}
$$

and we also know that $\{d \alpha\}=C\left\{d \varepsilon^{p}\right\}$ and $d W_{p}=\{\sigma\}^{T}\left\{d \varepsilon^{p}\right\}$

$$
\{d \sigma\}=[E]\left\{d \varepsilon^{e}\right\}=[E]\left(\{d \varepsilon\}-\left\{d \varepsilon^{p}\right\}\right)
$$

Solving for the plastic multiplier we get

$$
\begin{gathered}
d \lambda=\left\{C_{\lambda}\right\}^{T}\{d \varepsilon\} \\
\text { Where }\left\{C_{\lambda}\right\}^{T}=\frac{\left\{\frac{\partial F}{\partial \sigma}\right\}^{T}[E]}{\left\{\frac{\partial F}{\partial \sigma}\right\}^{T}[E]\left\{\frac{\partial Q}{\partial \sigma}\right\}-C\left\{\frac{\partial F}{\partial \alpha}\right\}^{T}\left\{\frac{\partial Q}{\partial \sigma}\right\}-\frac{\partial F}{\partial W_{P}}\{\sigma\}^{T}\left\{\frac{\partial Q}{\partial \sigma}\right\}}
\end{gathered}
$$

The size of plastic strain increment is therefore related to the total increment in strain, the current stress state, and the specific forms of yield and potential surfaces. The plastic strain is then computed by

$$
\left\{d \varepsilon^{p}\right\}=\left\{\frac{\partial Q}{\partial \sigma}\right\} d \lambda
$$

and stress increment is given by

$$
\{d \sigma\}=[E]\left(\{d \varepsilon\}-\left\{\frac{\partial Q}{\partial \sigma}\right\} d \lambda\right) \quad \text { or } \quad\{d \sigma\}=\left[E_{e p}\right]\{d \varepsilon\}
$$

Where

$$
\left[E_{e p}\right]=[E]-[E]\left\{\frac{\partial Q}{\partial \sigma}\right\}\left\{C_{\lambda}\right\}^{T}
$$


The above equation can be regarded as generalized form of tangent modulus $E_{t}$. The matrix $\left[\mathrm{E}_{\mathrm{ep}}\right]$ is symmetric if $F=Q$, it is valid even if the material is elastic - perfectly plastic.

The Von Mises Criterion, Kinematic Hardening: The commonly used forms are the VonMises yield criterion and its associated flow rule. These forms are popular for analysis of isotropic ductile metals.

The deviatoric stresses $\{\mathrm{s}\}$, which are associated with distortion of shape but produce no volume change is given by,

$\{s\}=\{\sigma\}-\sigma_{m}[111000]^{T}$ Where $\sigma_{m}=\frac{1}{3}\left(\sigma_{x}+\sigma_{y}+\sigma_{z}\right)$

Stress $\sigma_{m}$ is the mean or average normal stress.

The deviatoric stresses $\{s\}$ has two components $\left\{s_{\sigma}\right\}$ and $\left\{s_{\tau}\right\}$ which are given as follows $\{s\}=\left\{\begin{array}{c}s_{\sigma} \\ s_{\tau}\end{array}\right\} \quad$ Where $\left\{s_{\sigma}\right\}=\left\{\begin{array}{c}s_{x} \\ s_{y} \\ s_{z}\end{array}\right\}$ and $\left\{s_{\tau}\right\}=\left\{\begin{array}{l}\tau_{x y} \\ \tau_{y z} \\ \tau_{z x}\end{array}\right\}$

Similarly, the yield surface translation vector $\{\alpha\}$, can be split into two components $\left\{\alpha_{\sigma}\right\}$ and $\left\{\alpha_{\tau}\right\}$. If $\sigma_{Y}$ is the yield strength in a uniaxial tensile test ( $\sigma_{Y}$ is taken as the initial yield strength unchanged by subsequent plastic strains), the yield function is given by

$$
F=\left[\frac{3}{2}(\{s\}-\{\alpha\})^{T}(\{s\}-\{\alpha\})\right]^{\frac{1}{2}}-\sigma_{Y}=0
$$

The equivalent stress is $\sigma_{e}=\frac{3}{2}\left[(\{s\}-\{\alpha\})^{T}(\{s\}-\{\alpha\})\right]^{\frac{1}{2}}$

When $\sigma_{e}$ is equal to the uniaxial yield stress, $\sigma_{Y}$, the material is assumed to yield.

The associated flow rule $(\mathrm{Q}=\mathrm{F})$ yields the increment in plastic strain, which is normal to yield surface as follows

$$
\left\{d \varepsilon^{p}\right\}=\left\{\frac{\partial F}{\partial \sigma}\right\} d \lambda=\left(\frac{3}{2 \sigma_{Y}}\left\{\begin{array}{l}
s_{\sigma}-\alpha_{\sigma} \\
0
\end{array}\right\}+\frac{3}{\sigma_{Y}}\left\{\begin{array}{l}
0 \\
s_{\tau}-\alpha_{\tau}
\end{array}\right\}\right) d \lambda
$$

The above equation is known as Prandtl-Reuss relation. 
If the post yield portion of the stress-strain relation is not to be idealized as a straight line, one must store the following data for an isotropic material: $E, v, \sigma_{Y}$, and a functional or tabular representation of $H$ or $E_{t}$ versus $\varepsilon_{e f}^{P}$, where $\varepsilon_{e f}^{P}$ is an effective plastic strain defined by

$\varepsilon_{e f}^{P}=\frac{\sqrt{2}}{3}\left[\left(\varepsilon_{x}^{P}-\varepsilon_{y}^{P}\right)^{2}+\left(\varepsilon_{y}^{P}-\varepsilon_{z}^{P}\right)^{2}+\left(\varepsilon_{z}^{P}-\varepsilon_{x}^{P}\right)^{2}+\frac{3}{2}\left\{\left(\gamma_{x y}^{p}\right)^{2}+\left(\gamma_{y z}^{P}\right)^{2}+\left(\gamma_{z x}^{P}\right)^{2}\right\}\right]^{1 / 2}$

In the plastic range where Poisson's ratio is 0.5 , uniaxial stress $\sigma_{x}$ produces $\varepsilon_{e f}^{P}=\left|\varepsilon_{x}^{P}\right|$, so that data from a tension test are easily plotted and converted to a numerical representation. In computations with multiaxial states of stress and strain, all terms in the above equation maybe needed to compute $\varepsilon_{e f}^{P}$.

Elastic-Plastic action in uniaxial stress: Elastic-Plastic action in uniaxial stress can be summarized as follows. The yield criterion states that yielding begins when $|\sigma|$ reaches $\sigma_{Y}$, where $\sigma_{Y}$ is the tensile yield strength. Subsequent plastic deformation may alter the stress needed to produce renewed or continued yielding; this stress exceeds the initial yield strength $\sigma_{Y}$ if $E_{t}>0$. A flow rule can be written in multidimensional problems, it leads to a relation between stress increments $\{d \sigma\}$ and strain increments $\{d \varepsilon\}$.

In uniaxial stress this relation is simply $d \sigma=E_{t} d \varepsilon$, which describes the increment of stress produced by increment of strain, however if the material has yet to yield or is unloading then the relation is $d \sigma=E d \varepsilon$.

Finally, there is a hardening rule, which describes how the yield criterion is changed by history of plastic flow. For example if unloading occurs from point B as shown in Figure 3.6, with reloading from point $C$, response will be elastic until $\sigma>\sigma_{B}$, when renewed yielding occurs. If yielding reappears when $|\sigma|>\sigma_{\mathrm{B}}$, whether $\sigma$ is tensile or compressive, this type of behavior is termed as isotropic hardening rule. However, for common such a rule is in conflict with the observed behavior that yielding reappears at a stress of approximate magnitude $\sigma_{B}-2 \sigma_{Y}$ when loading is reversed. Accordingly, a better match to observed behavior is provided by the Kinematic-hardening rule, which (for uniaxial 
stress) says that, a total elastic range of $2 \sigma_{Y}$ is preserved. It is not essential that the postelastic response is idealized as a straight line, i.e., $E_{t}$ need not be constant.

As shown in the Figure 3.6 after the yielding has occurred, strain increment $d \varepsilon$ takes place. This strain increment can be regarded as composed of an elastic contribution $d \varepsilon^{e}$ and a plastic contribution $d \varepsilon^{p}$, so that $d \varepsilon=d \varepsilon^{e}+d \varepsilon^{p}$. The corresponding stress increment $d \sigma$ can be written as

$d \sigma=E\left(d \varepsilon-d \varepsilon^{p}\right) \quad d \sigma=E_{t} d \varepsilon \quad$ and $\quad d \sigma=H d \varepsilon^{p}$

Where $H$ is called the strain-hardening parameter and is given by

$$
H=\frac{E_{t}}{1-\left(E_{t} / E\right)} \text { or } \quad E_{t}=E\left(1-\frac{E}{E+H}\right)
$$

Where $E_{t}$ is the tangent modulus.

If $\mathrm{E}$ is finite and $E_{t}=0$, then $H=0$, and the material is called 'elastic-perfectly plastic'.
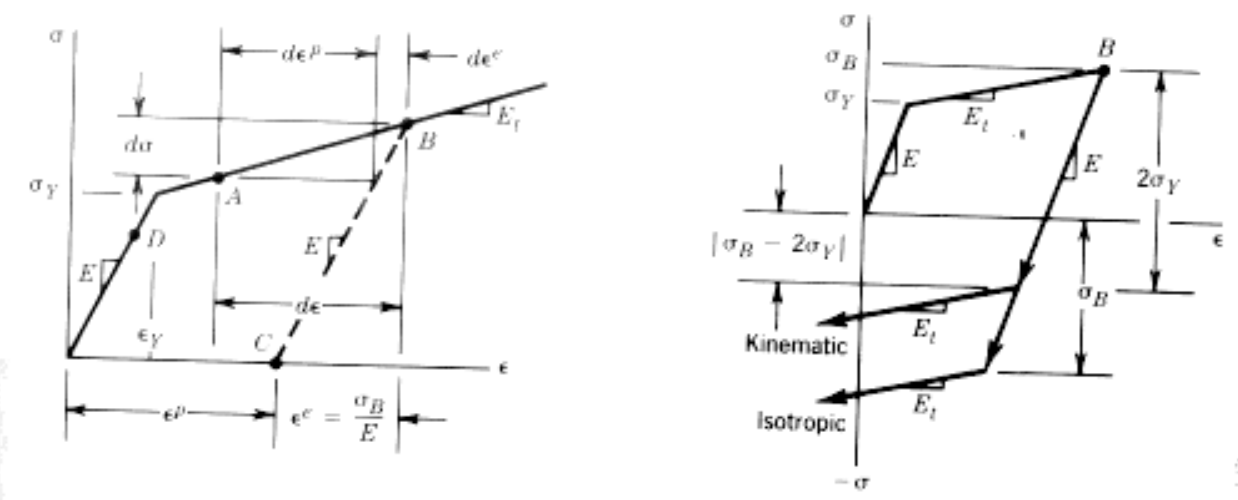

Figure 3.6 Stress - Strain Curves showing hardening rules

\subsection{FAILURE ANALYSIS}

Appropriate Failure criteria should be employed to predict the failure to the best extent. Generally metals are highly ductile and therefore the distortional energy density criterion (Von Mises Criterion) is applied to predict failure in them. This criterion states that yielding begins when distortional strain energy density at a point equals the distortional 
strain energy density at yield in uniaxial tension or compression. The distortional energy density is that energy associated with a change in the shape of a body.

The effects of progressive failure are neglected since the shape of failure contour observed in practical situations agrees well with those obtained using the current model, at least in qualitative sense.

\subsection{ASSUMPTIONS}

- Single particle erosion was considered.

- The target surface was assumed to be flat without influence of previous failure effects.

- The strain rate effects where neglected and rate independent plasticity was considered. As increasing strain rate increases flow stress.

- The target metal was assumed to be isotropic ductile metal.

- The impacting particle was assumed to be rigid in solutions.

- The impacting particle was spherical in shape indicating point contact.

- Vibrational effects during impact were neglected.

- The effect of temperature on the flow stress and the yield stress of the material has been neglected.

- The temperature rise in the target metal due to particle impact has not been considered in the analysis. 


\section{CHAPTER 4}

\section{MODEL DEVELOPMENT: FINITE ELEMENT ANALYSIS}

\subsection{INTRODUCTION}

This thesis deals with estimation of volume loss for aluminum model. The model was developed in INGRID and solved in LS-DYNA3D, the development of this model will be explained in detail in later sections of this chapter.

\subsection{FINITE ELEMENT MODEL}

The Process of Finite Element Analysis consists of three stages as shown in the Figure 4.1

1) Pre-Processing (LS-INGRID)

2) Analysis (LS-DYNA3D)

3) Post-Processing(LS-TAURUS)

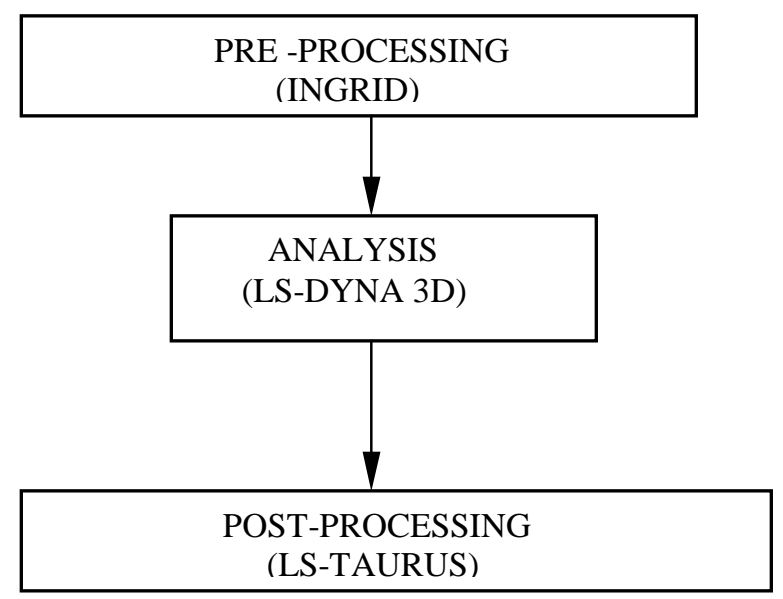

Figure 4.1 Three stages of finite element analysis 


\subsection{MESH GENERATION}

The first step in Pre-Processing is mesh generation. The mesh for the current model was generated using INGRID.INGRID provides the capability to generate complex models and specify boundary conditions. Also the interactive graphics in INGRID offer the ability to probe and interrogate the mesh structure, boundary conditions and sliding interfaces. To build an INGRID model, an input file must be created. The file must contain global control commands, part definitions and material command. Other definitions like boundary conditions, sliding interface can be added later or modified interactively in INGRID. The software makes no assumptions about the units in the input file. It expects that all input will be in a consistent unit system most convenient to the user.

The current model was developed with user defined unit system of micronewton, micrometer and microsecond. The mesh for the model was described using index progressions. The dimensions of the metal substrate and the size of the erodent are required. Since the size of the erodent is very small when compared to the target, the target medium should be considered as an infinite medium for analytical purposes. But, a computational model cannot handle infinite dimensions and hence proper dimensions have to be assumed for the target media. When making such a discretization, care should be to avoid.

- Unreasonable reaction forces at the restraints, which might affect stress distribution near impact region.

- An untraceable local region.

The erodent and the metal substrate are modeled using 8 noded hexahedron (Brick) elements. The dimensions for the metal and erodent particle for Aluminum model are shown in Figure 4.2. The target metal is $12.5 \mathrm{~mm}$ square by $3.125 \mathrm{~mm}$ thick and the glass particle is $3 \mathrm{~mm}$ in diameter. The dimensions of metal and erodent used in Aluminum model are same as the dimensions of the test specimen used in Sheldon's experimental work. 


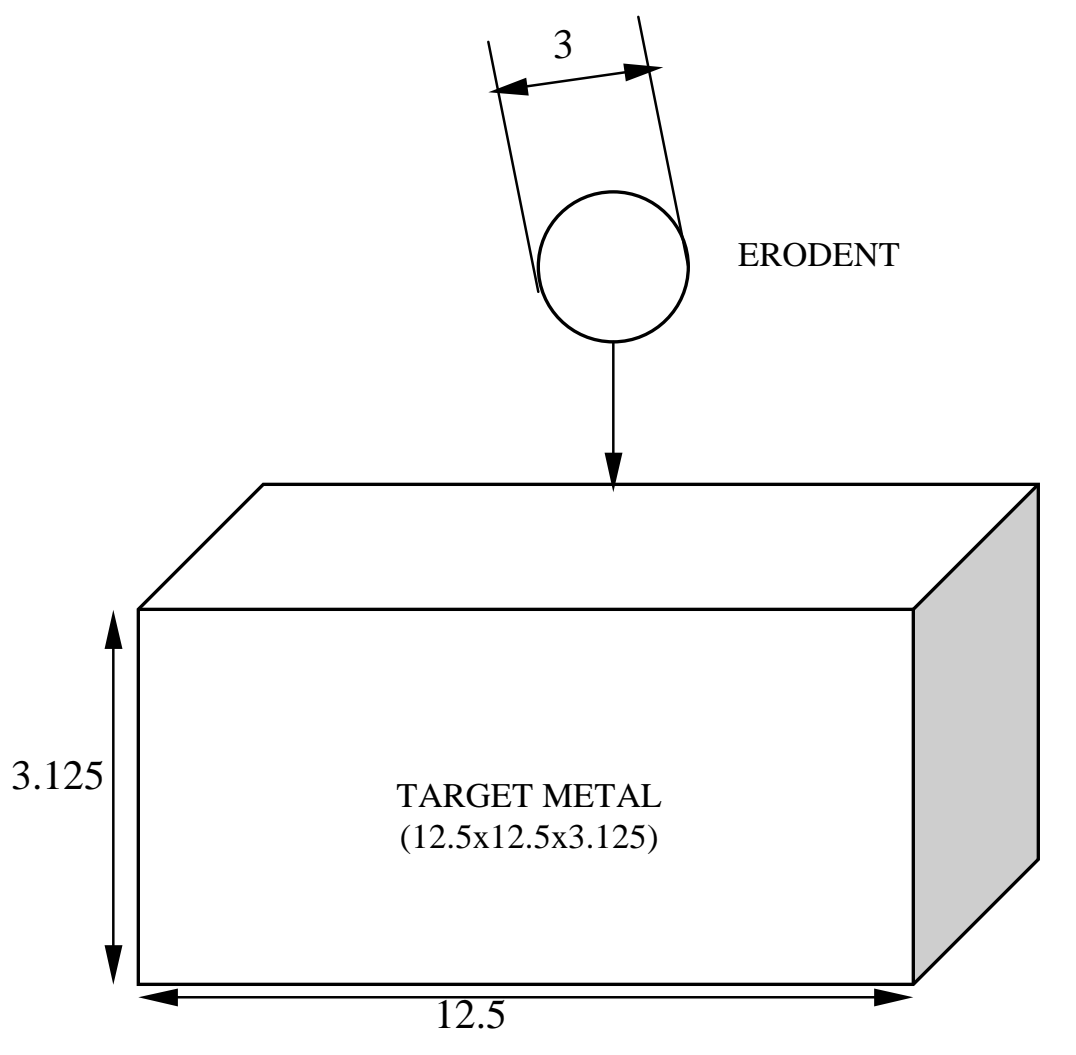

(All Dimensions are in Millimeters)

FIGURE 4.2 Schematic diagram of single particle impact 
Enough care was taken for both the models, to see that a fine mesh was generated near the contact area and a coarse mesh away from the point of contact. Since the analysis involved several parameters like angle of attack etc., the INGRID input file was written in such a way that the whole file can be modified with minimum user input. A model of Aluminum is shown in Figure 4.3.

\subsubsection{Solid Element}

In the present study a mesh of 8-node hexahedron solid element is used. A typical eightnode solid hexahedron element is shown below.

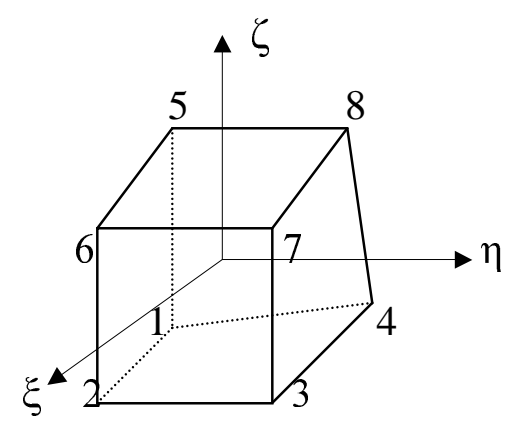

The node definition for the above eight-node hexahedron element is as follows

$\begin{array}{crrr}\text { Node } & \xi & \eta & \zeta \\ 1 & -1 & -1 & -1 \\ 2 & 1 & -1 & -1 \\ 3 & 1 & 1 & -1 \\ 4 & -1 & 1 & -1 \\ 5 & -1 & -1 & 1 \\ 6 & 1 & -1 & 1 \\ 7 & 1 & 1 & 1 \\ 8 & -1 & 1 & 1\end{array}$

For a mesh with an 8-node hexahedron solid element

$$
x_{i}\left(X_{\alpha}, t\right)=x_{i}\left(X_{\alpha}(\xi, \eta, \zeta), t\right)=\sum_{j=1}^{8} \phi_{j}(\xi, \eta, \zeta) \chi_{i}^{j}(t)
$$

Where $\phi_{j}$ is the shape function of the parametric coordinates $(\xi, \eta, \zeta)$ and $\chi_{i}^{j}$ is the nodal coordinate of the $j^{\text {th }}$ node in the $i^{\text {th }}$ direction. 
The shape function can be defined as

$$
\phi_{j}=\frac{1}{8}\left(1+\xi \xi_{j}\right)\left(1+\eta \eta_{j}\right)\left(1+\zeta \zeta_{j}\right)
$$

Where $\xi_{j}, \eta_{j}, \zeta_{j}$ take their nodal values of $( \pm 1, \pm 1, \pm 1)$ as shown in the Figure above.

An 8-node hexahedron solid element has a 6 × 24 strain displacement matrix and $3 \times 24$ rectangular interpolation matrix which are given by

$$
B=N\left[\begin{array}{ccc}
\frac{\partial}{\partial x} & 0 & 0 \\
0 & \frac{\partial}{\partial y} & 0 \\
0 & 0 & \frac{\partial}{\partial z} \\
\frac{\partial}{\partial y} & \frac{\partial}{\partial x} & 0 \\
0 & \frac{\partial}{\partial z} & \frac{\partial}{\partial y} \\
\frac{\partial}{\partial z} & 0 & \frac{\partial}{\partial x}
\end{array}\right]
$$

And

$$
N(\xi, \eta, \zeta)=\left[\begin{array}{cccccccc}
\phi_{1} & 0 & 0 & \phi_{2} & 0 & \cdots & 0 & 0 \\
0 & \phi_{1} & 0 & 0 & \phi_{2} & \cdots & \phi_{8} & 0 \\
0 & 0 & \phi_{1} & 0 & 0 & \cdots & 0 & \phi_{8}
\end{array}\right]
$$

Terms in the strain displacement matrix are

$$
\begin{aligned}
& \frac{\partial \phi_{i}}{\partial \xi}=\frac{\partial \phi_{i}}{\partial x} \frac{\partial x}{\partial \xi}+\frac{\partial \phi_{i}}{\partial y} \frac{\partial y}{\partial \xi}+\frac{\partial \phi_{i}}{\partial z} \frac{\partial z}{\partial \xi} \\
& \frac{\partial \phi_{i}}{\partial \eta}=\frac{\partial \phi_{i}}{\partial x} \frac{\partial x}{\partial \eta}+\frac{\partial \phi_{i}}{\partial y} \frac{\partial y}{\partial \eta}+\frac{\partial \phi_{i}}{\partial z} \frac{\partial z}{\partial \eta} \\
& \frac{\partial \phi_{i}}{\partial \zeta}=\frac{\partial \phi_{i}}{\partial x} \frac{\partial x}{\partial \zeta}+\frac{\partial \phi_{i}}{\partial y} \frac{\partial y}{\partial \zeta}+\frac{\partial \phi_{i}}{\partial z} \frac{\partial z}{\partial \zeta}
\end{aligned}
$$


Which can be rewritten as

$$
\left[\begin{array}{c}
\frac{\partial \phi_{i}}{\partial x} \\
\frac{\partial \phi_{i}}{\partial y} \\
\frac{\partial \phi_{i}}{\partial z}
\end{array}\right]=\left[\begin{array}{lll}
\frac{\partial x}{\partial \xi} & \frac{\partial y}{\partial \xi} & \frac{\partial z}{\partial \xi} \\
\frac{\partial x}{\partial \eta} & \frac{\partial y}{\partial \eta} & \frac{\partial z}{\partial \eta} \\
\frac{\partial x}{\partial \zeta} & \frac{\partial y}{\partial \zeta} & \frac{\partial z}{\partial \zeta}
\end{array}\right]\left[\begin{array}{c}
\frac{\partial \phi_{i}}{\partial x} \\
\frac{\partial \phi_{i}}{\partial y} \\
\frac{\partial \phi_{i}}{\partial z}
\end{array}\right]=J\left[\begin{array}{c}
\frac{\partial \phi_{i}}{\partial x} \\
\frac{\partial \phi_{i}}{\partial y} \\
\frac{\partial \phi_{i}}{\partial z}
\end{array}\right]
$$

Hence, inverting the Jacobian Matrix $\mathbf{J}$ as follows can solve the desired terms

$$
\left[\begin{array}{l}
\frac{\partial \phi_{i}}{\partial x} \\
\frac{\partial \phi_{i}}{\partial y} \\
\frac{\partial \phi_{i}}{\partial z}
\end{array}\right]=J^{-1}\left[\begin{array}{c}
\frac{\partial \phi_{i}}{\partial \xi} \\
\frac{\partial \phi_{i}}{\partial \eta} \\
\frac{\partial \phi_{i}}{\partial \zeta}
\end{array}\right]
$$

Volume integration for the element is carried out with Gaussian quadrature. If $\mathrm{g}$ is some function defined over volume, and $\mathrm{n}$ the number of integration points then

$$
\int_{v} g d v=\int_{-1}^{1} \int_{-1}^{1} \int_{-1}^{1} g|J| d \xi d \eta d \zeta
$$

The above equation may be approximated by

$\sum_{j=1}^{n} \sum_{k=1}^{n} \sum_{l=1}^{n} g_{j k l}\left|J_{j k l}\right| w_{j} w_{k} w_{l}$

Where $w_{j}, w_{k}, w_{l}$ are weighing factors and $g_{j k l}=g\left(\xi_{j}, \eta_{k}, \zeta_{l}\right)$ and $|J|$ is the determinant of the Jacobian matrix. For one point quadrature $n=1, w_{j}=w_{k}=w_{l}=2$ and $\xi_{1}=\eta_{1}=\zeta_{1}=0$ from which we can write

$$
\int g d v=8 g(0,0,0)|J(0,0,0)|
$$

note that $8|J(0,0,0)|$ gives an approximation to the element volume.

The biggest advantage of one-point integration is a substantial saving in the computer time and the disadvantage is that a fine mesh is needed. Anti-symmetry property of the strain matrix when $\xi_{1}=\eta_{1}=\zeta_{1}=0$, 
$\frac{\partial \phi_{1}}{\partial x_{i}}=\frac{-\partial \phi_{7}}{\partial x_{i}} \frac{\partial \phi_{3}}{\partial x_{i}}=\frac{-\partial \phi_{5}}{\partial x_{i}}$

$\frac{\partial \phi_{2}}{\partial x_{i}}=\frac{\partial \phi_{8}}{\partial x_{i}} \frac{\partial \phi_{4}}{\partial x_{i}}=\frac{-\partial \phi_{6}}{\partial x_{i}}$

reduces the amount of effort to compute strain matrix by 25 times over an 8-point integration. These cost savings can be extended for the strain and nodal force evaluations where the number of multiples is reduced by a factor of 16 . Since only one constitutive evaluation is required, the time spent on determining stresses is reduced by a factor of 8 . However, 8-point integration has another disadvantage in addition to cost. When fully integrated elements used in the solution of plasticity problems and other problems where Poisson's ratio approaches 0.5 results in the constant volume bending modes. An average pressure must be applied to all the elements to avoid the elements becoming locked in the constant volume bending modes; consequently, the hourglassing modes are resisted by the deviatoric stresses. If these deviatoric stresses become negligible when compared to the pressure or if the material failure causes loss of this stress state component, then hourglassing will still occur without any means to resist it. Most of the times the cost of fully integrated elements may be justified by increased reliability.

\subsection{MATERIAL MODELS}

The next step in modeling is to define the material properties of the metal, and the particle. This step is very important because the result of analysis depend on how accurately the material models are defined. There are several material models available in LS-DYNA3D. INGRID gives the option of defining the LS-DYNA3D material types in the input file itself. The effect of impact on the particle was neglected, as the current work was focused only on the erosion of the metal. Hence the particle was assumed to be rigid and was assigned rigid material type. This material type takes into account all the properties of the particle except that it won't show the deformation and other results of the particle. It also provides an inexpensive method for modeling portions of the model that are much stiffer than the regions of interest. The following properties are required to define rigid material type: 
Modulus of Elasticity.

Mass Density.

Poisson's Ratio.

\begin{tabular}{|l|l|}
\hline \multicolumn{2}{|l|}{ Properties of Silicon Dioxide Particle } \\
\hline Modulus of Elasticity(GPa) & 67 \\
\hline Mass Density $\left(\mathrm{kg} / \mathrm{m}^{3}\right)$ & 2180 \\
\hline Poisson Ratio & 0.21 \\
\hline
\end{tabular}

Table 4.1 Material Properties of Glass Particle 


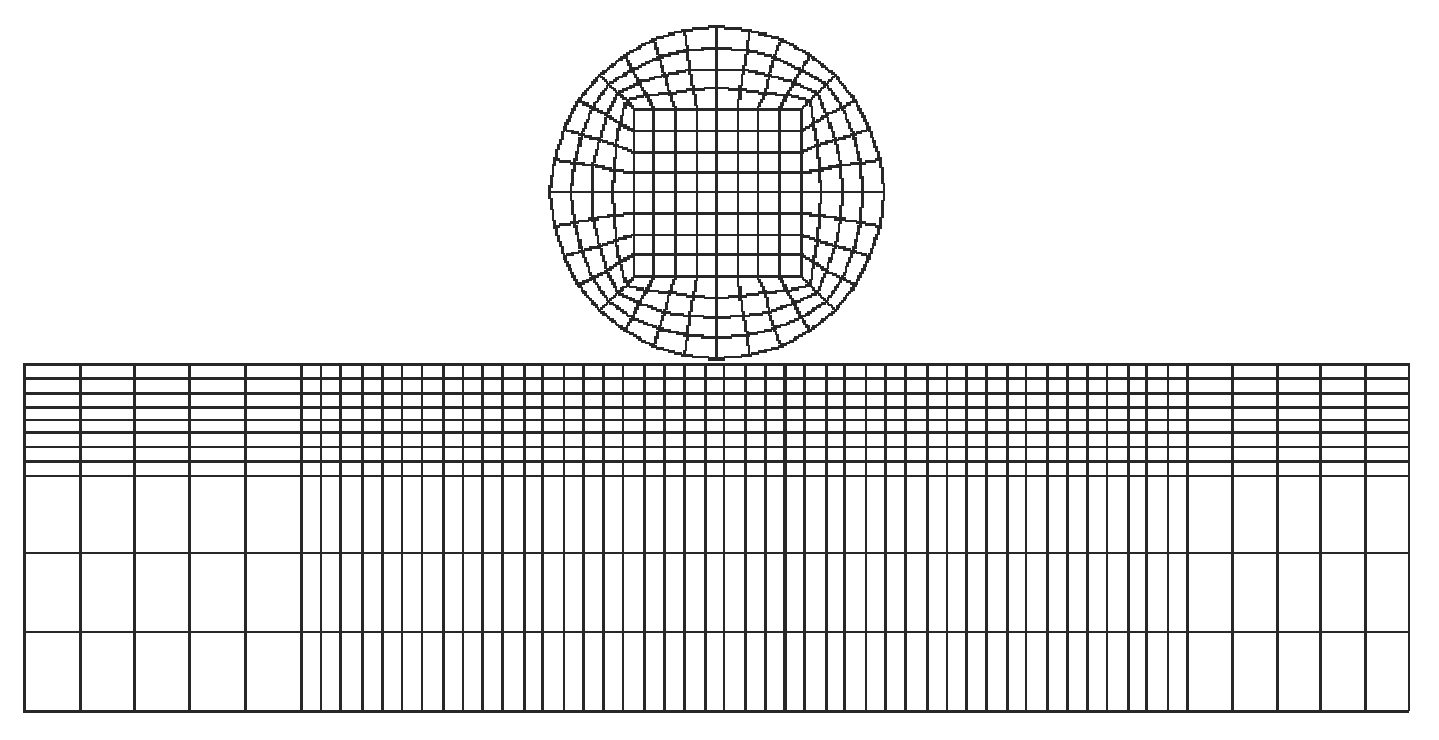

$$
\stackrel{\mathbf{z}}{\stackrel{y}{\longrightarrow}} \mathbf{x}
$$

Figure 4.3 Finite Element Model for Single Particle Impact on Aluminum Metal 


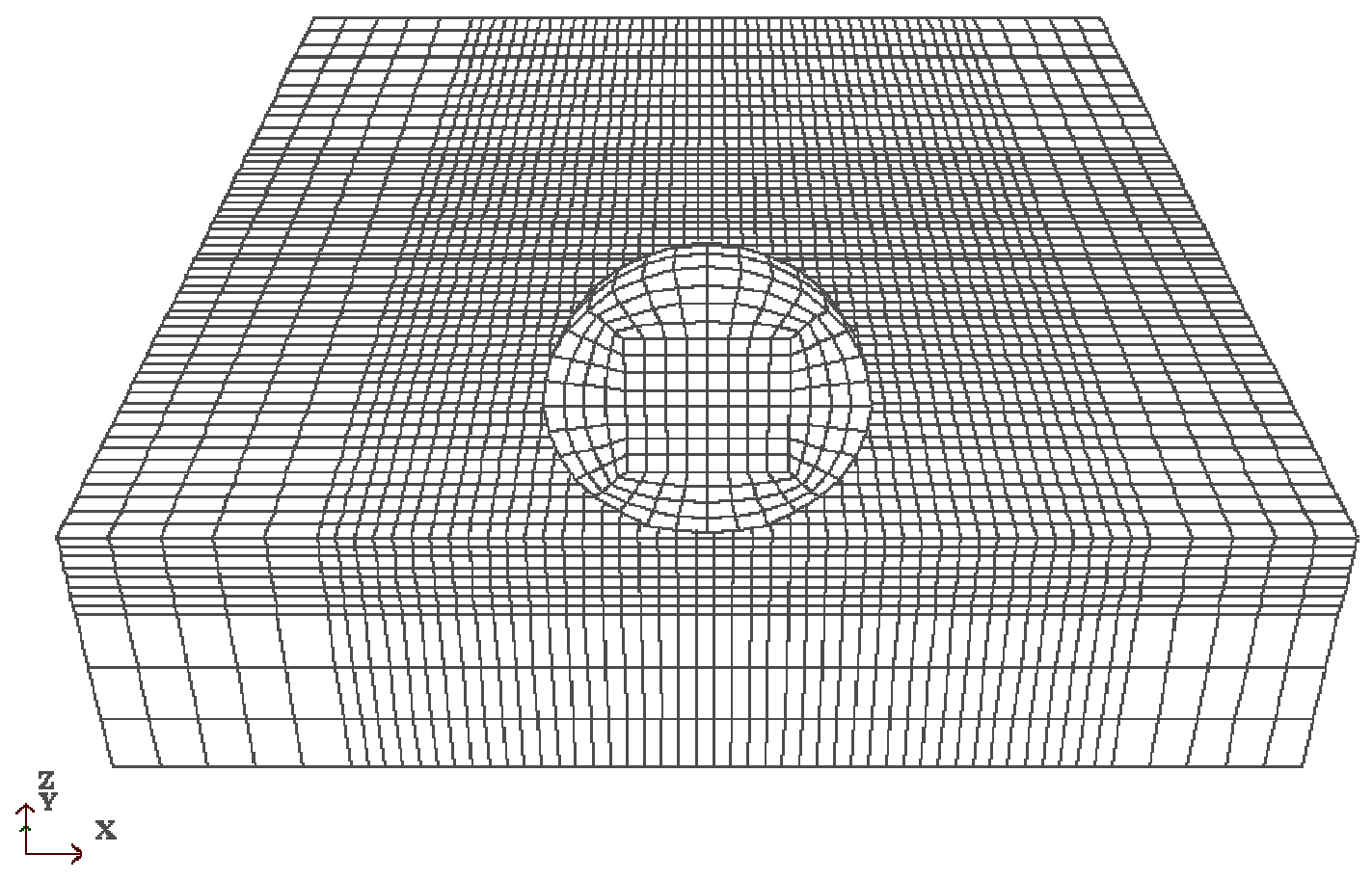

Figure 4.4 Finite Element Model of Al 6061 Metal 
The metal was taken as ductile in nature and was assigned Piecewise Linear Isotropic Plasticity type. The following properties are needed to define this material type:

Modulus of Elasticity.

Mass Density.

Poisson's Ratio.

Yield Stress.

Tangent Modulus.

\begin{tabular}{|l|l|}
\hline \multicolumn{2}{|l|}{ Properties of Aluminium Al 6061-T0 } \\
\hline Modulus of Elasticity(Gpa) & 68.9 \\
\hline Mass Density $\left(\mathrm{kg} / \mathrm{m}^{3}\right)$ & 2600 \\
\hline Poisson Ratio & 0.33 \\
\hline Yield Stress(Mpa) & 55.1 \\
\hline
\end{tabular}

Table 4.2 Material Properties of Al 6061-T0 target material

\subsection{BOUNDARY AND INITIAL CONDITIONS}

The effect of single particle impact is assumed to have only local effects. Therefore in the far field, the target medium is expected to have negligible deformation. Therefore all the nodes on the far boundary from the region of impact are totally restrained from undergoing any kind of deformation.

Only one half of the model was considered for analysis in order to reduce the computation time. Axi-symmetric boundary conditions were applied to take care of the other half. The metal was restrained at the bottom and on the sides in order to avoid rigid body motion of the whole body. A sliding surface, which takes into account the impact and friction, was defined between the particle and the metal. This particular sliding interface was designated as a type III algorithm i.e., sliding with friction. The spherical particles were taken as master nodes and those of the metal as slave nodes. The particle 
was given velocity in negative direction on to the target surface. The output of INGRID was fed to LS-DYNA3D to perform the analysis.

\subsection{PARAMETRIC MODELLING}

The parameters considered in this study are

- Velocity of erodent

- Angle of attack of erodent

- $\quad$ Size of erodent

\subsection{MODEL SOLUTION}

The next step in the analysis is the model solution using LS-DYNA3D. LS-DYNA3D is an explicit finite element code for analyzing the transient dynamic response of threedimensional solids and structures. LS-DYNA3D is a fully vectorized, explicit, three dimensional, dynamic analysis code capable of solving problems involving large deflections and high rates of deformation. Many material models are available in it to represent a wide range of material behavior, including elasticity, plasticity, composites, thermal effects and rate dependence. In addition, LS-DYNA3D has a sophisticated contact interface capability, to handle arbitrary mechanical interactions between independent bodies or between two portions of one body.

A nonlinear transient dynamic analysis is performed using LS-DYNA3D. It takes the results from the previous time step and calculates the present time step values. The time step for the analysis is based on the smallest element size in the model. The material properties are given in the INGRID input file itself, so they need not be given again in LS-DYNA3D input file. The LS-DYNA3D input file after checking for accuracy in coding and the default hour glassing is added it would be ready for the solution. The simulation is run until the erodent rebounds. The results can be viewed in the post processor called LS-TAURUS.

The total energy of the system is equal to the sum of the kinetic and internal energy. In the present work the system consists of metal and the impacting particle. The present 
system is energy conserved. So all times the total energy of the system should remain same, which is equal to the initial kinetic energy of the particle. In Figure 4.5 as the kinetic energy comes down, the internal energy goes up and only a small portion of initial kinetic energy is used up for plastic work. When the particle bombards with the target surface, it losses its kinetic energy and the target surface gains the internal energy. The kinetic and internal energies with respect to the total energy are shown in Figure 4.5. Hour glassing modes are zero energy modes. At this situation, the sum of internal and kinetic energies is not equal to the total energy. These undesirable hourglass modes are often observed to be oscillatory and they tend to have periods that are typically much shorter than the periods of structural response. If these hourglass modes tend to have periods that are comparable to the structural response periods then it forms a stable kinematic component of the global deformation and is admissible. One way of resisting zero energy modes is with a viscous damping or small elastic stiffness capable of stopping the anomalous modes while having a negligible affect on the state global deformation. The work done by the hourglass resistance is neglected because the zero energy modes are orthogonal to the real deformation, which may lead to the slight loss of energy. However hourglass control is always recommended for the underintegrated solid elements. The effective plastic strain in all the elements were calculated and compared with the failure strain of the material.

\subsection{POST PROCESSING}

The output file from the LS-DYNA3D has to be post processed in order to get the solution in the designed fashion. The LS-TAURUS was used as post processor in the analysis. LS-TAURUS is a powerful, interactive and user friendly software that can read binary plot files and time history files generated by LS-DYNA3D. Also the software has the feature of displaying results in various forms, like line plots, contour plots, arrow plots, data reports and XY graph plots. Typical results that could be obtained using LSTAURUS for the current model include stresses, plastic strains, strain energies etc.

In the present work the required result for the failure analysis are stresses and plastic strains. In this study stresses provide a qualitative estimate of deformation, by giving an 
estimate of the amount of metal plastically deformed. But the plastic strain results provide the quantitative estimate of the erosion loss. LS-TAURUS has the capability of calculating various stress components such as:

- Von Mises Effective stresses.

- Maximum shear stress.

- Maximum principle stress.

- Middle principle stress.

- Minimum principle stress.

Using these principle stresses values in the Von-Mises yield criteria the amount of material plastically yielded can be estimated.

In the present work various graphs can be generated in LS-TAURUS. The phase I of the TAURUS commands give a plot of plastic strain values against the element numbers and prints the data in HSPBULL file. An example of this plot is shown in Figure 4.6. LSTAURUS also has a built in command to identify the elements in a particular part that have exceeded a user defined plastic strain and then give the volume fraction of critical elements. These plot and data were used in estimation of volume loss due to particle impact.

\subsection{FAILURE CRITERIA AND MATERIAL LOSS ESTIMATION}

Earlier Yelamanchalli [1997] and Tangirala [1998], in their work have studied Brittle Erosion and estimated volume loss. They also studied the effect of various parameters on the volume loss. In their work they used Von-Mises stress for the estimation of volume loss. Basically the procedure involved identifying the elements that have exceeded the threshold stress at the time of maximum internal energy and picking them up as critical

elements for calculating volume loss. Balasubramaniyam [1998] who also studied Brittle erosion used critical strain to estimate volume loss, and stated in his study the reason for his using this criterion. The reason is that for angular impact the Von-Mises stress level in element decreases as the erodent moves away from the target, therefore they may not be picked up as critical elements at the time of maximum internal energy. 
For Brittle erosion study using threshold stress i.e., fracture stress as the failure criteria is justified, as the brittle material fails once it reaches the yield or fracture stress with no prior yielding.

But the same criteria cannot be used to estimate volume loss in ductile erosion, which is studied in this present work, as the ductile metal begins to deform plastically once it reaches yield stress and fails only after considerable plastic deformation. But the above procedure of identifying the elements that have exceeded threshold stress, used for brittle erosion can be used to estimate the amount of material that is plastically yielded in ductile erosion. But this estimate may not be accurate for angular impact. Because in some elements the stress level may exceed the threshold stress during the initial contact with the erodent and may not have the same stress level at the point of maximum internal energy since the erodent is making a glancing impact and moving away from these elements. Hence these elements may not be picked up as critical elements.

Hence ' Strain at failure' is used as the criteria for failure in ductile erosion and to estimate the volume loss in the Al 6061-T0 model due to glass particle impact. As mentioned earlier, progressive failure is not considered in the analysis, meaning the elements that exceed the critical strain are not deleted during the analysis. LS-TAURUS has built in command that give a plot of plastic strain against the number of elements and prints the data to HSPBULL, this file is scanned to pick the elements which have exceeded the critical failure strain and hence an estimate of volume loss of the target material. An estimate of volume loss can also be done by this method, LS-TAURUS has a built in command to identify the elements in a particular part (here the target metal) that have exceeded a user defined plastic strain and then give the volume fraction of critical elements. This is the ratio of the volume of critical elements to the volume of the entire metal substrate. By this method we can get a curve of this volume fraction with time for any plastic strain. A typical volume fraction curve is shown in Figure 4.7.

After yielding, strain increment $d \varepsilon$, can be regarded as composed of an elastic contribution $d \varepsilon^{e}$ and a plastic contribution $d \varepsilon^{p}$, so that $d \varepsilon=d \varepsilon^{e}+d \varepsilon^{p}$. The elements that have reached the yield stress at any instance would still retain the unrecoverable plastic strain during unloading also. 
The critical failure strain for Al 6061-T0 material was obtained by performing the tensile test using the Instron Machine in Materials Laboratory at WVU. The stress-strain curve and the flow curve for $\mathrm{Al}$ 6061-T0 obtained from the test are shown in appendix $\mathrm{C}$. 


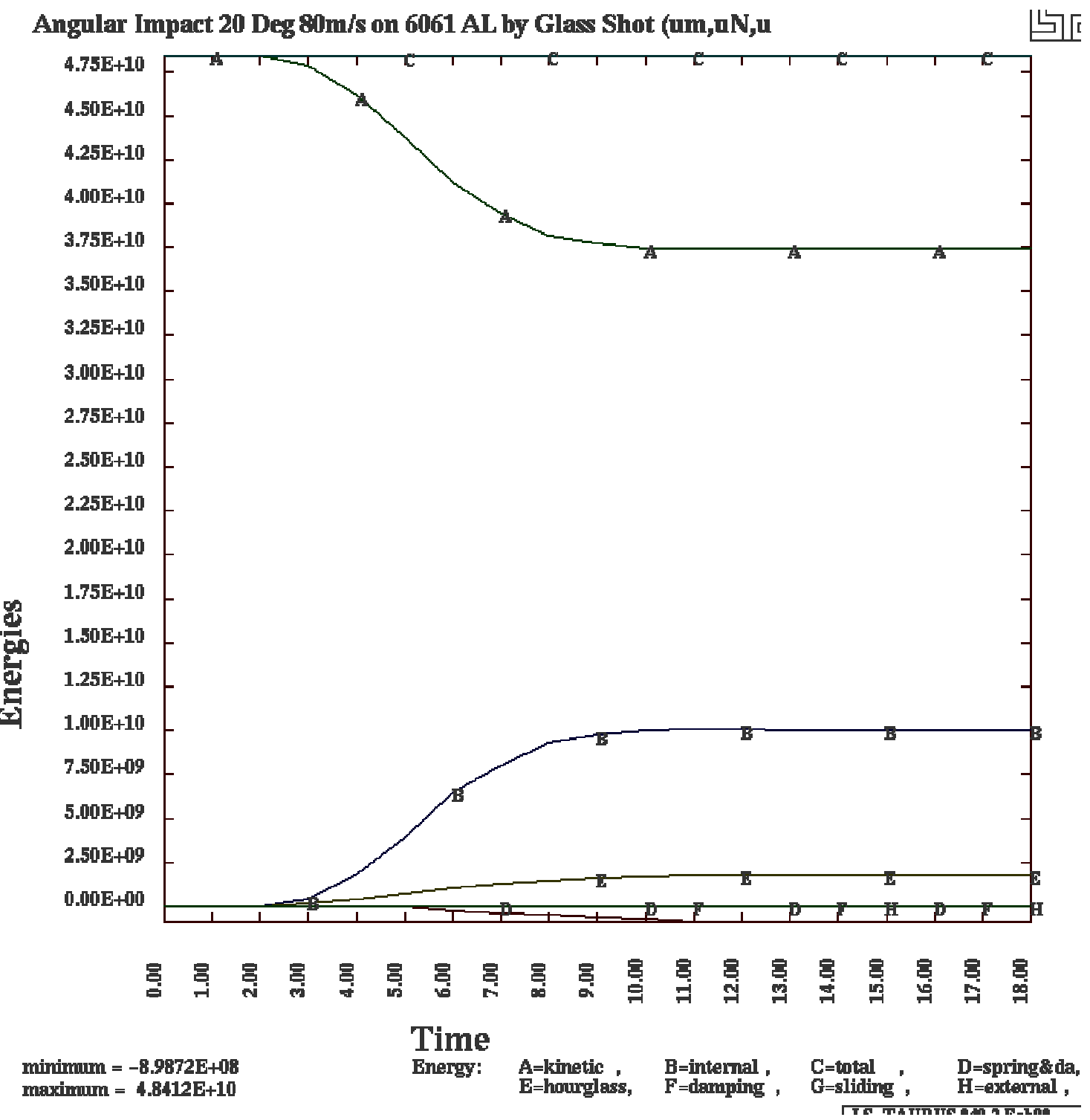

Figure 4.5 Plot showing various energies Vs time (in usec) 
Angular Impact $20 \mathrm{Deg} 80 \mathrm{~m} / \mathrm{s}$ on $6061 \mathrm{AL}$

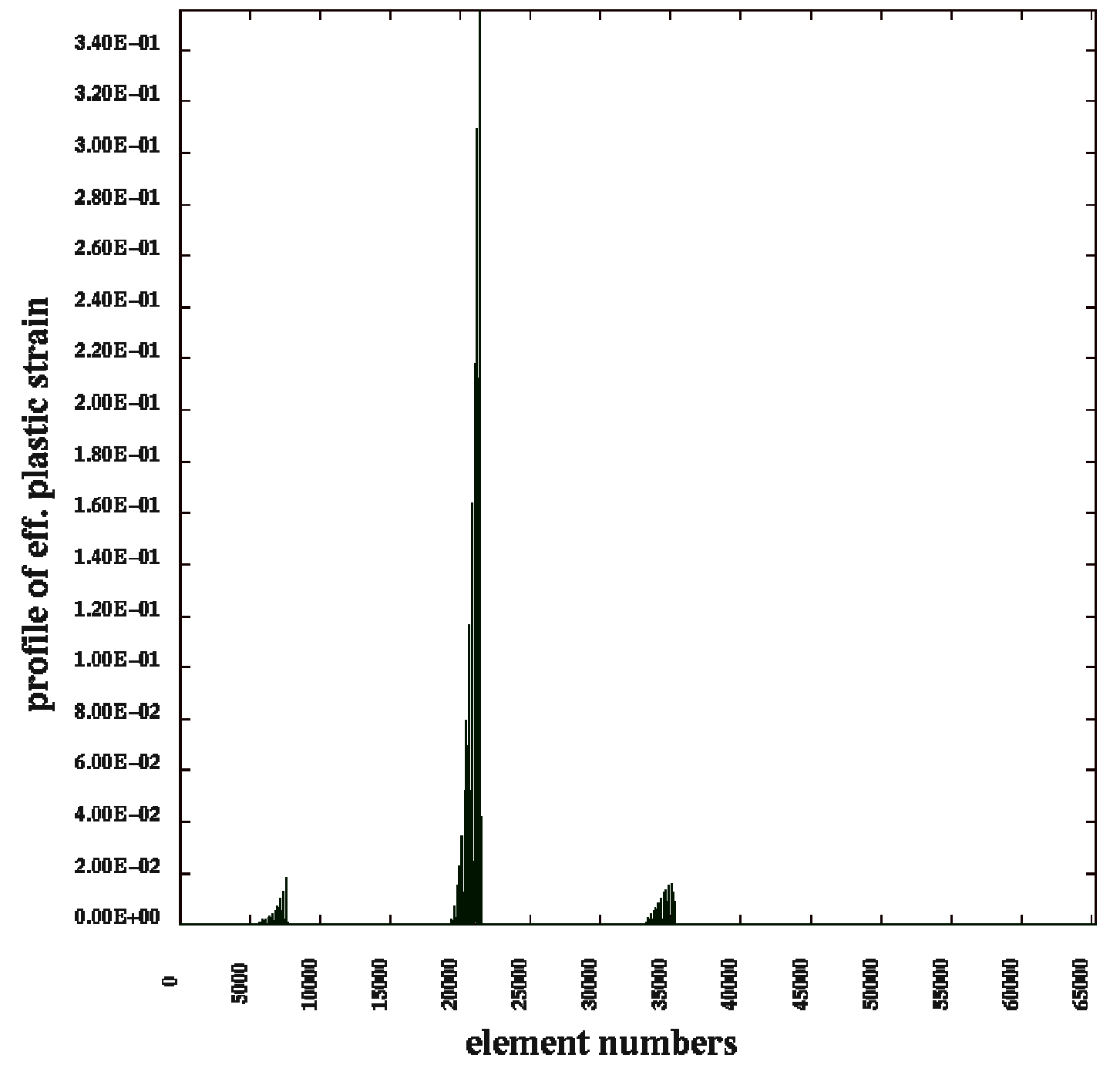

minimum $=0.0000 \mathrm{E}+00$ at element 65340

maximum $=3.5551 \mathrm{E}-01$ at element 21379

Figure 4.6 Plot of effective Plastic strain Vs elements 
Angular Impact $20 \mathrm{Deg} 80 \mathrm{~m} / \mathrm{s}$ on $6061 \mathrm{AL}$

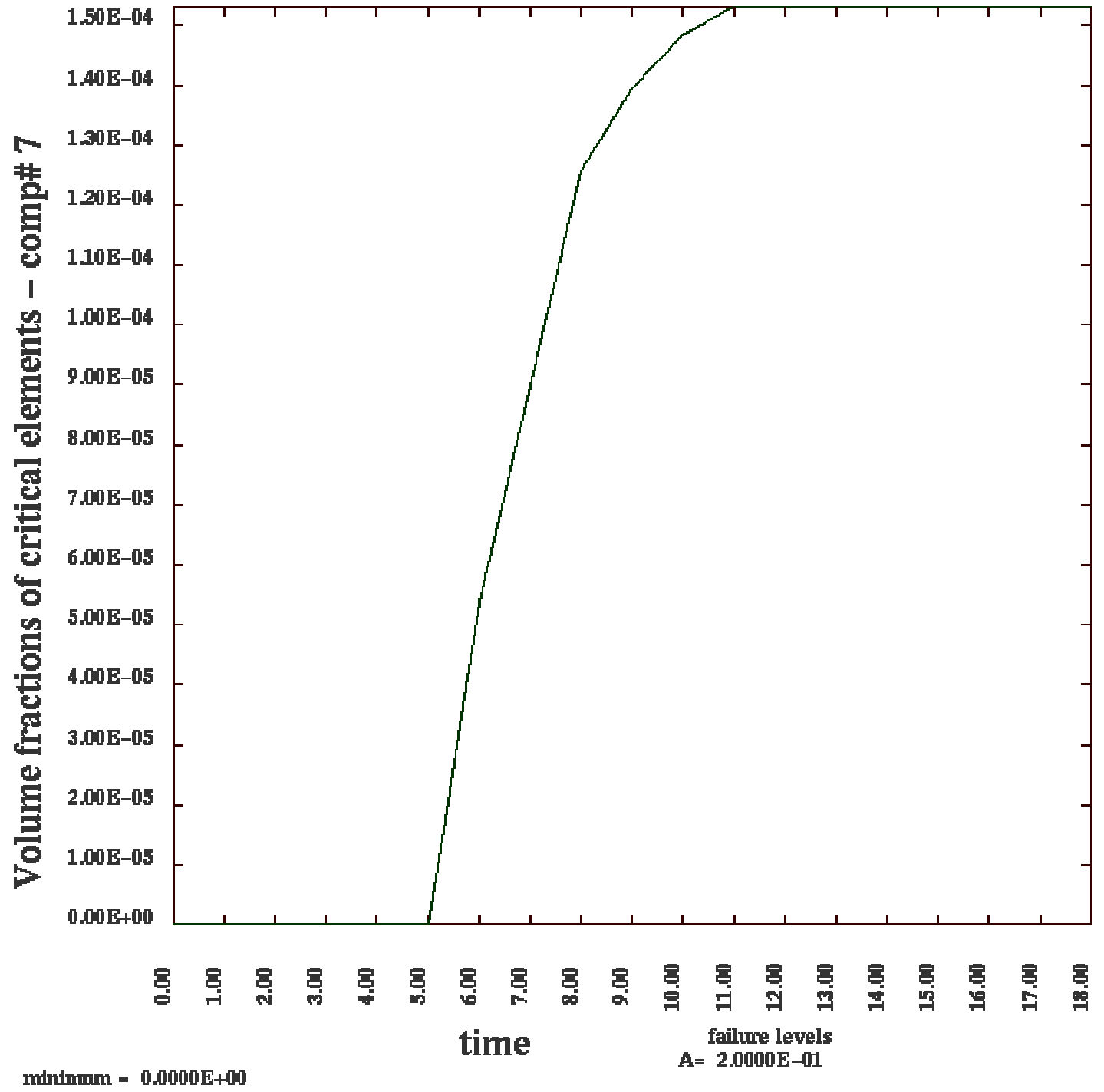

maximum - 1.5308E-M

Figure 4.7 Typical volume fraction curve (time in usec) 


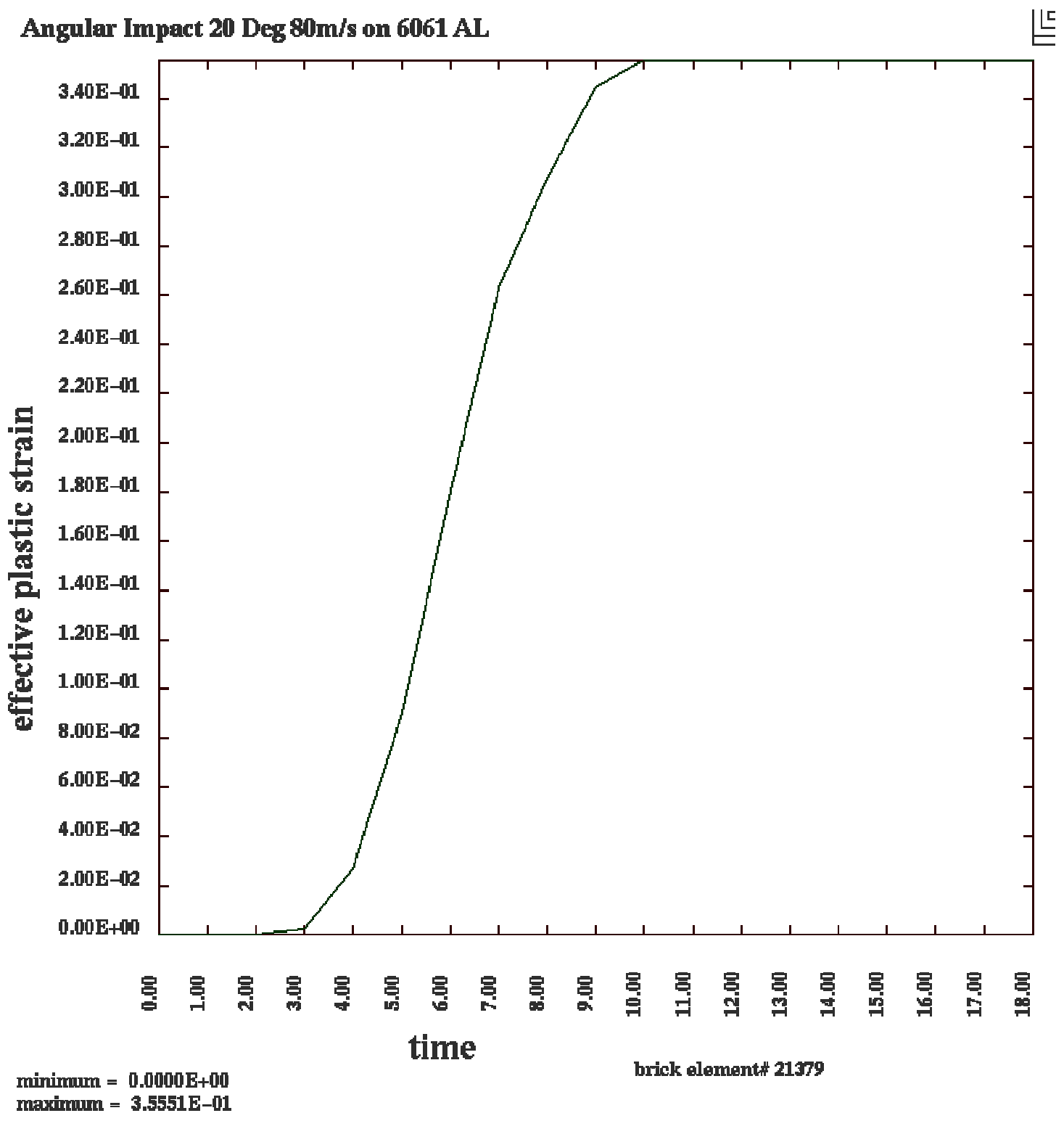

Figure 4.8 Effective plastic strain in a brick element Vs time (in usec) 


\section{CHAPTER 5}

\section{RESULTS AND DISCUSSION}

\subsection{INTRODUCTION}

This chapter deals with the estimation of volume loss due to solid particle impact for aluminum model. The procedure explained in the previous chapter is used for the estimation of volume loss of the material, hence predicting the erosion loss in the model. The results were compared with the experimental results of Sheldon et al. The erosion results obtained from the model were not exactly the same as experimental results of Sheldon, the reason for which may be rounding error in FEM erosion estimation and because only a fraction of the critical volume that is calculated is lost due to erosion. But the model showed good correlation with the experimental models for erosion loss dependence on velocity of erodent, size of erodent as shown in later sections. The FEM model for single particle normal impact showed good agreement with Hutchings single particle model.

The results based on the finite element model developed in previous chapter are presented here in terms of the following parameters.

- Velocity of Erodent

- Angle of impact

- Size of Erodent

The effect of velocity and angle of attack on erosion was studied for a $3 \mathrm{~mm}$ diameter spherical particle. The size effects were tested for diameters ranging from $1 \mathrm{~mm}$ to $3 \mathrm{~mm}$. The results are presented in the form of graphs between the volume loss and the parameter affecting erosion.

\subsection{PARAMETRIC RANGES}

The following cases were studied.

- Angular Impact at 20 degrees with $3 \mathrm{~mm}$ diameter erodent in the velocity range of 80$240 \mathrm{~m} / \mathrm{sec}$.

- Angular Impact at $80 \mathrm{~m} / \mathrm{sec}$ with diameter of erodent $1-3 \mathrm{~mm}$ in steps of $0.5 \mathrm{~mm}$. 
- Impact with $3 \mathrm{~mm}$ diameter erodent at velocity $80 \mathrm{~m} / \mathrm{sec}$, varying the attack angle from 20-90 deg in steps of 20 degrees.

\subsection{MODEL VALIDATION}

In the current work the aluminum model is quantitatively verified with the experimental results of Sheldon et.al. The erosion loss values for aluminum, obtained from the current work are compared with the erosion loss data for aluminum obtained by Sheldon in his experimental work. The erosion loss values obtained from the current work are shown in table 5.1.

The results of the parametric study are qualitatively compared with the experimental results of ductile materials, available in literature and the results of the parametric study showed good agreement with the experimental results.

\subsection{ALUMINUM MODEL}

The model consists of a glass (Silicon dioxide) particle and aluminum metal. The properties of aluminum metal and glass particle were taken from material handbook. The model developed was based on the experimental work of Sheldon. The dimensions of the target metal were $12.5 \times 12.5 \times 3.125 \mathrm{~mm}^{3}$. The particle was spherical in shape with $3 \mathrm{~mm}$ diameter. It was impacted against the metal with a velocity of $80 \mathrm{~m} / \mathrm{s}$ at 20 deg angle of attack. The erosion loss was estimated for this model and compared with Sheldon's work. The erosion was estimated in milligrams of aluminum per gram of glass particle. In the current work, finite element method (FEM) was used to simulate the experimental work. The analysis was performed using LS-INGRID and LS-DYNA3D.

The FEM results when compared with the experimental results show a variation. This variation in the erosion values could be attributed to the experimental error and rounding error in the FEM erosion estimation procedure. The rounding error occurs as the volume loss was estimated by calculating the volume fraction of the critical elements, which are above a certain critical strain. Hence there is a chance of variation, as all of this critical volume may not be loss due to erosion, only a fraction (2-10\%) of this volume may actually be lost when the elements in critical volume are sufficiently strained to fracture 
and fracture is not considered in the current study. The critical strain value used in volume estimation was taken as failure strain value obtained from uniaxial tension test. The failure strain value obtained from tension test can be significantly less than the plastic strain value obtained from the FEM model which is under dynamic loading and multiaxial state of stress, therefore significantly large number of elements are picked up as critical elements thus giving a considerably large value for critical volume loss. The same value was used for volume estimation for all cases, and this may also lead to some variation. But the results of volume loss with different parameters as shown in Figures 5.6-5.8 have shown good correlation qualitatively with the theories of literature. And as can be seen from Figures 5.2-5.4 the critically strained region (the red region in Figures) is near the lip of the crater where erosion is likely to occur as predicted in theory.

\begin{tabular}{|l|l|l|}
\hline S.No & Velocity and Angle & FEM Results \\
\hline 1. & $80 \mathrm{~m} / \mathrm{s}$ and $20 \mathrm{deg}$ & $4.08 \mathrm{mg} / \mathrm{g}$ \\
\hline 2. & $245 \mathrm{~m} / \mathrm{s}$ and $20 \mathrm{deg}$ & $84.4 \mathrm{mg} / \mathrm{g}$ \\
\hline 3. & $245 \mathrm{~m} / \mathrm{s}$ and $90 \mathrm{deg}$ & $198 \mathrm{mg} / \mathrm{g}$ \\
\hline
\end{tabular}

Table 5.1 Weight of critical volume per gram of particle for AL6061-T0

\subsubsection{Effect of Velocity}

The velocity range considered is $80-240 \mathrm{~m} / \mathrm{sec}$ where most erosion behavior of interest seems to occur. The analysis was performed for $20^{\circ}$ angle of attack, while the velocity was varied from 80 to $240 \mathrm{~m} / \mathrm{sec}$, which is the typical range of jet engine applications. A plot of critical volume against velocity is shown in Figure 5.7. The critical volume was found to increase with increase in velocity. The plot shows that the volume loss varies nonlinearly with velocity, which is in agreement with theories of volume loss dependence on velocity. The velocity exponent obtained from the curve for volume loss vs velocity is 2.4, which is in agreement with the velocity exponent values for ductile erosion predicted 
in theory, which is in between 2 and 3. Sheldon predicted a velocity exponent value of 3 for ductile erosion in his experimental work.

\subsubsection{Effect of Angle of Attack}

In the present work angle of attack was varied from 20-90 deg for $3 \mathrm{~mm}$ spherical particle keeping the velocity constant at $80 \mathrm{~m} / \mathrm{s}$. Plastic strain contours at various time steps are shown in Figures 5.2-5.5 for 20 deg and 90 deg angles of attack, respectively. The critical zone is shown red in color. It can be seen from Figures 5.2-5.5 that the location of maximum plastic strain is near the lip of the crater and hence material is expected to be loss from that region. More number of elements are picked up as critical elements for 90 deg angle of attack as can be seen in Figures 5.9-5.11 than at 20 deg angle of attack, as the contact surface area of the particle with the metal is more during normal impact hence more elements are picked up as critical elements. Whereas at lower angles the particle impacts the surface at glancing angles, therefore the contact area is less and hence only a small number of elements are picked up as critical elements thus giving a low critical volume value. The actual volume loss for normal impact may be less than 20 deg impact, as the material evenly flows around indentation crater. Whereas for 20 deg impact a lip is formed in front of the crater as shown in Figure 5.3, which may be lost subsequently when strained to fracture. The plot of critical volume versus angle of attack is shown in Figure 5.6. This plot is gives maximum critical volume at normal impact as explained above, therefore it may not qualitatively represent the dependence of volume loss on angle of attack for ductile metals, as volume loss for ductile metals according to literature is maximum at lower angles.

The Energy plot for normal impact is shown in Figure 5.1. The rebound energy 3-6\% of initial KE, which is good correlation with Hutching's theory for single particle normal impact. In his energy balance study he estimated that the erodent has $10 \%$ of the initial kinetic energy after impact. Where as for smaller angle of attack the rebound energy is $60-80 \%$ of initial KE of the particle, which can be attributed to the fact that the particle is impacting the metal at glancing angle and hence only a small fraction of its initial $\mathrm{KE}$ is gained as internal energy of the metal, part of which maybe used for plastic work. Hence as a large fraction of initial $\mathrm{KE}$ is gained as internal energy of metal for normal impact 
than for smaller angle impact, therefore more amount of plastic work is done in that case. But Sheldon's experimental values show that erosion loss is same for both 20 deg and 90 deg impacts at $245 \mathrm{~m} / \mathrm{s}$ impact velocity, for which he gave no reason in his paper.

\subsubsection{Effect of Size of Erodent}

Erodent sizes from 1-3mm were considered. The plot of critical volume vs erodent diameter is shown in Figure 5.8. The volume loss increased linearly. Particles above $3 \mathrm{~mm}$ were not considered in this study, as $3 \mathrm{~mm}$ diameter particle is a significantly large particle and for ductile erosion as predicted in theory, volume loss is independent of size of erodent after a certain critical size. 


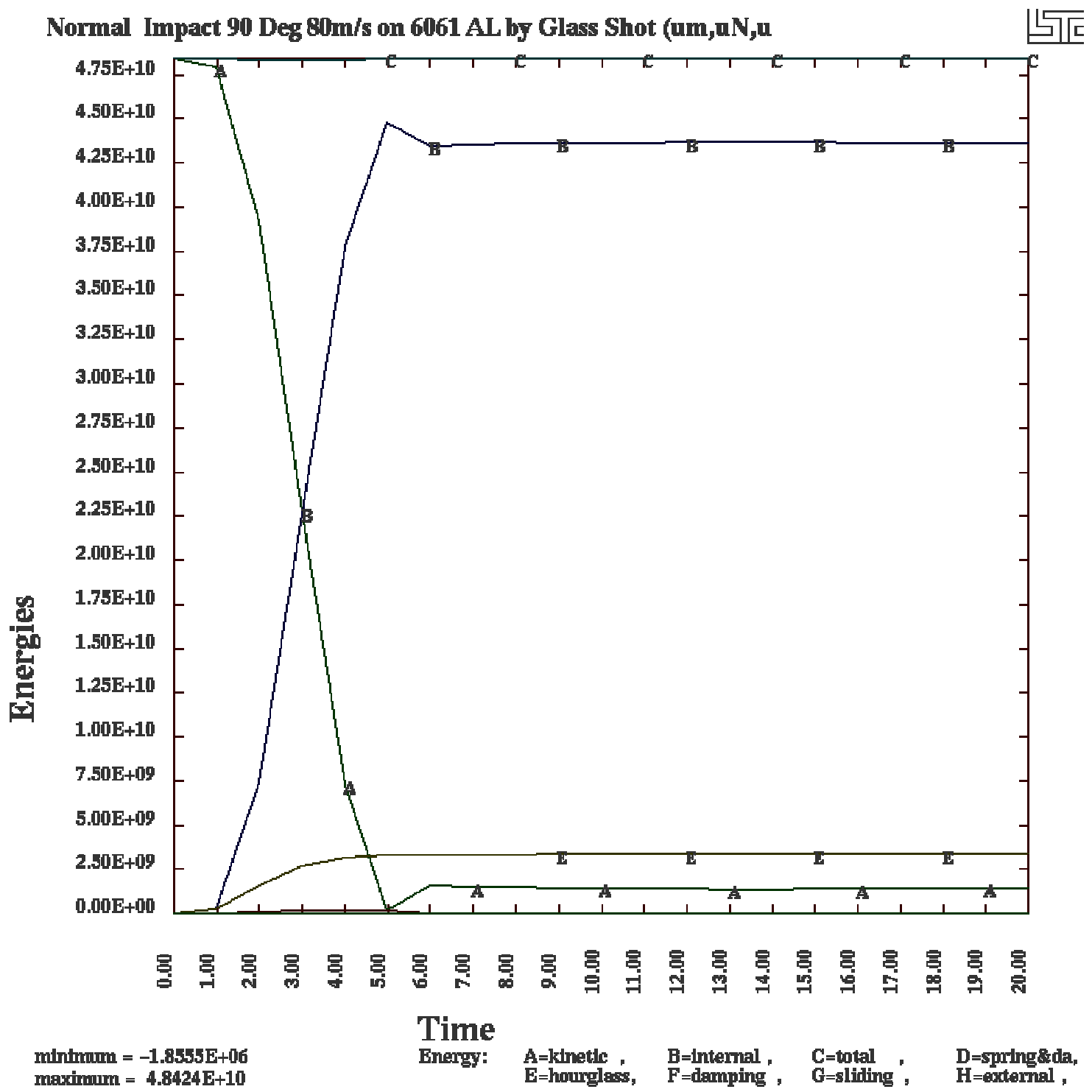

Figure 5.1 Energy Balance for Normal Impact 
Angular Impact $20 \mathrm{Deg} 80 \mathrm{~m} / \mathrm{s}$ on $6061 \mathrm{AL}$ time $=0.00000 \mathrm{E}+00$
fringes of eff. plastic strain

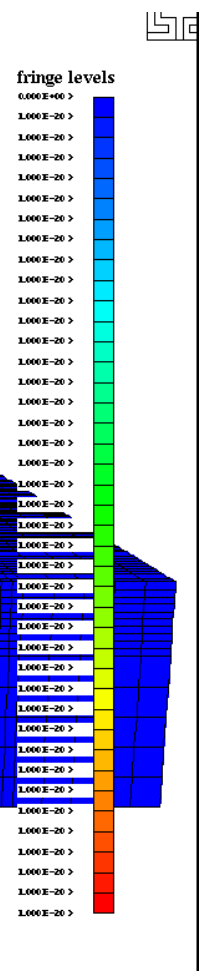

$\stackrel{\mathrm{z}}{\mathrm{y}} \mathrm{x}$

பㄴㄷ담

Angular Impact $20 \mathrm{Deg} 80 \mathrm{~m} / \mathrm{s}$ on $6061 \mathrm{AL}$

time $=1.98661 \mathrm{E}+00$
fringes of eff. plastic strain

$\min =0.000 \mathrm{E}+00$ in element 66364

$\max =1.681 \mathrm{E}-02$ in element 21370

fringe levels

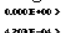

c.SOEE E-As)

LAE-63)

2S2E- -193

2ब(2E-63)

3*2F-93

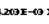

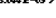

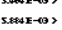

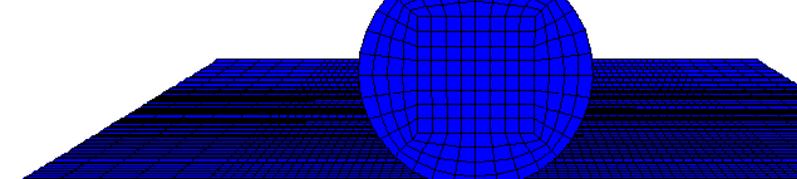

III

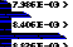
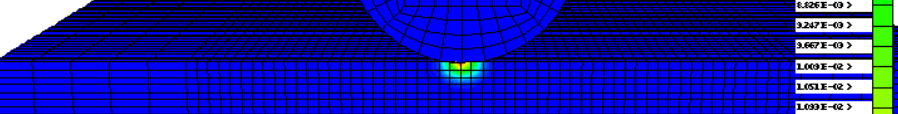

UTSE-(2)

UTFE-12

DMPE-(Q)

LOSE-10)

LSPF-12)

LEMIE-(2)

$\stackrel{\mathrm{z}}{\mathrm{y}} \mathrm{x}$

Figure 5.2 Fringes of Plastic Strain for 3mm particle impacting at 20deg with a velocity of $80 \mathrm{~m} / \mathrm{s}$ 
Angular Impact $20 \mathrm{Deg} 80 \mathrm{~m} / \mathrm{s}$ on $6061 \mathrm{AL}$ time $=4.99666 \mathrm{E}+00$
fringes of eff. plastic strain

$\min =0.000 \mathrm{E}+00$ in element 66364

$\max =1.813 \mathrm{E}-01$ in element 21366

fringe levels

asse- 19 ,

S.RESE-63)

LSSEE-(2)

LOBE-(2)

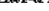

3.065-16s

ase 10 (a)

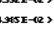

(T)EF-(1)

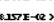

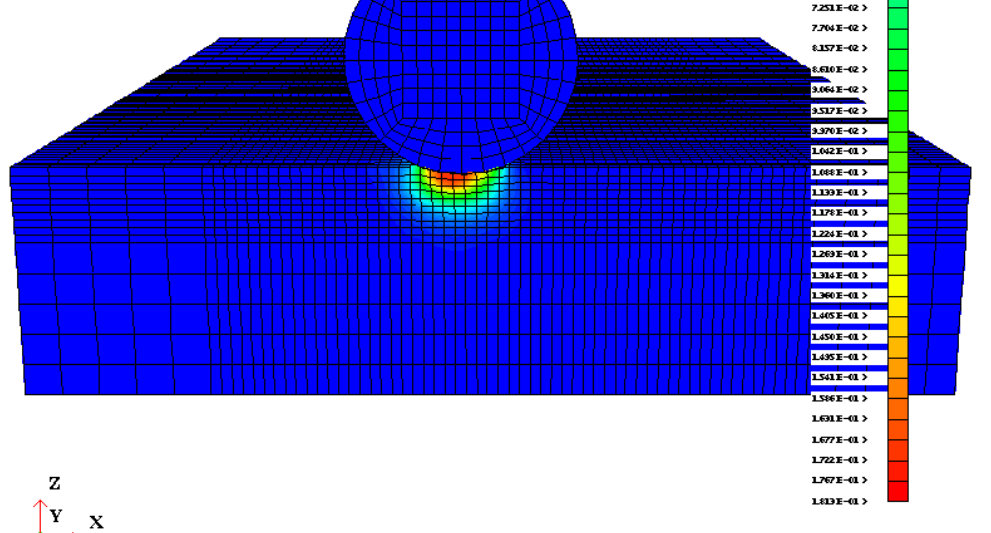

$\stackrel{\mathrm{Y}}{\longrightarrow} \mathrm{x}$

㫐

Angular Impact $20 \mathrm{Deg} 80 \mathrm{~m} / \mathrm{s}$ on $6061 \mathrm{AL}$

time $=6.98959 \mathrm{E}+00$
fringes of eff. plastic strain

$\min =0.000 \mathrm{E}+00$ in element 6636

$\max =2.700 \mathrm{E}-01$ in element 21365

fringe levels

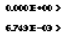

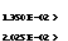

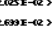

$3375-123$

L.093E-(2)

STAE-(R)

S393E-12s

Gate-1es

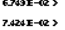

(Cose-12)

(MTE-

anserse

(1)

בA7E-C1)

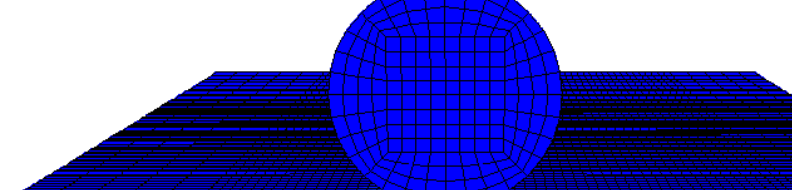

12025-11,
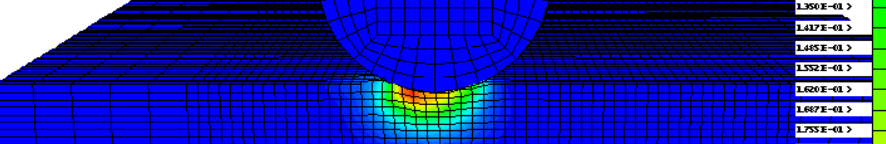

प्रSE-11)

L22E-12)

LB:FE-(1)

2700E-1a)

$\stackrel{\mathrm{y}}{\longrightarrow} \mathrm{x}$

Figure 5.3 Fringes of Plastic strain for particle impacting at 20deg with a velocity of $80 \mathrm{~m} / \mathrm{s}$ 
Angular Impact $20 \mathrm{Deg} 80 \mathrm{~m} / \mathrm{s}$ on $6061 \mathrm{AL}$

time $=8.98897 \mathrm{E}+00$

fringes of eff. plastic strain

$\min =0.000 \mathrm{E}+00$ in element 66364

max $=3.443 \mathrm{E}-01$ in element 21379

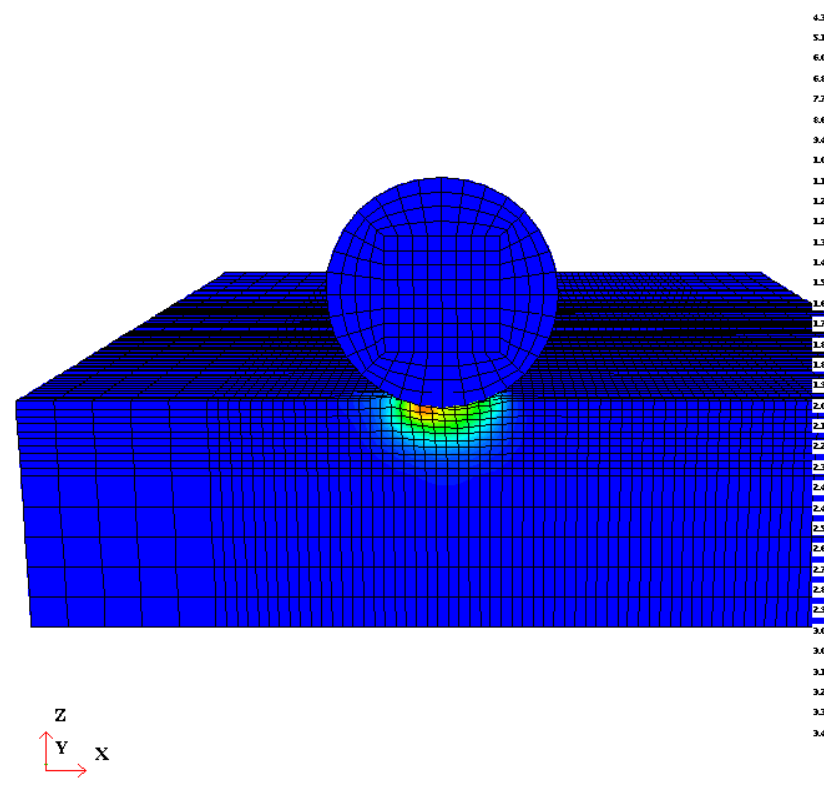

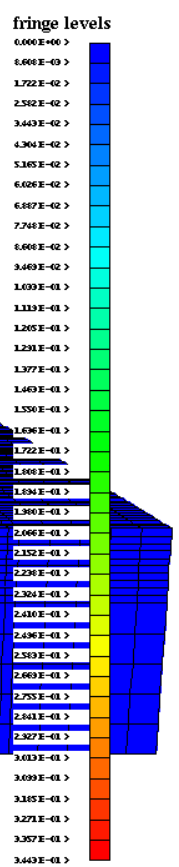

Angular Impact $20 \mathrm{Deg} 80 \mathrm{~m} / \mathrm{s}$ on $6061 \mathrm{AL}$

time $=1.19973 \mathrm{E}+01$
fringes of eff. plastic strain

$\min =0.000 \mathrm{E}+00$ in element 66364

$\max =3.555 \mathrm{E}-01$ in element 21379

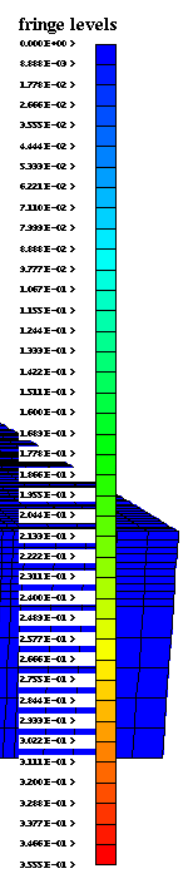

$\stackrel{\mathrm{Z}}{\mathrm{y}} \mathrm{x}$

$3 . \sec E-1 \mathrm{a})$

Figure 5.4 Fringes of plastic strain for $20 \mathrm{deg}$ impact at $80 \mathrm{~m} / \mathrm{s}$ velocity 
Angular Impact $20 \mathrm{Deg} 80 \mathrm{~m} / \mathrm{s}$ on $6061 \mathrm{AL}$ time $=1.69925 \mathrm{E}+01$
fringes of eff. plastic strain

$\min =0.000 \mathrm{E}+00$ in element 6636

$\max =3.555 \mathrm{E}-01$ in element 21379

fringe levels

Max= 3.55se 01 in elonont 21379

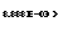

CefE-eres

2जSE-12)

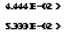

62ME-12)

7mies

7.mes

(3)

LOEE-CI)

wSE-a)

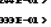

LazE-a)

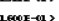

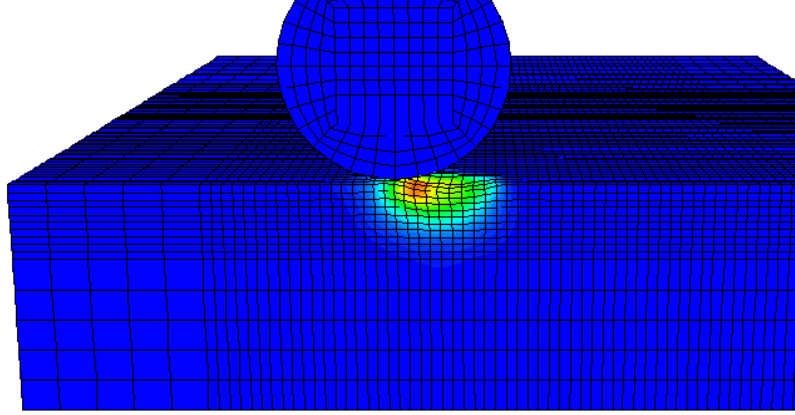

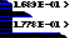
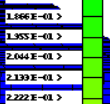

m2E-(1)

MIE-11)

2400E-01)
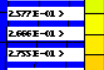

2.sese-a)

Figure 5.5 Fringes of plastic strain for $20 \mathrm{deg}$ impact at $80 \mathrm{~m} / \mathrm{s}$ velocity 
Critical Volume Vs Angle of Attack

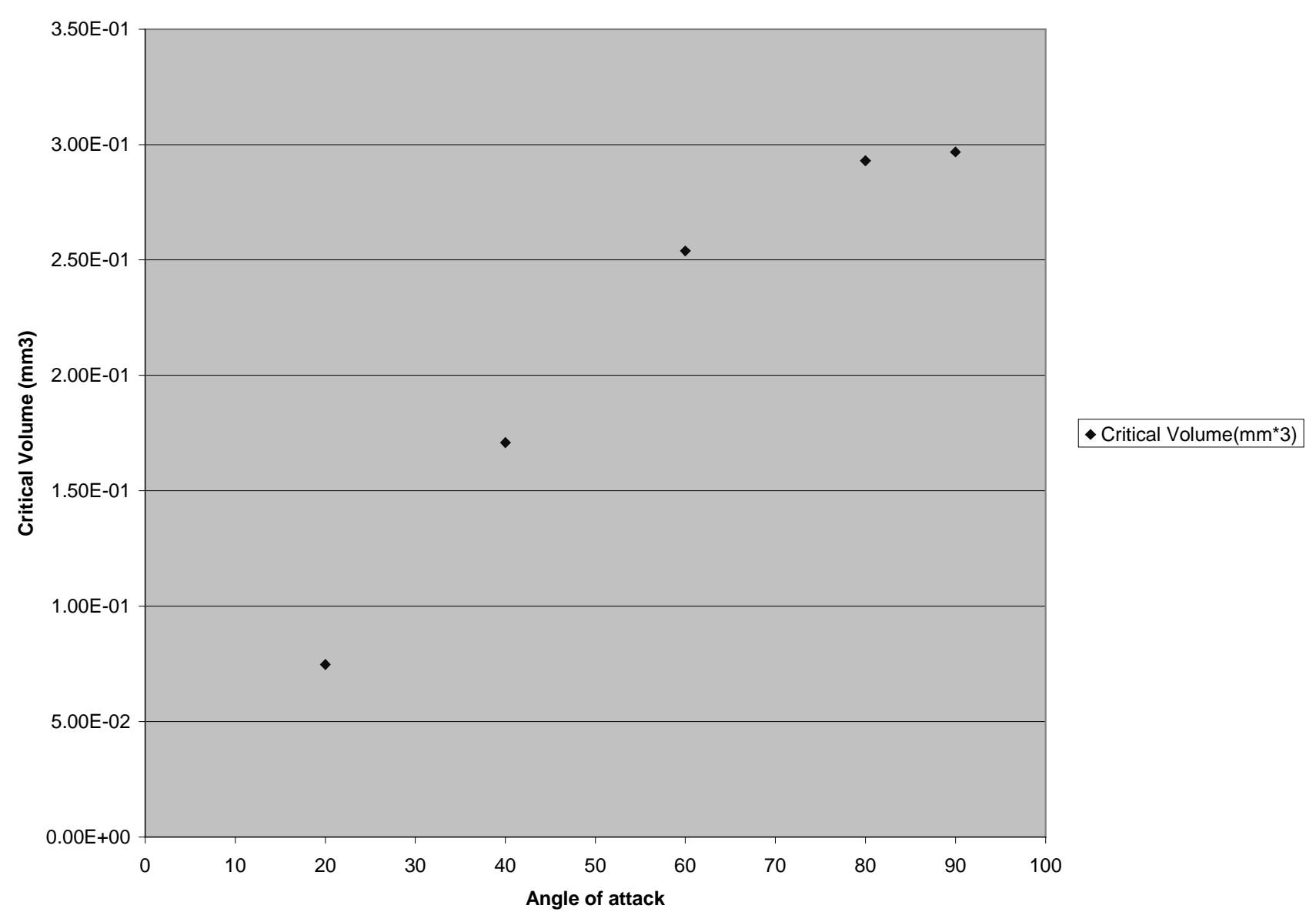

Figure 5.6 Critical Volume Vs Angle of Attack 
Critical Volume Vs Velocity

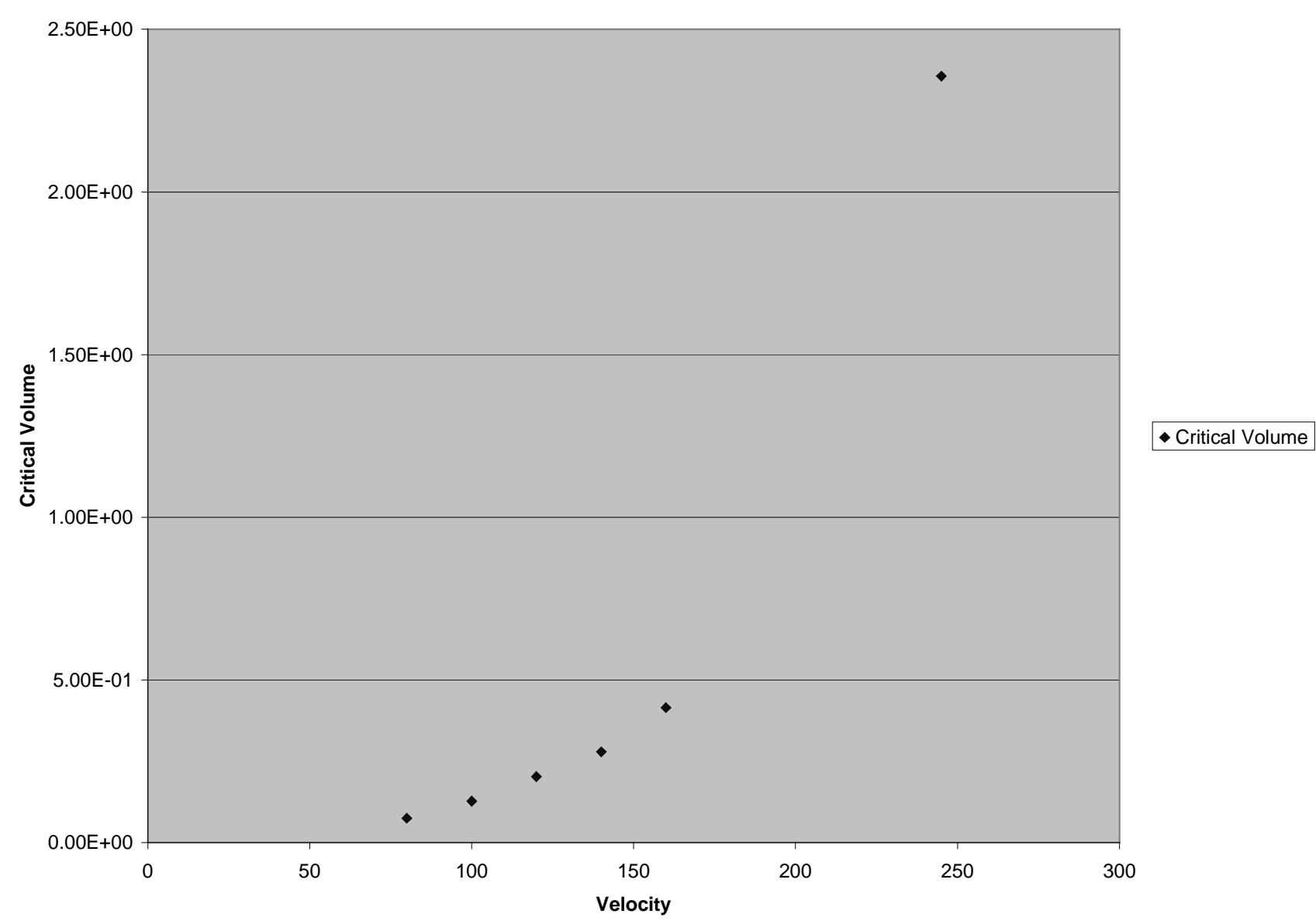

Figure 5.7 Critical Volume Vs Velocity of Impact 
Critical Volume vs Erodent Size

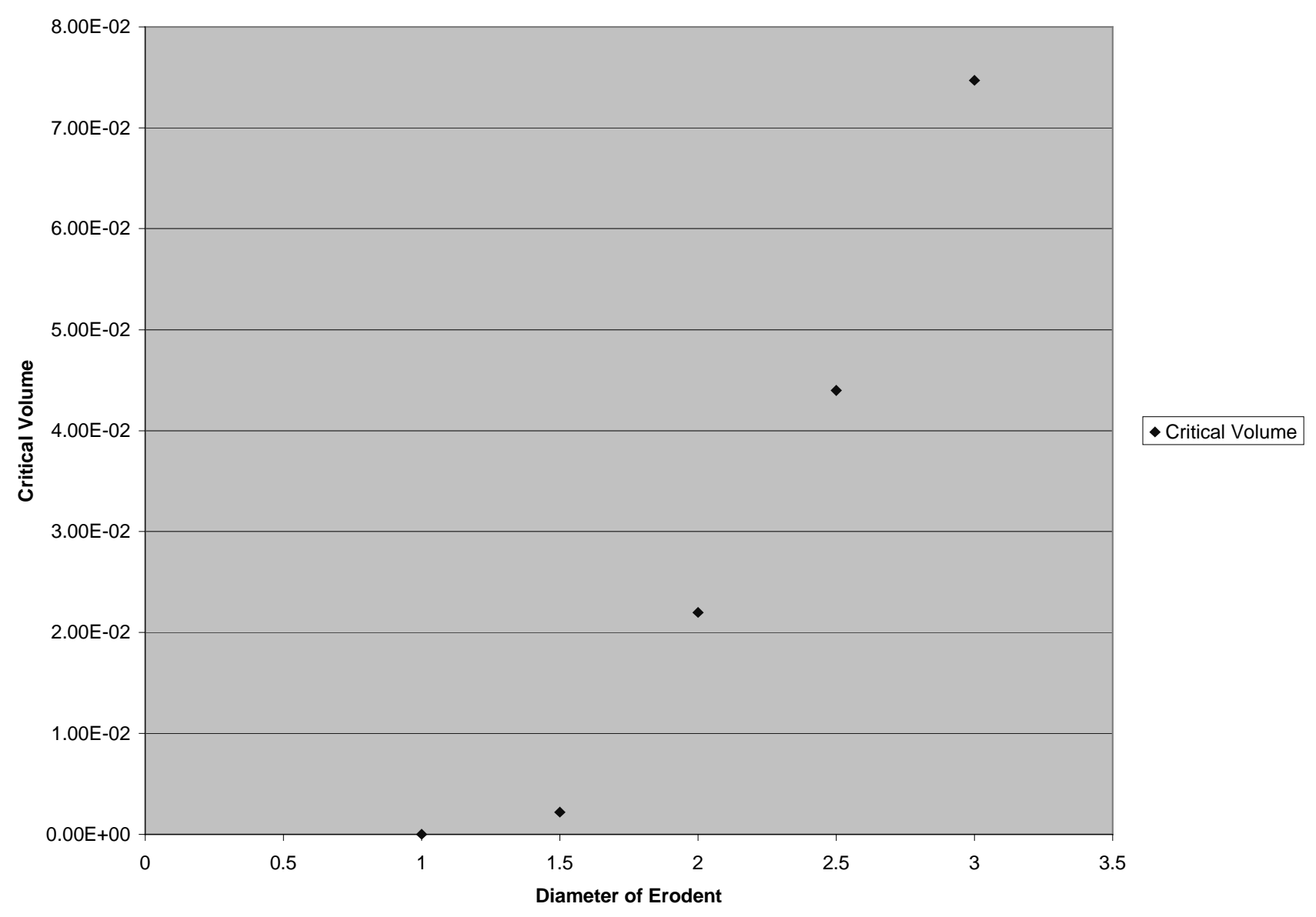

Figure 5.8 Critical Volume Vs Diameter of Erodent 
Normal Impact 90 Deg $80 \mathrm{~m} / \mathrm{s}$ on $6061 \mathrm{AL}$

time $=0.00000 \mathrm{E}+00$
fringes of eff. plastic strain

$\min =0.000 \mathrm{E}+00$ in element 66364

$\max =0.000 \mathrm{E}+00$ in element 66364

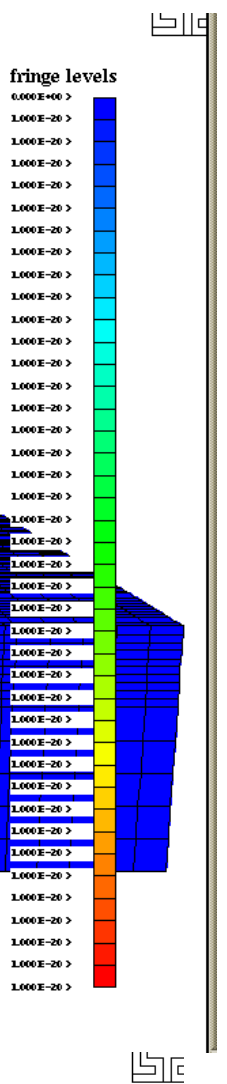

Normal Impact $90 \mathrm{Deg} 80 \mathrm{~m} / \mathrm{s}$ on $6061 \mathrm{AL}$

time $=1.99964 \mathrm{E}+00$
fringes of eff. plastic strain

$\min =0.000 \mathrm{E}+00$ in element 66364

$\max =2.194 \mathrm{E}-01$ in element 21399

fringe levels

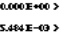

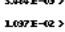

LASE-T2)

ZMAE-10)

2742E-(2)

32315-12)

4)

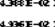

S.A4SE-1es

Segse-res

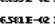

THOE-Re

THEOE-(5)

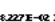

(2)

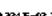

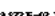

$20025-112$

Legre-15)

URE-(1)

1207E-(1)

LRE-(1)

MIEE-(1)

DARE-12)

LAZEF-11)

LS1E-11)

LSEE-11)

LSOE-11)

LESET-11)

LTOE-(1)

LSTE-11)

LE10E-01 >

S20E-(1)

Bretas

$2005-11)$

$20035-11)$

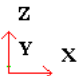

(1)

Figure 5.9 Fringes of Plastic Strain for Normal Impact at $80 \mathrm{~m} / \mathrm{s}$ 
Normal Impact $90 \mathrm{Deg} 80 \mathrm{~m} / \mathrm{s}$ on $6061 \mathrm{AL}$

$.99260 \mathrm{E}+00$

fringes of eff. plastic strain

$\min =0.000 \mathrm{E}+00$ in element 66364

$\max =2.982 \mathrm{E}-01$ in element 21185

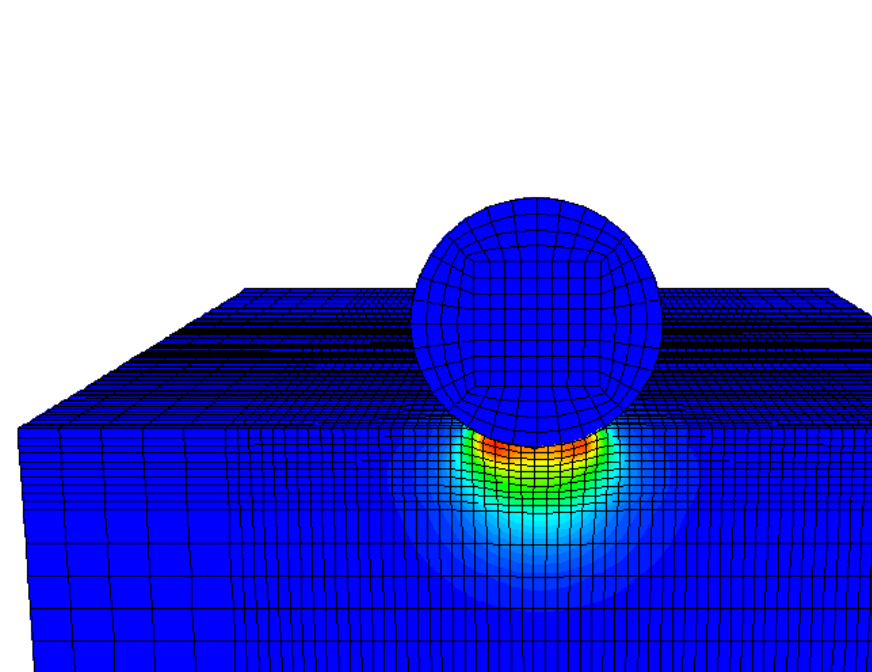

Z

$\stackrel{y}{\longrightarrow}$

fringe levels

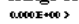

T.ASSE- $a$ >

LSME- (1)

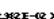

[491E-a1)

SEGE-(1)

(5)

LTEE-A1)

LEAE-(1)

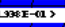

2013E-(1)

2(697)-21)

IRE-(1)

ए207E-19>

(S6E-1)

ZSGEF

एकSEE-11)

2695-11)

2NEE-11)

2925-(a) >

Normal Impact $90 \mathrm{Deg} 80 \mathrm{~m} / \mathrm{s}$ on $6061 \mathrm{AL}$

time $=9.99391 \mathrm{E}+00$
fringes of eff. plastic strain

$\min =0.000 \mathrm{E}+00$ in element 66364

$\max =2.985 \mathrm{E}-01$ in element 21185

fringe levels

fringe levecos?

7.ATE-69)

2DAF-12)

TESE-QR)

MIE- (a)

SOME-

STaF-16)

GTSE-1(?)

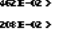

ESTSE-Res

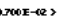

Lasse-a)

I2SE-G1,

2ง3E-11)

LAIEE-a)

LAS3E-(1)

\section{LA2E-11 ?}

ITEET(1)

\section{LIIE-(1)}

ITIE-a1)

LESTEE-(1)

2015E-11)

एव:SE-(1)

2063E-11)

21ESE-A1)

ए23E-11)

231E-11)

ए3:E-11)

248E-11)

एक्सE-11)

(aste-ais)

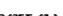

2M10-11)

Z

$\stackrel{Y}{\longrightarrow} x$

Figure 5.10 Fringes of Plastic Strain for Normal Impact at $80 \mathrm{~m} / \mathrm{s}$ 
Normal Impact $90 \mathrm{Deg} 80 \mathrm{~m} / \mathrm{s}$ on $6061 \mathrm{AL}$

time $=1.99930 \mathrm{E}+01$
fringes of eff. plastic strain

四 $匚 5$

$\min =0.000 \mathrm{E}+00$ in element 66364
$\max =2.985 \mathrm{E}-01$ in element 21185

fringe levels

7.461E-69)

LAS2E-12)

2ZEE-Re

2055-(R)

MMIE-(2)

4.47FE-(2)

S2OEE-12)

STEF-15)

GISE-TR?

7.4रEE-(12)

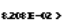

: 3565 (2)

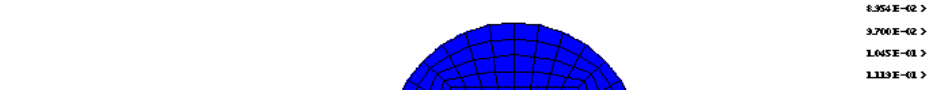

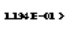

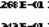
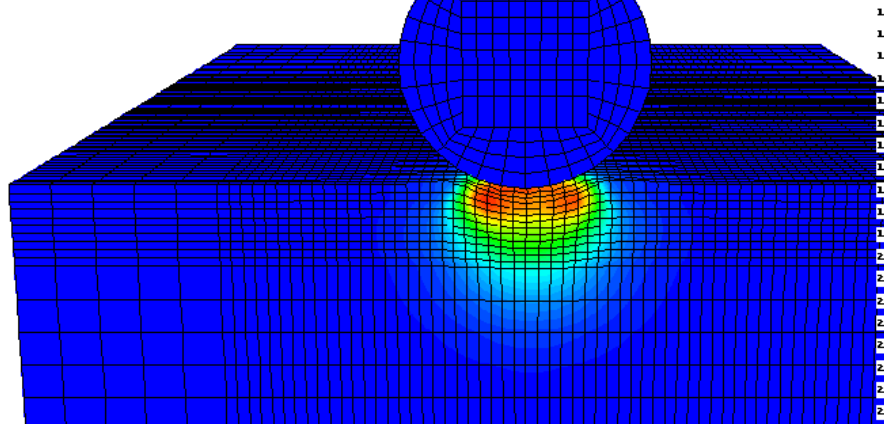

[ASTE-a1)

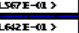

LEA2E-(1) >

LTEE-01)

LeFse-01 >

ISTOE-011)

2015E-01)

2063E-01 >

2ZBE-01 >

2315E-01 >

23:FE-01)

एखसE (1)

रस2E-11)

206E-11)

2तAE-12 ?

2305E-A1)

z

2M10E-(1)

$\stackrel{\mathrm{Y}}{\longrightarrow} \mathrm{x}$

Figure 5.11 Fringes of Plastic Strain for Normal Impact at $80 \mathrm{~m} / \mathrm{s}$ 


\section{CHAPTER 6}

\section{CONCLUSIONS AND RECOMMENDATIONS}

\subsection{CONCLUSIONS}

The following conclusions were drawn from the current work.

Finite element results of aluminum model were in agreement with the theoretical studies.

The variation of FE results from the experimental results was accounted to the rounding error in FEM erosion estimation procedure.

The angle of attack was kept constant at 20 deg and the variation of volume loss with velocity was studied for $3 \mathrm{~mm}$ spherical particle. The analysis was performed for several velocities ranging from 80 to $240 \mathrm{~m} / \mathrm{s}$. The volume loss increased with increase in velocity and the volume loss dependence on velocity obtained was in good correlation with that given in theoretical studies.

The effect of angle of attack was studied by impacting a $3 \mathrm{~mm}$ particle on to the target surface with a velocity of $80 \mathrm{~m} / \mathrm{s}$ for different angles of attack varying from 20-90 deg. The variation of critical volume with angle of attack is different from the volume loss dependence on angle of attack for ductile materials given in theory and the reason for this has been stated in the previous chapter.

The other major parameter that was studied was size of the impacting particle. The analysis was performed for different diameter erodent ranging from 1 to $3 \mathrm{~mm}$, impacting the target surface at $20-$ deg impact angle with $80 \mathrm{~m} / \mathrm{s}$ impact velocity. The critical volume increases with the size of the erodent, which is in agreement with the theory for erosion loss dependence for ductile materials on size of erodent. According to theory erosion loss for ductile materials increases till certain critical size after which it is independent of size of erodent.

The location of maximum critical strain is shown to be at the lip of the crater, from where erosion of material is likely to occur and this is in good agreement with theory.

The other good conclusions that can be drawn from the study are. 
1. Similar crater shape to the experimental single particle erosion tests.

2. Critical strain volume is in the lip of crater where tests show erosion takes place.

3. Under normal impact the rebound $\mathrm{KE}$ of the particle is same as that shown by Hutchings in his experimental work.

4. The velocity exponent is in the range shown by experiments for ductile material.

5. Also shown, size effects of the particle are similar to experimental works up to $3 \mathrm{~mm}$.

Variance with experiments.

For Angle of attack study the model did not agree with experiment due to the failure criteria not being able to distinguish material eroded and material deformed.

Failure Criterion

A better failure criterion has to be found out as the failure strain is dependent on additional factors besides the static test strain, these may include strain rate, work hardening. A better method of determining failure strain is needed. Also temperature effects may be a factor.

\subsection{RECOMMENDATIONS FOR FUTURE WORK}

This thesis dealt with the erosion of ductile metal due to single particle impact. The effect of multiple particle impact needs to be studied.

In the present work the target surface was assumed to be free from previous impacts, but in real life it is not so. The material properties changes after a series of impacts, the material work hardens. A procedure has to be developed to estimate erosion loss for material with previous damage. In this study effective plastic strain was used as the criteria to estimate the critical volume loss of the material. In this study effective plastic strain was used as the criteria to estimate the critical volume loss of the material. By incorporating fracture in the model, a better work of estimation of erosion loss of the material can be done. 


\section{REFERENCES}

1. Finnie, I., "An Experimental Study of Erosion," Proceedings of Society for Experimental Stress Analysis, Vol. 17, No 2, 1960, pp. 65-70.

2. Finnie, I., " The Mechanism of Erosion of Ductile Metals," Proceedings of $3^{\text {rd }}$ US National Congress of Applied Mechanics, 1958, pp. 527 - 532.

3. Finnie, I., "Erosion of Surfaces by Solid Particles," Wear, Vol. 3, 1960, pp. 87 - 103.

4. Bitter, J.G.A., “ Study of Erosion Phenomenon -1,2,” Wear, Vol. 5-21, 1963, pp. 169 -190 .

5. Nelson, J.H. and Gilchrist, A., "Erosion by Stream of Solid Particles," Wear, Vol. 11, 1968, pp. $111-122$.

6. Sheldon, G.L., and Kanhere, A., " Investigation of Impingement Erosion Using Single Particles," Wear, Vol. 21, 1972, pp. 195 - 208.

7. Hutchings, I. M., and Winter, R. E., " Particle Erosion of Ductile Metals: A Mechanism of Material Removal," Wear, Vol. 27, 1974, pp. 121 - 128.

8. Tilly, G.P., “ Two Stage Mechanism of Ductile Erosion,” Wear, Vol. 23, 1973, pp. 87 $-96$.

9. Goodwin, J. W., Sage, W., and Tilly, G. P., " Study of Erosion by Solid Particles," Proceedings of Institution of Mechanical Engineers, Vol. 184, 1969, pp. 279 -292.

10. Sheldon, G. L., " Similarities and Differences in Erosion Behavior of Materials," Transactions ASME, Journal of Basic Engineering, Vol. 92, 1970, pp. 619 - 626.

11. Morrison, C. T., Scattergood, R, O, and Routbort, J. L., "Erosion of 304 Stainless Steel,"Wear, Vol. 111, 1986, pp. 1 - 13.

12. Hutchings, I. M., and Levy, A.V., "Thermal Effects in the Erosion of Ductile Metals," Wear, Vol. 131, 1989, pp. $105-121$.

13. Bellman Jr, R., and Levy, A. V., " Platelet Mechanism of Erosion of Ductile Metals," Proceedings of International Conference on Wear of Materials, ASME, 1981, pp. 564 $-576$. 
14. Finnie, I., Levy, A. V., and McFadden, D. J., "Fundamental Mechanism of the Erosive Wear of Ductile Metals by Solid Particles," Erosion: Prevention and Useful Applications, STP 664, ASTM, 1979, pp. 36 - 58.

15. Mayville, R. A., "Mechanism of Material Removal in the Solid Particle Erosion of Ductile Metals," M.S. thesis, University of California - Berkeley, 1978.

16. Young, J. P., and Ruff, A. W., "Particle Erosion Measurements on Metals," Transactions of ASME, Journal of Engineering Materials and Technology, 1977, pp. $121-125$.

17. Hutchings, I. M., and Winter, R. E., "Solid Particle Erosion Studies Using Single Angular Particles," Wear, Vol. 27, 1974, pp. 121 - 128.

18. Yalamanchilli Chandra., "Computational Model of Brittle Erosion.”, Master's Thesis, WVU 1997.

19. Ravi Tangirala., " Computational Models of Particle Size Effects on Brittle Oxide Scale Erosion," Master's Thesis, WVU 1998.

20. Shan Balasubramaniyam., "Computational Modelling of Brittle Impact Erosion Mechanisms," Master's Thesis, WVU 1998. 


\section{APPENDIX A}

\section{SAMPLE INGRID INPUT FILE}

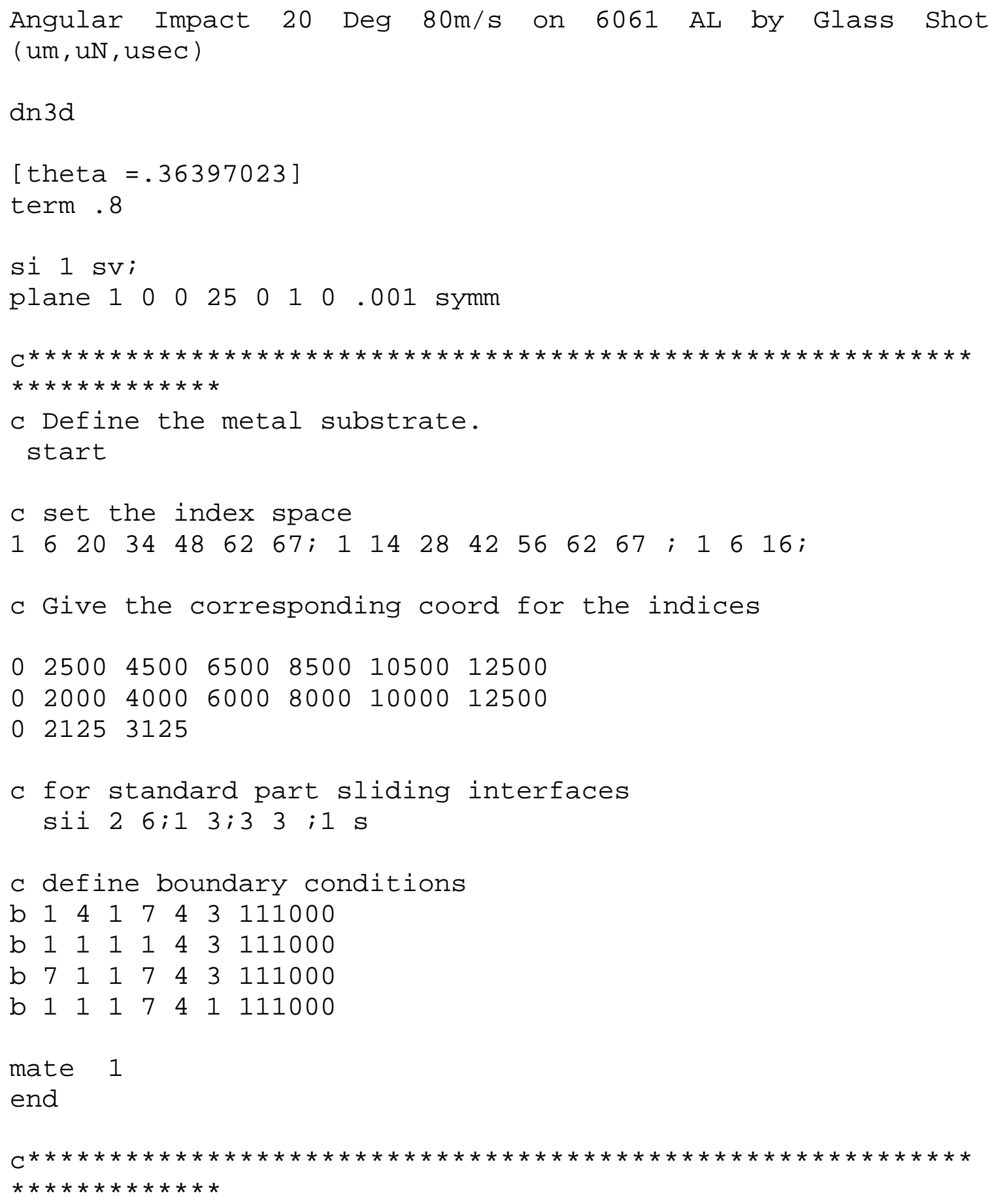




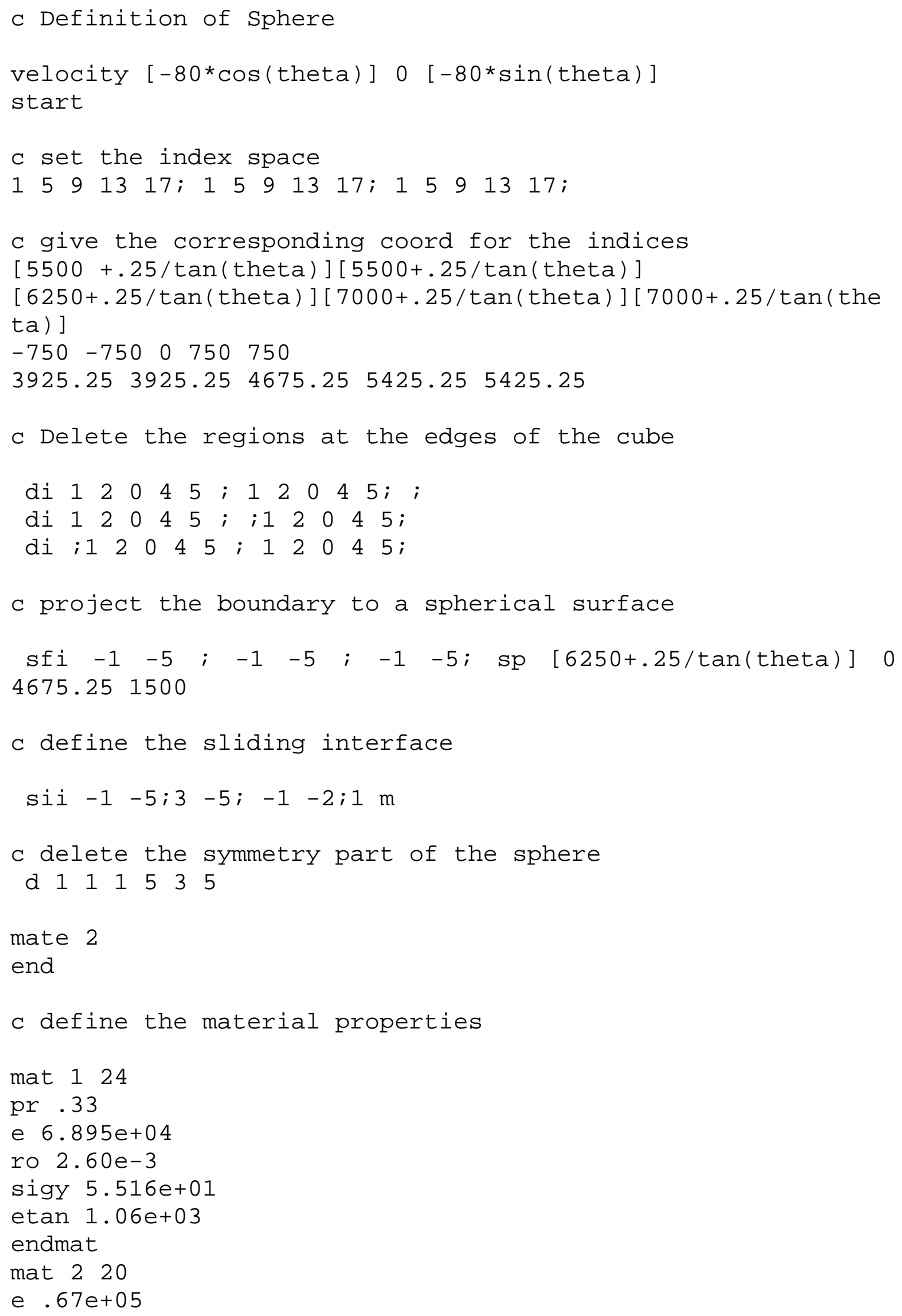


ro $2.180 e-3$

pr. 21

endmat

end

\section{APPENDIX B}

\section{SAMPLE LS-DYNA3D INPUT FILE}

Angular Impact 20 Deg $80 \mathrm{~m} / \mathrm{s}$ on 6061 AL by Glass Shot (um, uN, usec) 93 large

* CARD 1: Model Size-General

$\begin{array}{lllll}2 & 73273 & 66364 & 0 & 0\end{array}$

$0 \quad 0 \quad 0 \quad 0$

* CARD 2: Model Size-Boundary Conditions

$\begin{array}{llllllll}0 & 0 & 0 & 0 & 0 & 0 & 0 & 0\end{array}$

* CARD 3: Model Size-Loading

$\begin{array}{llllllll}0 & 0 & 0 & 0 & 0 & 0 & 0 & 0\end{array}$

* CARD 4: Model Size-Constraints and Contact

$0 \quad 0 \quad 0$

* CARD 5: Model Size-Rigid Body Parameters

$\begin{array}{lllllll}0 & 0 & 0 & 0 & 0 & 0 & 0\end{array}$

* CARD 6: Model Size-Seat Belts

* CARD 7: Model Size-Output Options

* CARD 8: Computation Options-Termination

$1.80000+1 \quad 00.0000000 \quad 0$

* CARD 9: Computation Options-Time Step Size Control

$0.00000009 .00000-1 \quad 00.00000000 .0000000$

$0 \quad 0 \quad 0$

* CARD 10: Computation Options-Body Forces

$$
\begin{array}{lllllll}
0 & 0 & 0 & 0 & 0 & 0 & 0
\end{array}
$$

* CARD 11: Computation Options-Input Control

$$
100020.0 \quad 0 \quad 0
$$

* CARD 12: Computation Options-Beams and Shells

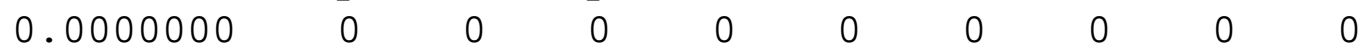

$0 \quad 0$

* CARD 13: Computation Options-Material Related Input

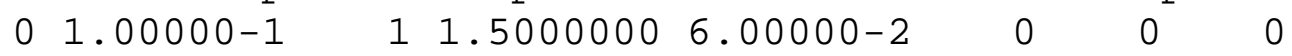

* CARD 14: Computation Options-Damping/Dynamic Relaxation $00.0000000 \quad 0 \quad 2501.00000-3 \quad 9.95000-10.0000000$ $0.0000000 \quad 00.0000000$

* CARD 15: Computation Options-Contact 
$\begin{array}{llllllllll}1.0000000 & 0.0000000 & 0 & 2 & 0 & 0 & 0 & 2 & 0 & 0\end{array}$

$1001.0000000 \quad 00$

* CARD 16: Computation Options-Parallel and Subcycling 10073178

* CARD 17: Computation Options-Coupling Control

$0.00000000 .0000000 \quad 0.0000000 \quad 0 \quad 000 \quad 0.0000000 \quad 0$

$0 \quad 0$

* CARD 18: Computation Options-Output Control

$\begin{array}{llllllllll}0 & 1 & 0 & 0 & 0 & 0 & 1 & 0 & 0 & 0.0000000\end{array}$

* CARD 19: Computation Options-Output Energy

20020

* CARD 20: Computation Options-TAURUS Database Control I

$1.00000000 .00000001 .0000000 \quad 0 \quad 000000$

0

* CARD 21: Computation Options-TAURUS Database Control II

$\begin{array}{lllllllllll}0 & 0 & 0 & 3 & 1 & 1 & 1 & 1 & 1 & 0 & 1\end{array}$

$0 \quad 0 \quad 0 \quad 000$

* CARD 22: Computation Options-ASCII Output Control I

$0.0000000 \quad 0.0000000 \quad 0.00000000 .00000001 .0000000$

0.00000001 .00000000 .0000000

* CARD 23: Computation Options-ASCII Output Control II

$0.0000000 \quad 0.0000000 \quad 0.00000000 .00000000 .0000000$

0.00000000 .00000000 .0000000

* CARD 24: Computation Options-ASCII Output Control III

$0.0000000 \quad 0.0000000 \quad 0.00000000 .00000000 .0000000$

$0.0000000 \quad 0.00000000 .0000000$

* CARD 25: ALE Options-Control I

$0.0000000 \quad 0.0000000$

$0 \quad 0 \quad 0.00000000 .0000000$

* CARD 26: ALE Options-Control II

$0.00000000 .0000000 \quad 0.0000000 \quad 0 \quad 0.00000000 .0000000$

0

*

*-------------- MATERIAL CARDS

*

$\star * *$ MATERIAL: 1

$\begin{array}{llllllll}1 & 24 & 2.60000-3 & 0 & 0 & 0.0000000 & 0 & 0.0000000\end{array}$

$0.0000000 \quad 0 \quad 0 \quad 0$

material type \# 24 (elastic-plastic with failure)

$68950.0000 .00000000 .00000000 .0000000 \quad 0.0000000 \quad 0.0000000$

0.00000000 .0000000

$0.3300000 \quad 0.0000000 \quad 0.0000000 \quad 0.0000000 \quad 0.0000000 \quad 0.0000000$

0.00000000 .0000000

$55.160004 \quad 0.0000000 \quad 0.0000000 \quad 0.0000000 \quad 0.0000000 \quad 0.0000000$

$0.0000000 \quad 0.0000000$ 

$1060.0000 \quad 0.0000000$
0.00000000 .00000000 .00000000 .0000000
0.0000000
0.0000000
$0.0000000 \quad 0.0000000$
0.00000000 .00000000 .00000000 .0000000
0.0000000
0.0000000
0.0000000
0.0000000
0.0000000
0.0000000
$0.0000000 \quad 0.0000000$
0.0000000
0.0000000

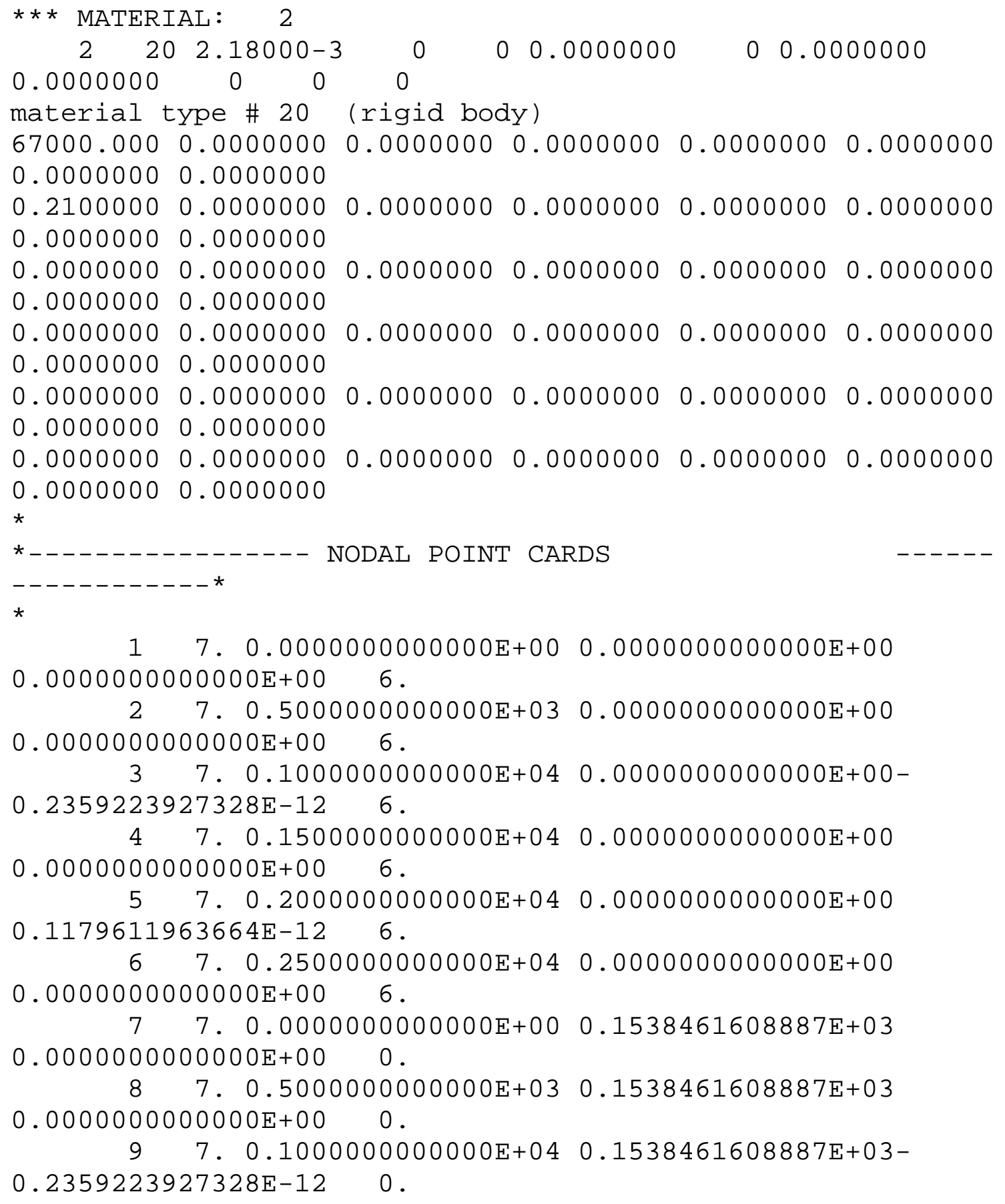


$107.0 .1500000000000 \mathrm{E}+04 \quad 0.1538461608887 \mathrm{E}+03$ $0.0000000000000 \mathrm{E}+00 \quad 0$.

$117.0 .2000000000000 \mathrm{E}+04 \quad 0.1538461608887 \mathrm{E}+03$ $0.1179611963664 \mathrm{E}-1200$.

$127.0 .2500000000000 \mathrm{E}+04 \quad 0.1538461608887 \mathrm{E}+03$ $0.0000000000000 \mathrm{E}+00 \quad 0$.

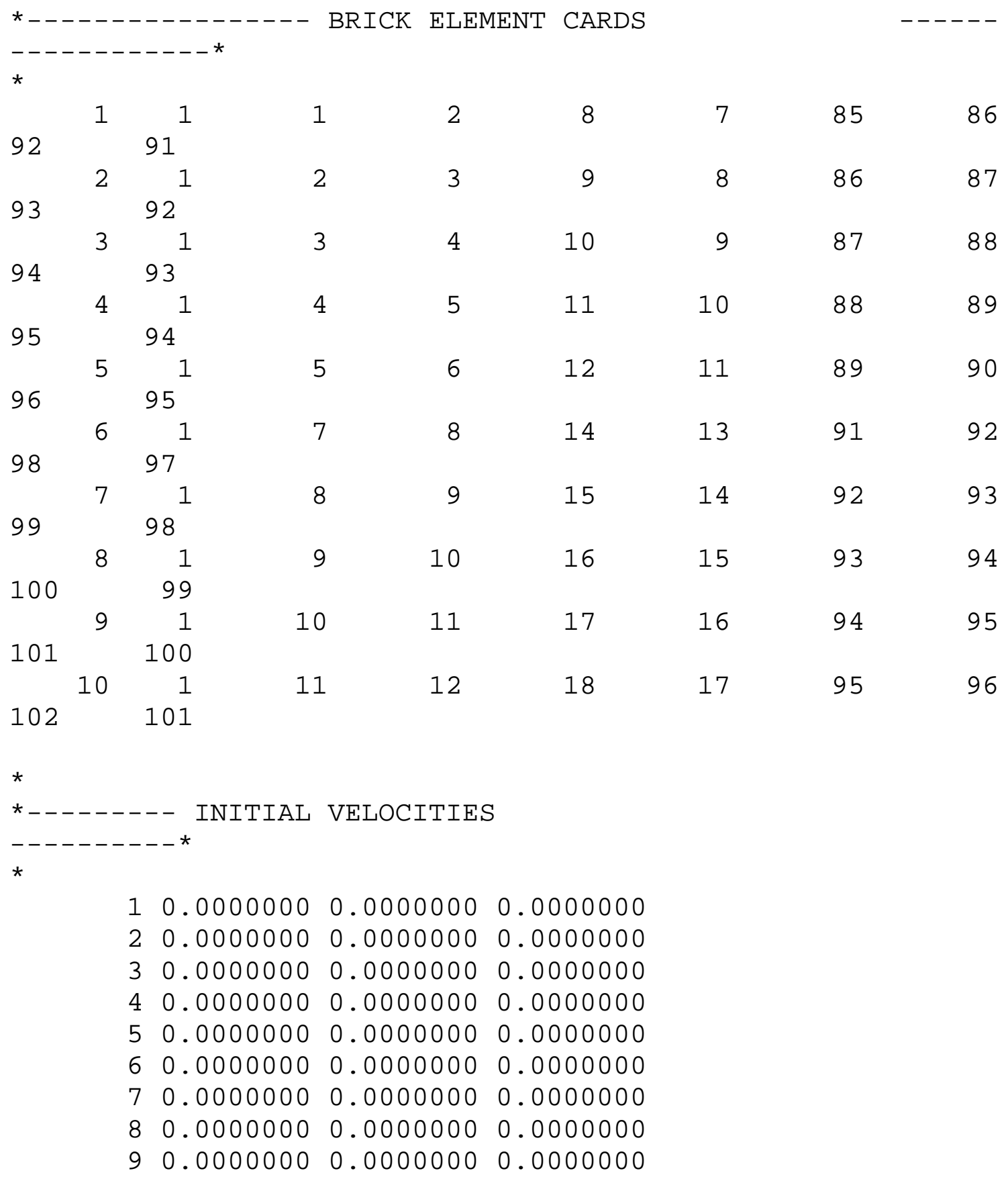


$100.0000000 \quad 0.0000000 \quad 0.0000000$

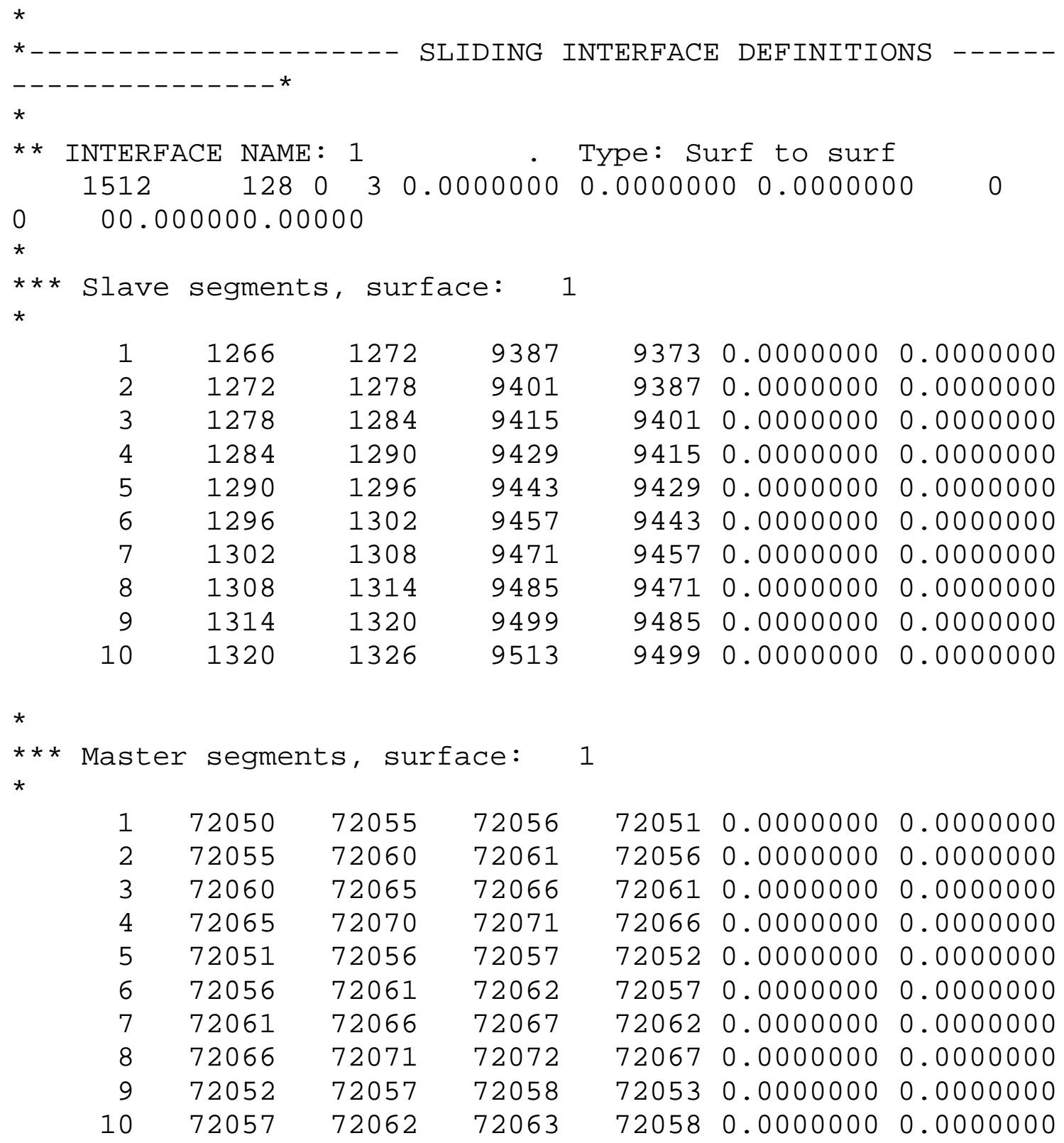




\section{APPENDIX C}

\section{TRUE STRESS- TRUE STRAIN (FLOW) CURVE FOR AL6061-T0 OBTAINED FROM TENSION TEST}

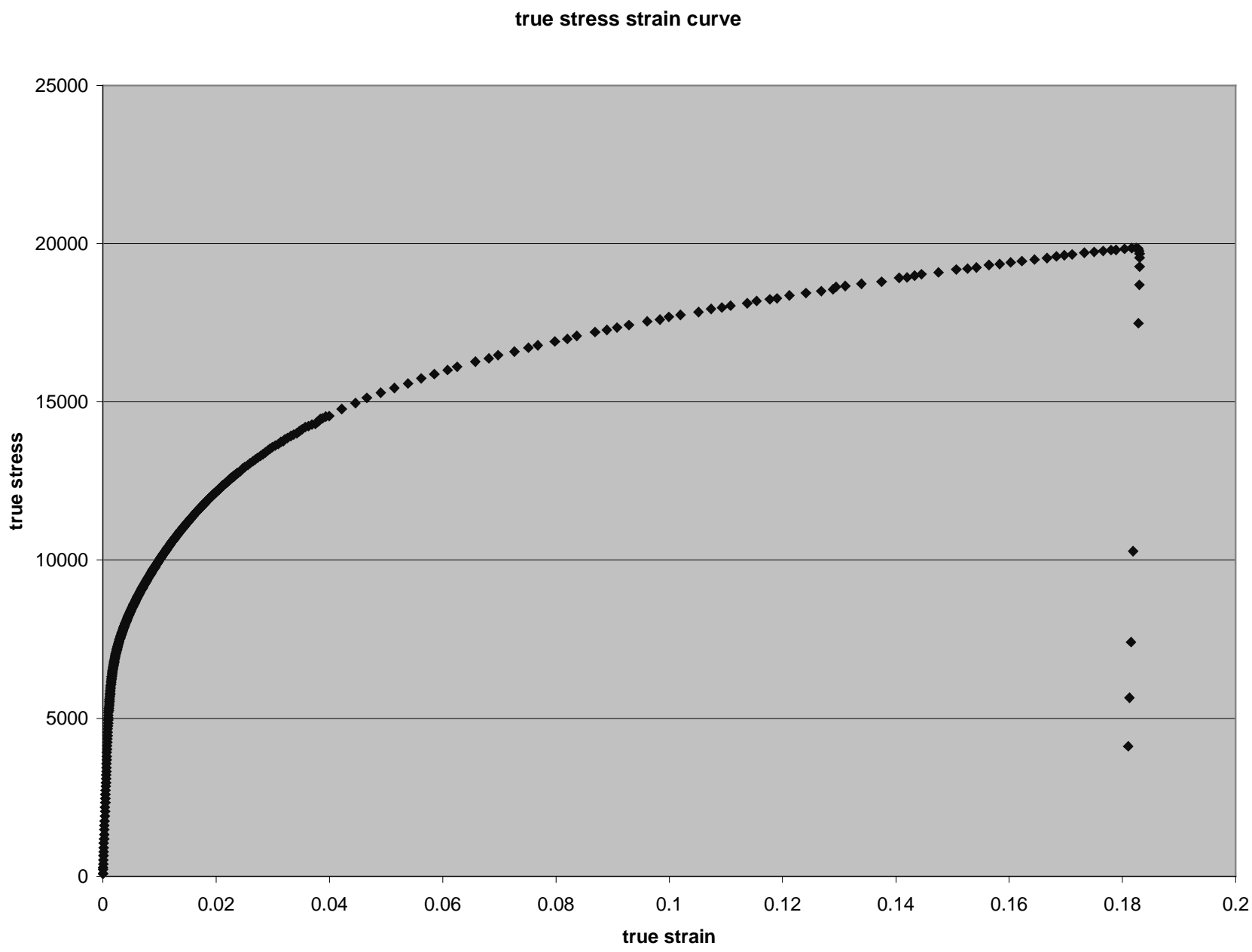


STRESS-STRAIN CURVE FOR AL6061-T0 FROM THE TENSION TEST

stress-strain curve

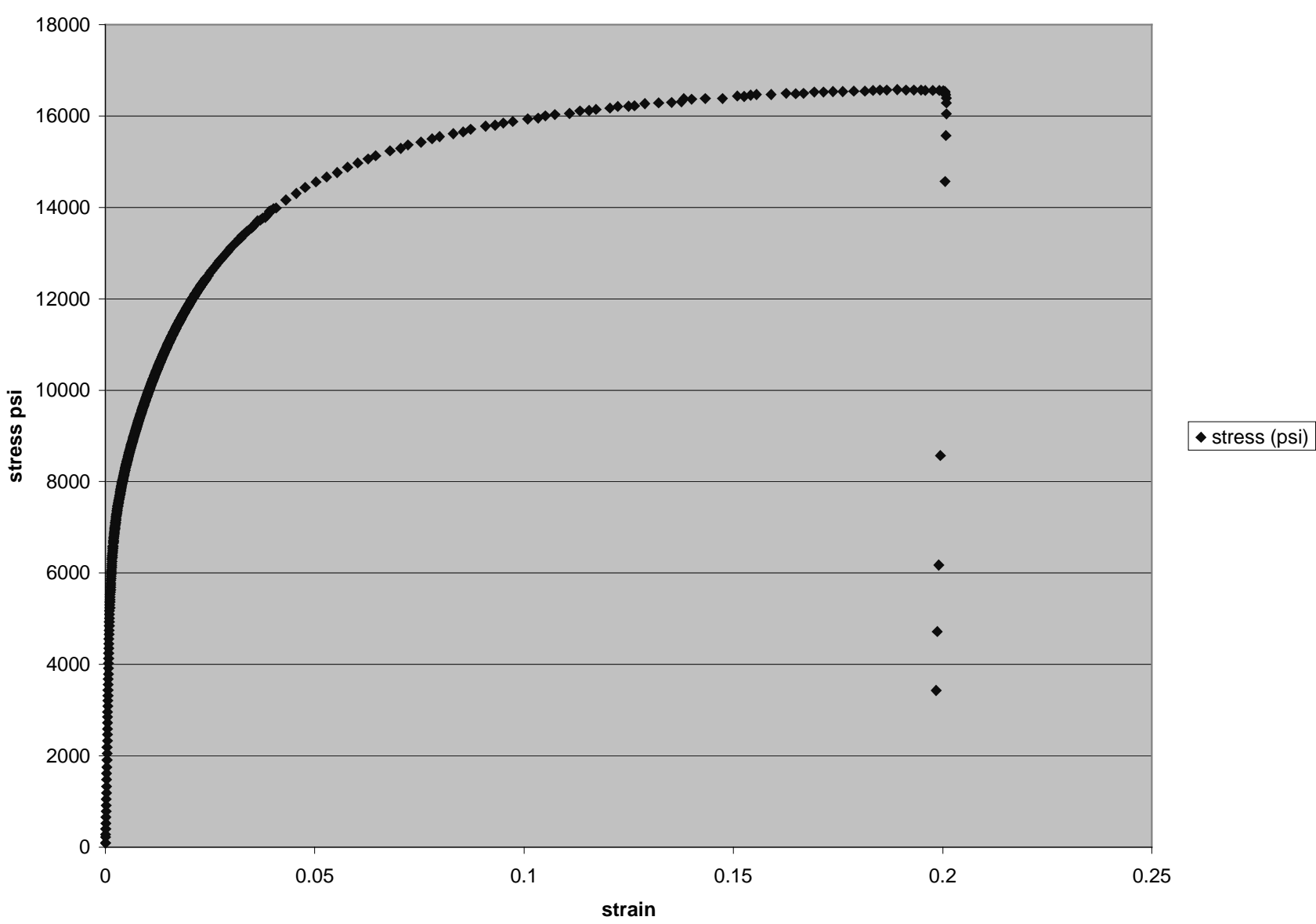




\section{APPENDIX D}

\section{BILINEAR STRESS STRAIN CURVE}

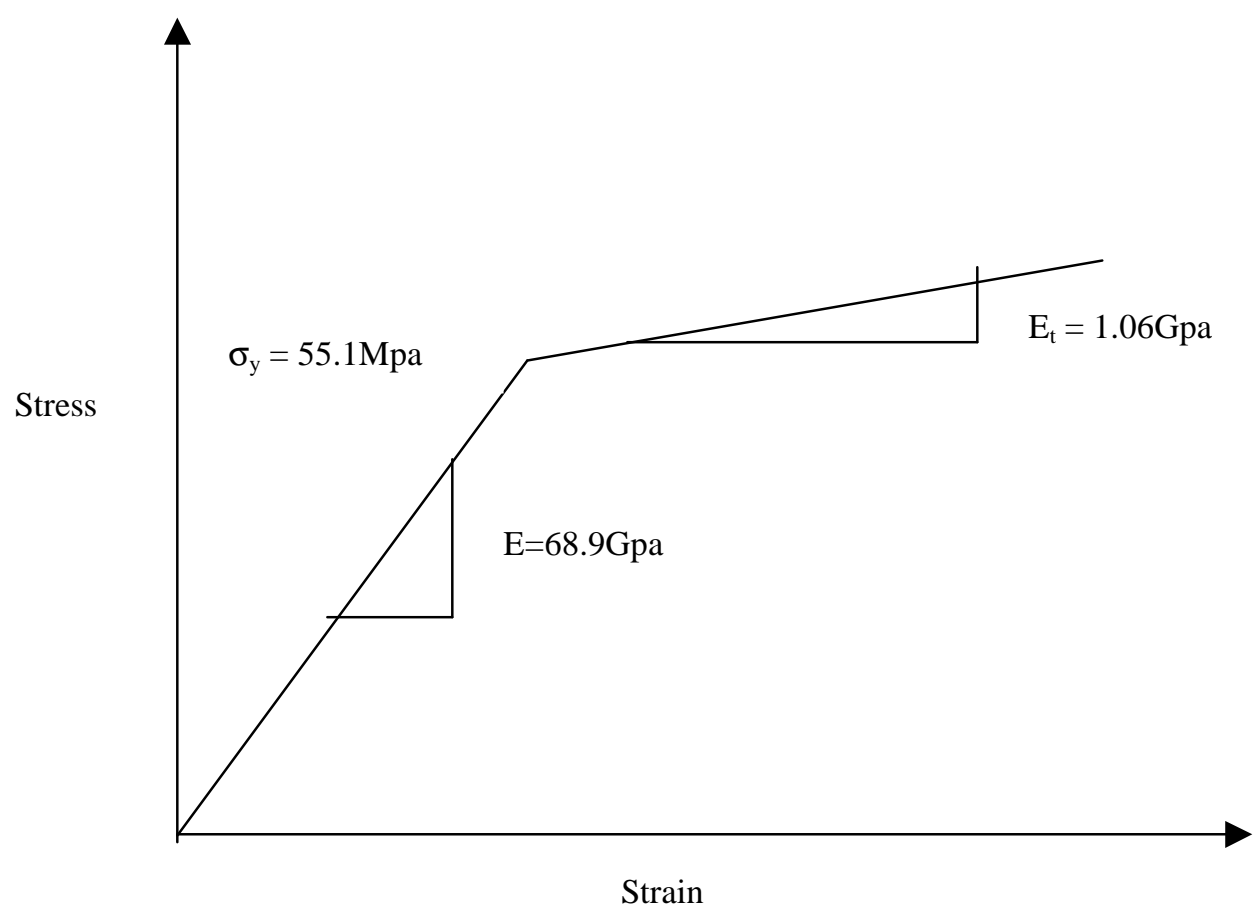

